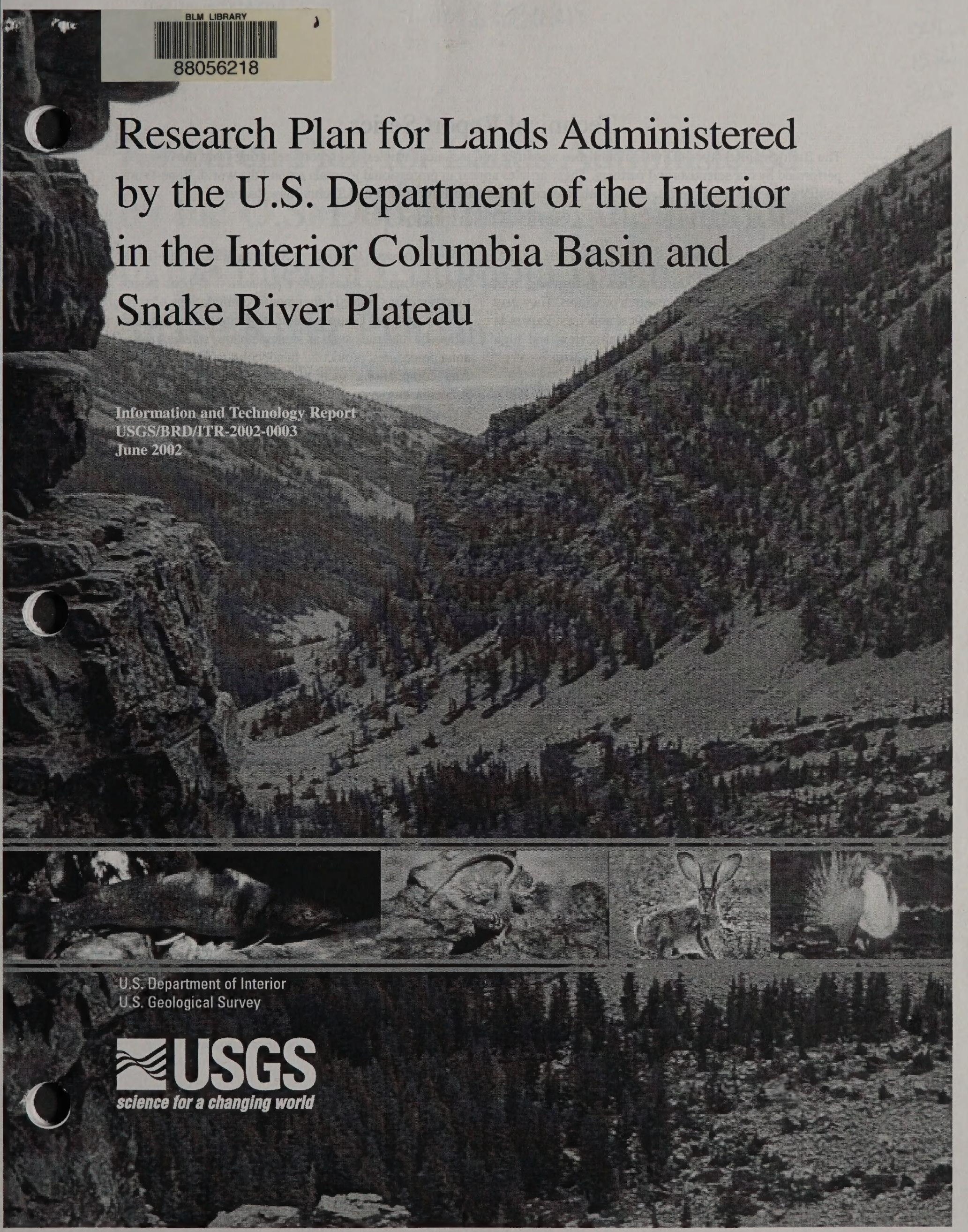




\section{Technical Report Series}

The Biological Resources Division publishes scientific and technical articles and reports resulting from the research performed by our scientists and partners. These articles appear in professional journals around the world. Reports are published in two report series: Biological Science Reports and Information and Technology Reports.

\section{Series Descriptions}

\section{Biological Science Reports}

ISSN 1081-292X

This series records the significant findings resulting from sponsored and co-sponsored research programs. They may include extensive data or theoretical analyses. Papers in this series are held to the same peer-review and high quality standards as their journal counterparts.

\section{Information and Technology Reports ISSN 1081-2911}

These reports are intended for publication of book-length monographs; synthesis documents; compilations of conference and workshop papers; important planning and reference materials such as strategic plans, standard operating procedures, protocols, handbooks, and manuals; and data compilations such as tables and bibliographies. Papers in this series are held to the same peer-review and high quality standards as their journal counterparts.

Copies of this publication are available from the National Technical Information Service, 5285 Port Royal Road, Springfield, Virginia 22161 (1-800-553-6847 or 703-487-4650). Copies are also available to registered users from the Defense Technical Information Center, Attn.: Help Desk, 8725 Kingman Road, Suite 0944, Fort Belvoir, Virginia 22060-6218 (1-800-225-3842 or 703-767-9050).

A limited number of hard copies are available from the senior author; an electronic version of the text is available on the Internet at http://fresc.usgs.gov/.

Cover photo Credits: Front cover - Great Basin National Park, Erik Beever, USGS; bull trout, Russ Thurow, USDA - Forest Service, Rocky Mountain Research Station; collared lizard, Great Basin National Park; sage grouse, (O) Terry Steele. Back cover - Steens Mountain (lower right), Tamzen Stringham, Oregon State University. Others are public domain.

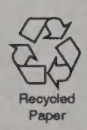




\section{Research Plan for Lands Administered by the U.S. Department of the Interior in the Interior Columbia Basin and Snake River Plateau}

Information and Technology Report USGS/BRD/ITR-2002-0003

June 2002

by

Erik A. Beever

David A. Pyke

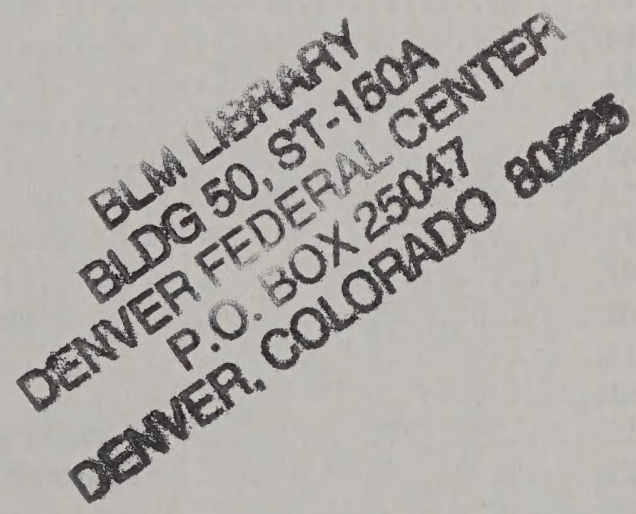

with contributions from

Robert Gresswell

Susan M. Haig

Steve Knick

Edward Starkey

\section{U.S. Geological Survey}

Forest and Rangeland Ecosystem Science Center Corvallis, Oregon

in cooperation with the U.S. Department of the Interior Bureau of Land Management

Fish \& Wildlife Service

National Park Service

Bureau of Reclamation 
Beever, E.A., and D.A. Pyke. 2002. Research Plan for Lands Administered by the U.S. Department of the Interior in the Interior Columbia Basin and Snake River Plateau. U.S. Geological Survey, Information and Technology Report USGS/BRD/ITR-2002-0003. 76 pp. 


\section{Contents}

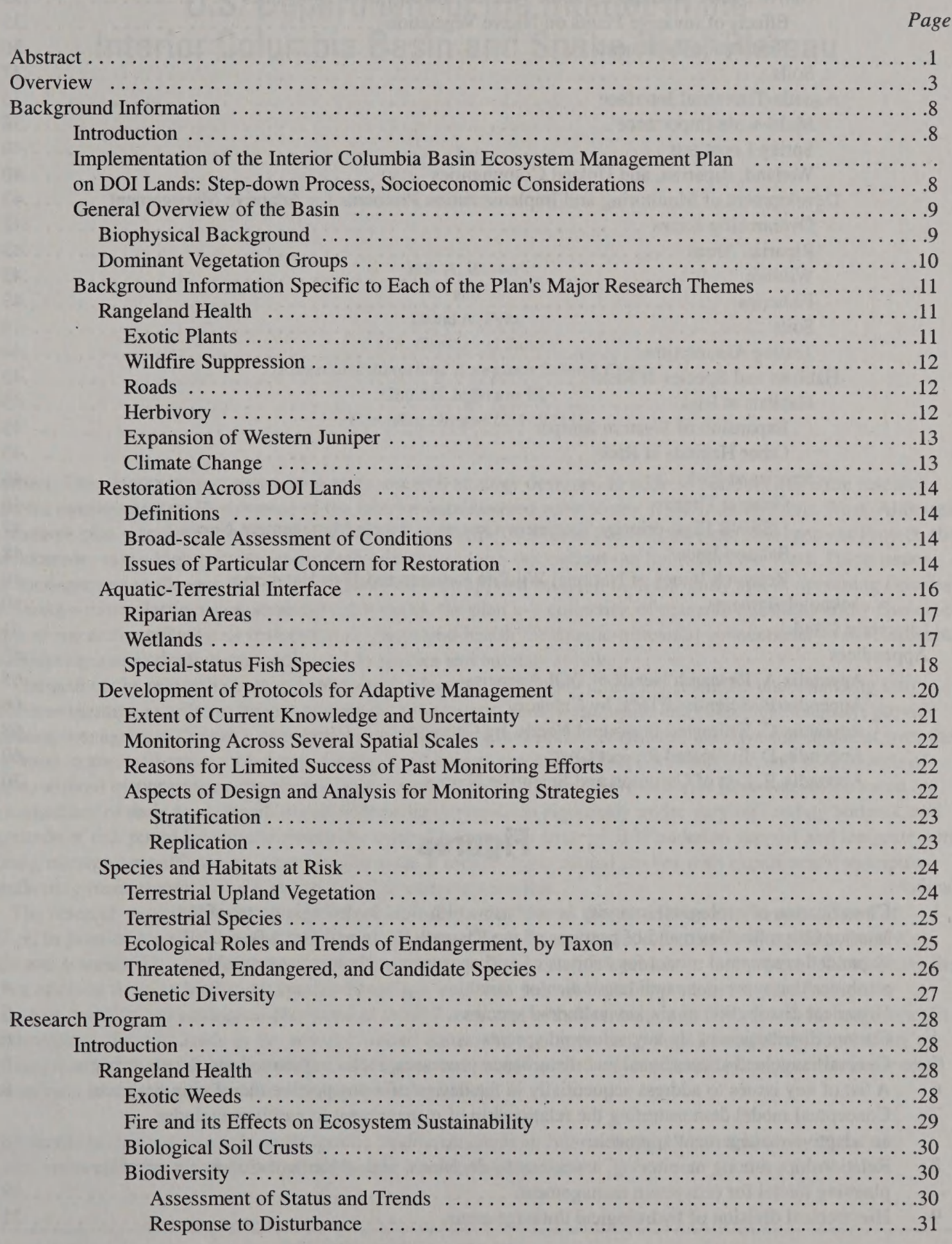




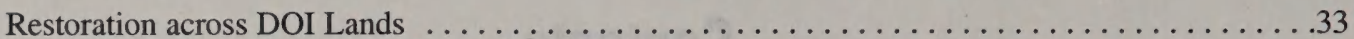

Landscape Ecology: Habitat Fragmentation, Connectivity, Boundary Effects . . . . . . 33

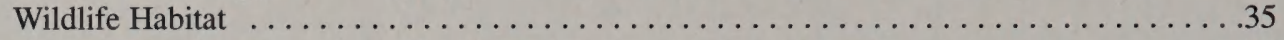

Native Plant Communities in the Face of Encroachment by Exotics . . . . . . . . . . 35

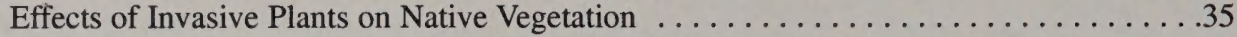

Restoration Treatments .................................... 36

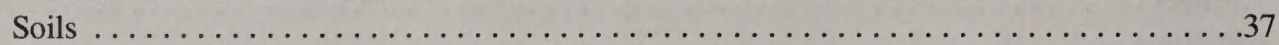

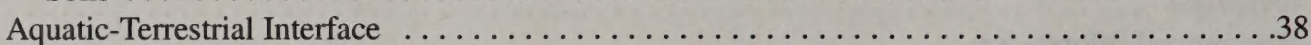

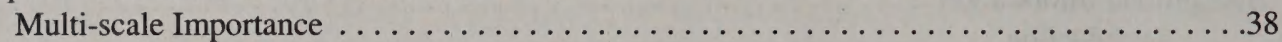

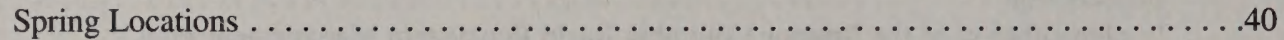

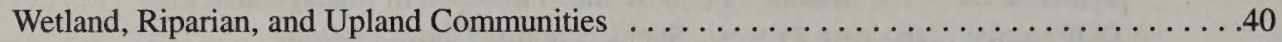

Development of Monitoring and Implementation Protocols for Adaptive Management . . . . .42

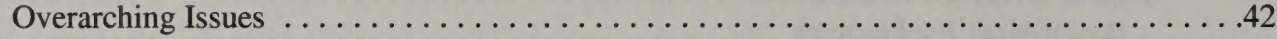

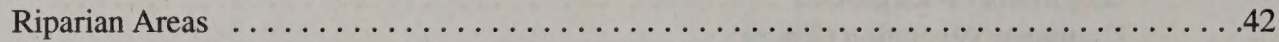

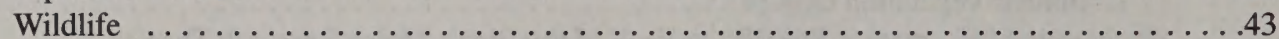

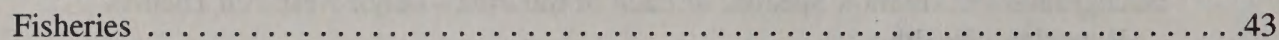

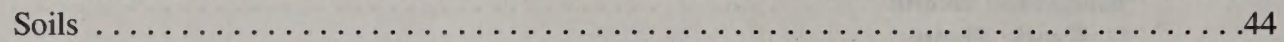

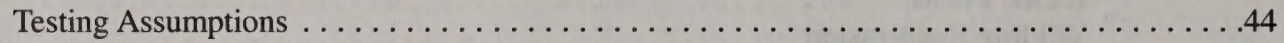

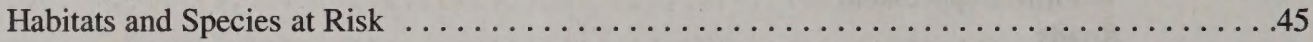

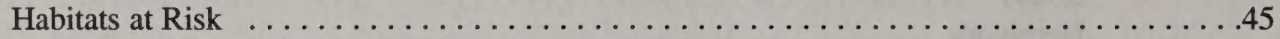

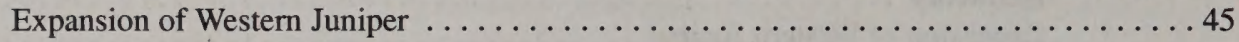

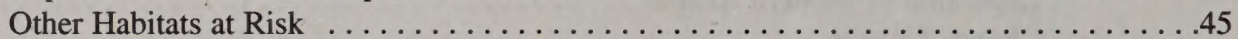

Species at Risk .......................................... 46

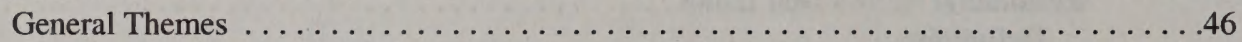

USFWS High-priority Species or Groups and their Management Needs . . . . . . . . 47

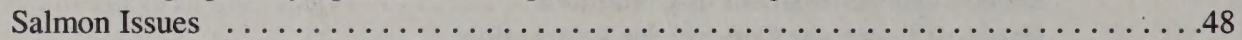

Research Issues of National Wildlife Refuges and Fish Hatcheries . . . . . . . . . 49

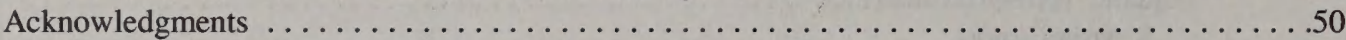

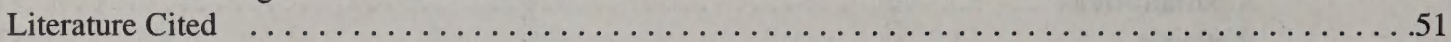

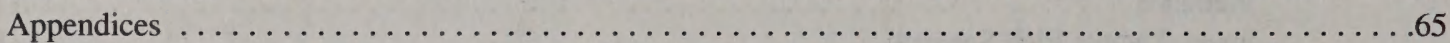

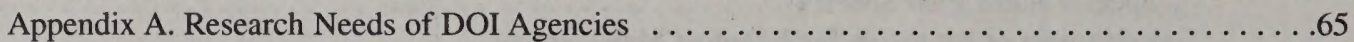

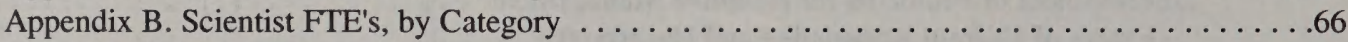

Appendix C. Estimated Personnel Needs, by Category . . . . . . . . . . . . . . . . . 68

Appendix D. Estimated Project Costs . . . . . . . . . . . . . . . . . . . . . . . 69

Appendix E. List of Common and Scientific Names ..................... 70

\section{Figures}

Number

1 Classification of ecological integrity in subbasins (4th-field hydrologic units) of the Interior Columbia Basin and of portions of the Klamath Basin and Great Basins . . . . . . . . . . 3

2 Expanded conceptual model for habitats of arid ecosystems, showing measurable attributes that represent candidate indicator variables. . . . . . . . . . . . . . . . . . . . . 4

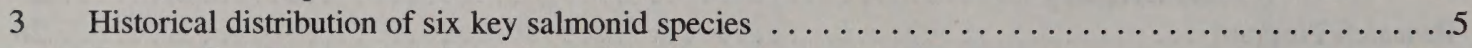

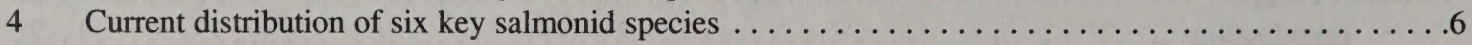

5 General rangeland successional and disturbance processes, including altered sagebrush-steppe . . . . 10

6 A list of key issues to address sequentially in the design of a prospective monitoring program. $\ldots .18$

7 Conceptual model demonstrating the relationship of management to monitoring under

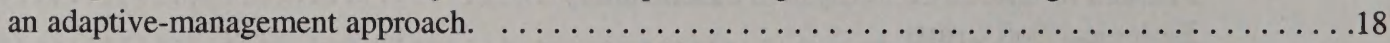

8 Relationships among monitoring, assessments, decisions, and implementation in a general planning model for ecosystem management. . . . . . . . . . . . . . . . . . . . . 19

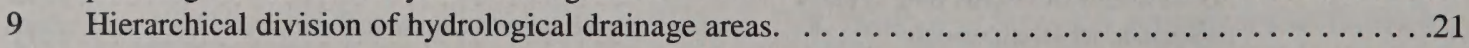




\title{
Research Plan for Lands Administered by the U.S. Department of the Interior in the Interior Columbia Basin and Snake River Plateau
}

\author{
By \\ Erik A. Beever ${ }^{1}$ \\ and \\ David A. Pyke \\ U.S. Geological Survey \\ Forest and Rangeland Ecosystem Science Center \\ 3200 SW Jefferson Way \\ Corvallis, Oregon USA 97331
}

\begin{abstract}
This document presents a long-term research strategy designed to address current and future research needs for management of Department of the Interior-administered ecosystems in the Intermountain West. Although the research plan was developed in the context of the Interior Columbia Basin Ecosystem Management Project, the plan addresses many high-priority issues facing land managers throughout the Intermountain West. These issues pose management challenges that may be addressed with applied research both currently and in upcoming decades. Possessing a particular focus on semiarid ecosystems, the plan is a collection of research questions under five categories of research emphases: 1) restoration; 2) rangeland health; 3) aquatic-terrestrial connections; 4) development of monitoring and evaluation protocols; and 5) species and habitats at risk.

The goal of the research strategy is to provide ideas for integrating emerging scientific understanding into future management in order to restore and maintain long-term ecosystem health and ecological integrity; provide consistent management direction over broad spatial and temporal scales; emphasize adaptive management over the long term; restore and maintain habitats for plant and animal species; and support economic and social needs of people, without compromising the above goals. Research questions are prioritized into three categories based on the immediacy of their need, feasibility of addressing the question rigorously under varying funding budgets, and magnitude of risk posed by not addressing the issue. The research strategy is intended to support and integrate with existing management efforts and strategies. As such, it melds observational studies with experimental manipulation, treating management actions as experiments whenever feasible.

The research strategy focuses on disturbance processes and events that have been the primary drivers of change, to provide a predictive model for future changes. These drivers include fire, nonnative plants, herbivory, roads and associated human influences, and climate change. Whereas management in the western United States has striven to move from an inefficient species-based approach to a habitat-based approach, the plan focuses on ecosystem function and ecological processes as critical measures of habitat response. Because of the large amount and contiguity of public lands in the western United States, the region presents both a compelling opportunity to implement landscape-level science and a challenge to understand a relatively understudied region that is expected to contribute heavily to national biotic integrity in the future.
\end{abstract}

Key Words: prioritized research needs, public lands management, Intermountain West, arid ecosystems, rare species, restoration, monitoring, rangeland health, aquatic habitats.

${ }^{1}$ Contact: erik_beever@usgs.gov; (541) 758-7785; FAX (541) 758-7761 


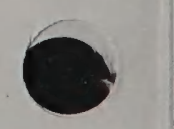




\section{OVERVIeW}

The Interior Columbia Basin encompasses 125 million acres (50.6 million ha) in eastern Oregon, eastern Washington, Idaho, and western Montana, and more than half of the Basin is managed by federal agencies. Within this area, Department of the Interior (DOI) agencies are responsible for management of 37 wildlife refuges and hatcheries, numerous Bureau of Reclamation reservoirs and watersheds, 15 American Indian reservations, 11 National Park Service units, and 26 million acres (10.5 million ha) of land across 10 Bureau of Land Management (BLM) districts. Research is needed to address management challenges associated with the current condition of public lands in the western United States. For example, $51 \%$ of BLM- and Forest Service -administered lands in the Basin have low ecological integrity, compared with only $23 \%$ that possess high integrity (Figure 1). Because of the large amount and contiguity of public lands in the western United States, the region presents both a compelling opportunity to implement landscape-level science and a challenge to understand a relatively understudied region that is expected to contribute heavily to national biotic integrity in the future.

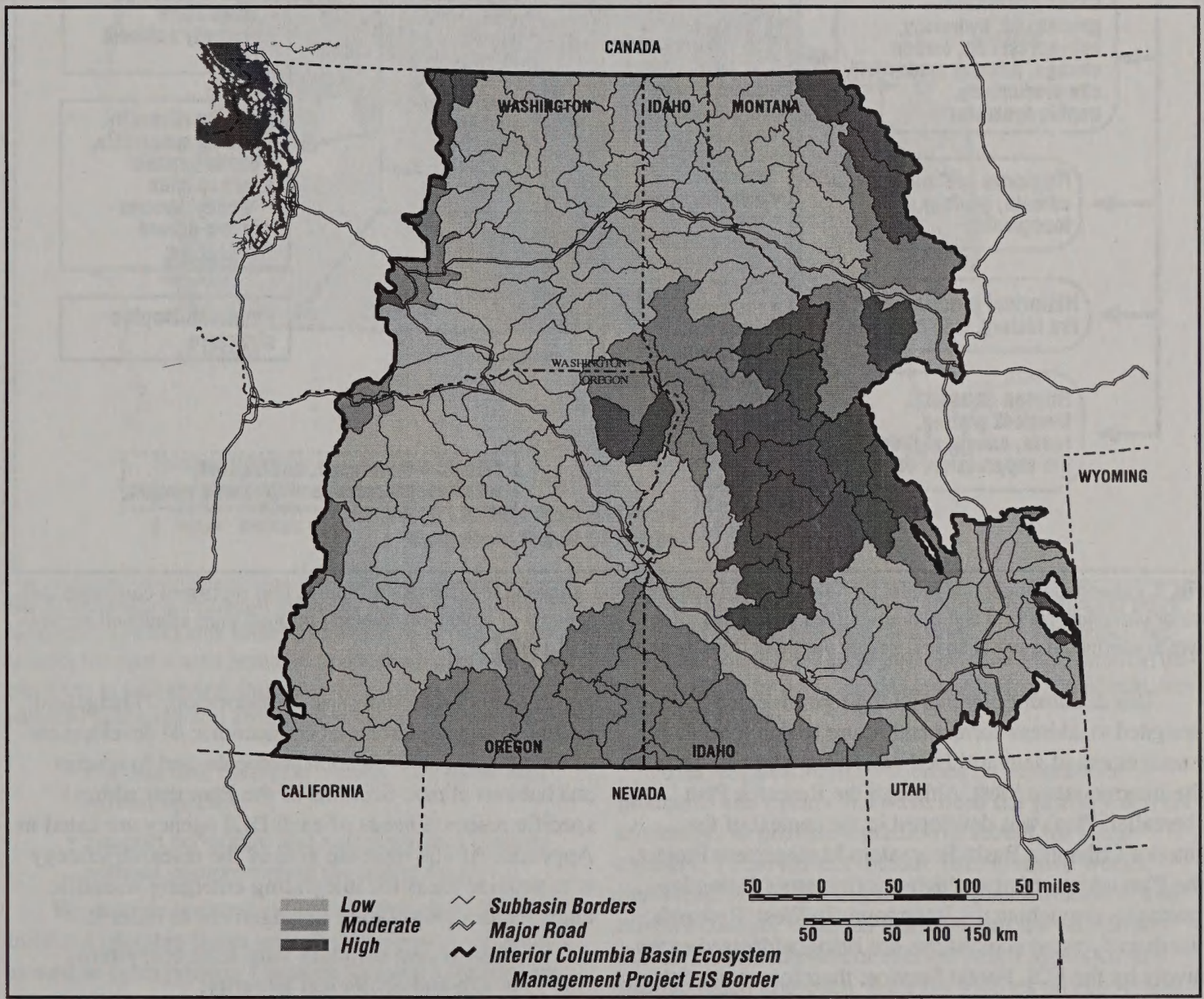

Fig. 1. Classification of ecological integrity in subbasins (4th-field hydrologic units) of the Interior Columbia Basin and of portions of the Klamath Basin and Great Basin. Composite ratings of ecological integrity synthesized integrity ratings of forest, rangeland, forest and rangeland hydrologic, and aquatic component classifications, and were compared against knowledge of actual onthe-ground conditions. Classifications are based on average trends of subwatershed composite departure from the historical range of variability (based in turn on vegetation composition, structure, size, proximity to other patches of vegetation, and succession and disturbance processes), aquatic habitat conditions, and road density. Adapted from USDA and USDI (2000a). 


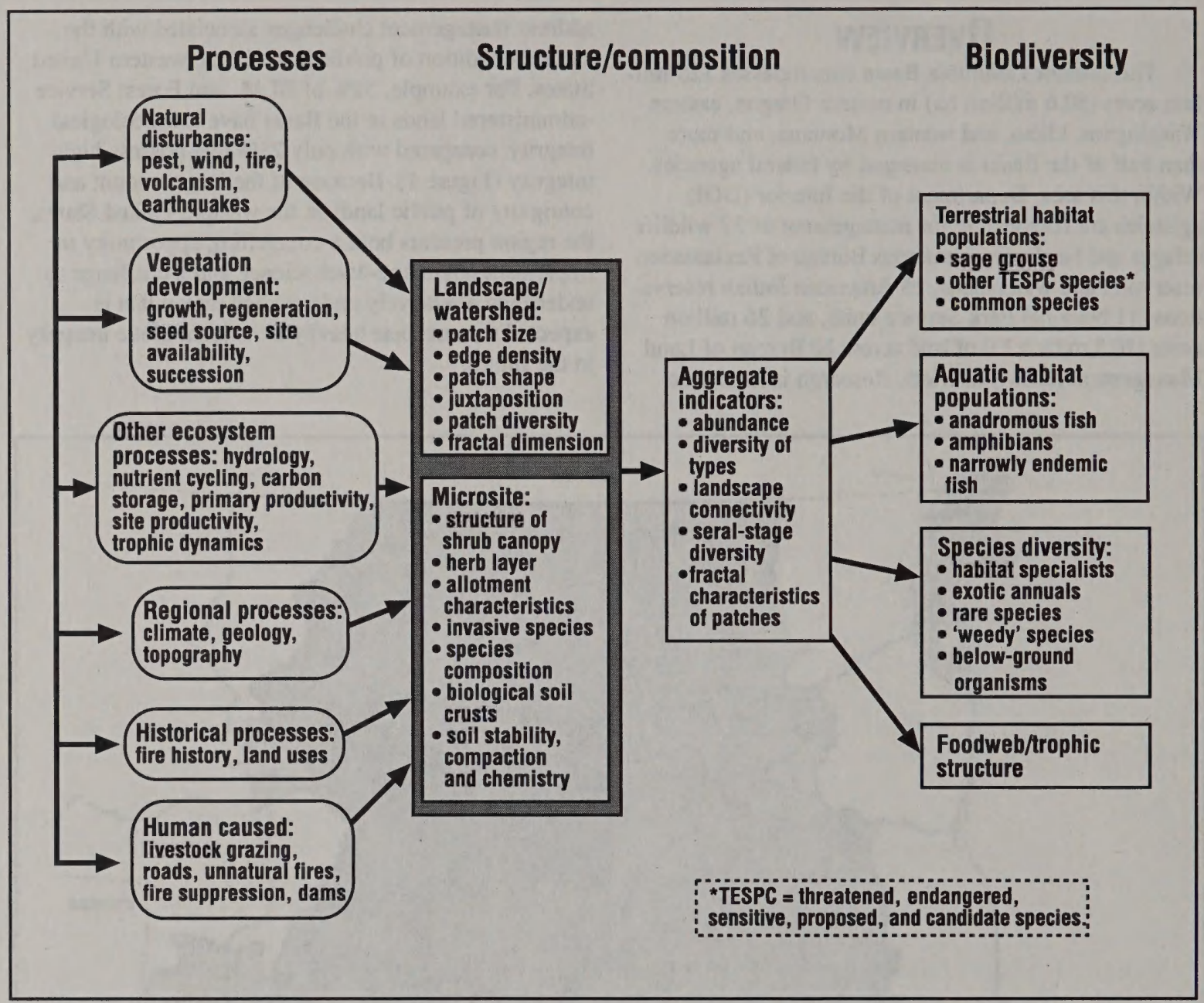

Fig. 2. Expanded conceptual model for habitats of arid ecosystems, showing measurable attributes that represent candidate indicator variables. Natural and human-caused processes affect components of biological diversity through their effects on ecosystem properties at several spatial scales. Adapted from Hemstrom et al. (1999).

This document presents a long-term research strategy designed to address current and future research needs for management of semiarid DOI-administered ecosystems in the Intermountain West. Although the Research Plan (hereafter, Plan) was developed in the context of the Interior Columbia Basin Ecosystem Management Project, the Plan addresses many high-priority issues facing land managers throughout the Intermountain West. Research needs in forested ecosystems are being addressed extensively by the U.S. Forest Service; therefore, scientists and managers at a joint meeting in June 1999 agreed that this research strategy should focus particularly (but not exclusively) on rangelands.

At the request of the constituent agencies participating in the June 1999 meeting, the Plan contains five cate- gories of research emphases: 1) restoration; 2) rangeland health; 3) aquatic-terrestrial connections; 4) development of monitoring and evaluation protocols; and 5) species and habitats at risk. Sections of the Plan that address specific research needs of each DOI agency are listed in Appendix A. The ultimate goal of the research strategy is to provide ideas for integrating emerging scientific understanding into future management in order to

- Restore and maintain long-term ecosystem health and ecological integrity;

- Provide consistent management direction over broad spatial and temporal scales;

- Emphasize adaptive management over the long term; 


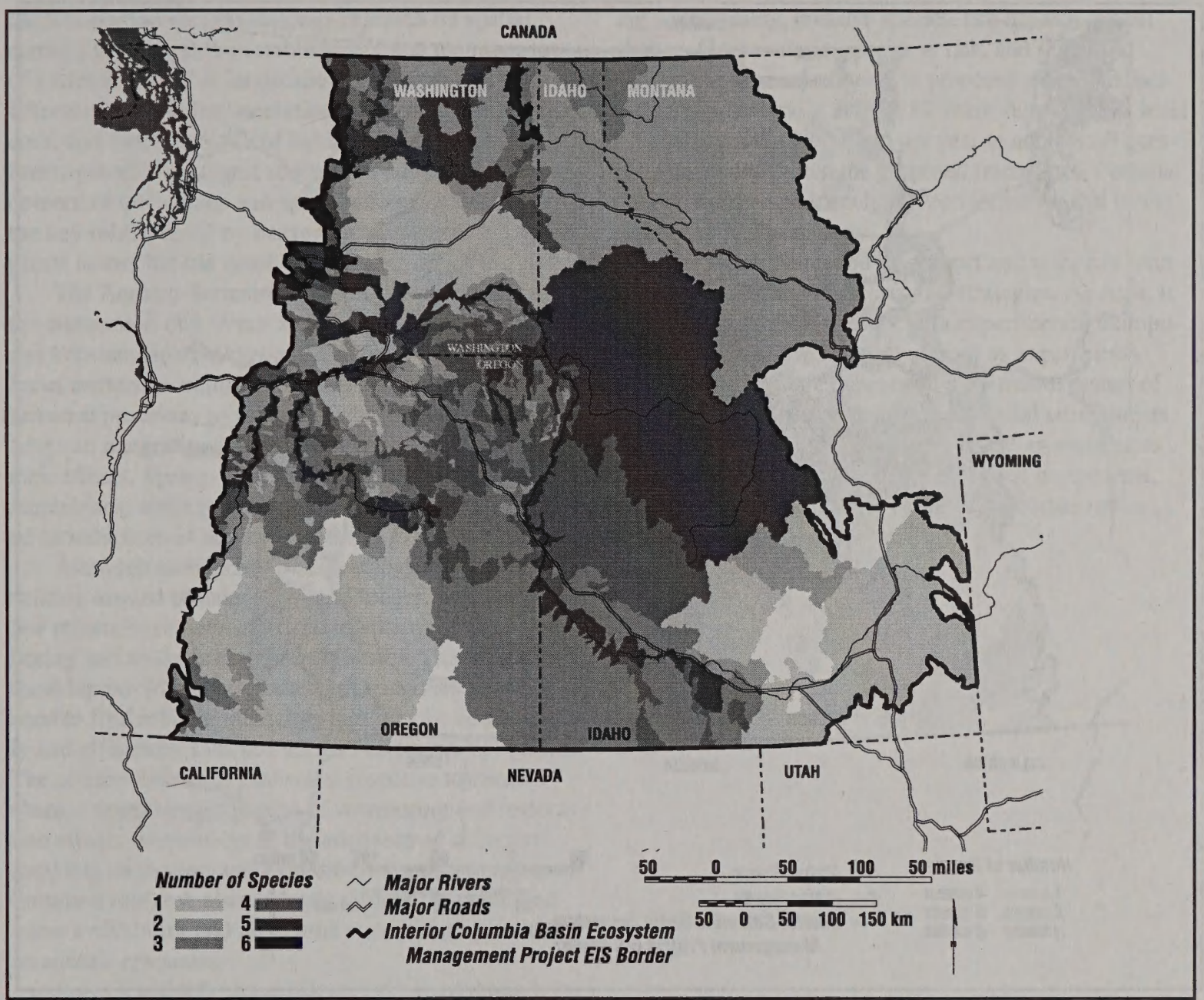

Fig. 3. Historical distribution of six key salmonid species (bull, westslope cutthroat, Yellowstone cutthroat, and redband trout; steelhead; and chinook salmon) in watersheds and subwatersheds of the northern Intermountain West. This distribution represents the speculated potential range of species before European settlement. Ranges were characterized from historical distributions in preexisting databases (created by expected distributions modified by professional judgment) and augmented with selected published and anecdotal accounts. Adapted from USDA and USDI (2000a).

- Restore and maintain habitats for plant and animal species;

- Support economic and social needs of people, without compromising the above goals.

We provide background information, extracted from Interior Columbia Basin science assessments and reports, as well as from primary literature sources. This contains relevant information about the region as a whole, as well as information specific to each of the five research foci. The information is intended to familiarize readers with species, habitats, communities, ecosystems, and major drivers of change in the interior Columbia River, Snake River, Klamath, and Great Basins.
The research strategy focuses on disturbance processes and events that have been the primary drivers of change, to provide a predictive model for future changes. These drivers include fire, invasive weeds, herbivory, roads and associated human influences, and climate change. Whereas management has striven to move from an inefficient species-based approach to a habitat-based approach, the Plan focuses on ecosystem function and ecological processes as critical measures of habitat response (Figure 2). However, single species (e.g., sage grouse) that are both highly charismatic and assumed to act as umbrellas for other taxa within a habitat type receive special attention in a few cases. 


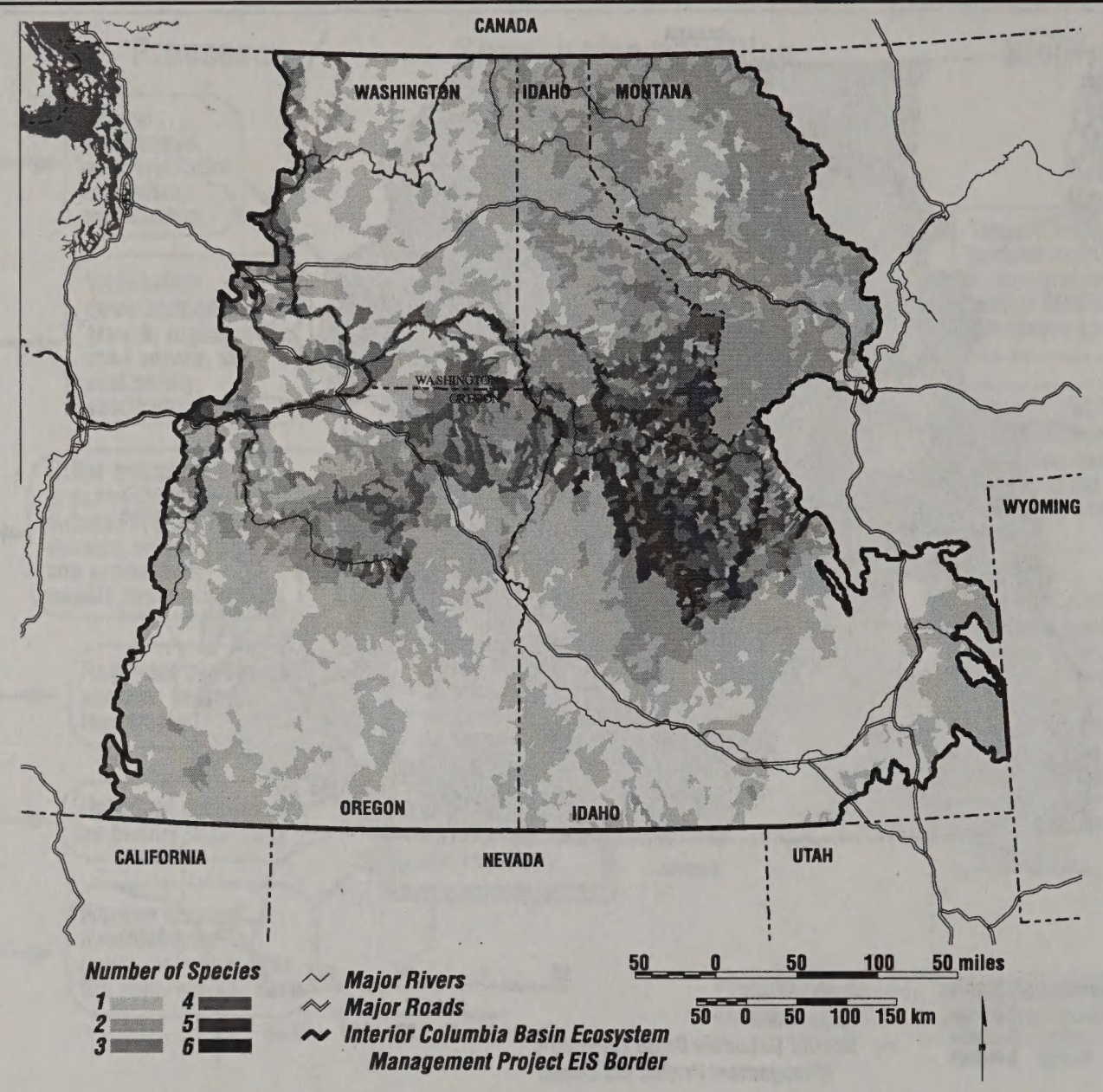

Fig. 4. Current distribution of six key salmonid species (bull, westslope cutthroat, Yellowstone cutthroat, and redband trout; steelhead; and chinook salmon) in watersheds and subwatersheds of the northern Intermountain West. This distribution was determined through the classification of subwatersheds (6th-field hydrologic units) by private, agency, and tribal fishery biologists, and augmented with information from existing electronic databases maintained by state and federal agencies, and other sources. Adapted from USDA and USDI (2000a).

For each research issue, the Plan provides a broad framework of questions within which specific questions and hypotheses can be designed. Information regarding the need and importance of research also accompanies each issue. Research questions in the Plan possess designations to guide prioritization. Designations reflect the magnitude and immediacy of the research need, as well as the relative risk associated with not undertaking the research.

The Rangeland Health section explores the role of exotic weeds in shaping community dynamics of plants, biophysical dynamics of soils, and the factors that determine weed distributions. Also included are investi- gations of how fire affects various components of ecosystems, and how the dynamics of prescribed fires compare with those of wildfires. We propose research that addresses ecological roles of biological soil crusts (i.e., soil-surface mosses, lichens, and bacteria) and their response to various disturbances. Status and trends of various groups such as bats, sagebrush-dependent species, and wild horses also receive attention.

Active restoration has been proposed as the most effective means to address the deteriorated structure, composition, and function of ecosystems of the Interior Columbia Basin. An important element of restoration is the spatial relationships among habitats. Accordingly, 
the Restoration section suggests research on spatial ecology to support the establishment and maintenance of native diversity at landscape to regional scales. Effects of habitat fragmentation, connectivity via corridors, and characteristics of habitat patches are also investigated. We suggest research to support the development of techniques and spatial strategies to address the key roles played by beavers, amphibians, and exotic plants across habitat types.

The Aquatic-Terrestrial Interface section recognizes the connection of habitats within and across watersheds, and between riparian/wetland and upland areas. Our focus centers on natural and management-induced disturbance processes as drivers of change, and again we adopt an integrative, landscape-level approach to assess their effects. Spring- and stream-dwelling invertebrates, amphibians, and aquatic nuisance species are investigated as indicators of aquatic health.

Although management and ecological research are shifting toward broader areas and longer time scales, few efforts have been able to integrate meaningful monitoring and analysis across these scales. The Monitoring for Adaptive Management section addresses agencies' need to find reliable indicators that may be economically and efficiently sampled across various spatial scales. The section addresses biological response to climate change, spatial prioritization of monitoring and restoration efforts, assessment of the adequacy of different sampling strategies, and explicit testing of assumptions. Proposed research also addresses effects of decreased water availability and numerous recreational activities on aquatic resources.

Species and habitats at risk are addressed through research that strives to move from single-species approaches for resource management and conservation to habitat- or functional group-based approaches. Habitats particularly at risk include sagebrush-steppe areas, springs, ephemeral wetlands, and areas affected by either road networks or expansion of western juniper and other woody species. Focal species include narrowly distributed rare fishes, key salmonids (i.e., trout and salmon; Figures 3 and 4), wide-ranging top predators, and listed and candidate species on individual DOI management units.

Many research issues in the Plan require collaboration across political and disciplinary boundaries, and involve mapping, hydrological, geomorphological, and biological expertise (see Appendix B). U.S. Geological Survey (USGS), with its multidisciplinary structure, is well suited to provide rigorous, integrated science information relevant to management in the Interior Columbia Basin. Furthermore, the Plan includes many issues that are national-level priorities for USGS, includ- ing water quality, invasive species, fire hazards, global change, GAP analysis, species at risk, and status and trends. The research strategy is proposed as a multidisciplinary framework of at least 10 years' duration, at a level of approximately $\$ 7$ million per year to address all questions contained within the proposed framework. Potential cooperators and partners have been identified and included in shaping the strategy.

The Plan is intended to support and integrate with existing management efforts and strategies. As such, it melds observational studies with experimental manipulation, treating management actions as experiments whenever feasible. Consequently, numerous issues of research design are described as essential components to a successful research strategy. The Plan recognizes the dynamic and unpredictable nature of ecosystems, and explicitly allows for a range of outcomes rather than an unvarying endpoint. 


\section{BACKGROUND INFORMATION}

\section{Introduction}

The Interior Columbia Basin Ecosystem Management Plan (ICBEMP) owes its beginning to the Northwest Forest Plan, which was initiated in the early 1990 s in response to controversy regarding management of old forests and associated species on federal lands in the Pacific Northwest. Issues such as management of old forests, anadromous fishes, riparian areas, and forest health spawned a similar controversy in the interior portion of the Pacific Northwest. This occurred because traditional U.S.D.A. Forest Service (FS) and U.S.D.I. Bureau of Land Management (BLM) approaches that addressed single-resource issues often produced disparate and conflicting management prescriptions. Thus, in July 1993, the President directed the FS to "develop a scientifically sound and ecosystem-based strategy for management" of forests in Oregon and Washington located east of the crest of the Cascade Range. The BLM joined the effort later in 1993 to work with the FS on the Eastside and Columbia Basin draft Environmental Impact Statements. By 1996 and 1997, scientific assessments were produced that examined historical and current ecological, social, and economic systems on all lands in the project area, which included portions of seven states. Subsequently, numerous management options were proposed to address the challenges posed by the results of the assessment, and three of the options (including continuation of current management strategies) remained feasible options in the Supplemental Draft Environmental Impact Statement (USDA and USDI 2000a).

In June 1999, biologists and managers from several management and research agencies met to devise a research strategy for lands administered by DOI in the Interior Columbia Basin Plan area. Because ICBEMP has often given greater attention to forested systems in the Basin, constituent agencies agreed that the research strategy should focus particularly on rangelands, although not exclusively. The participants specified major issues that resource managers will face in implementing ICBEMP, and identified five categories of research emphases: 1) restoration; 2) rangeland health; 3) aquatic-terrestrial connections; 4) development of monitoring and evaluation protocols; and 5) species and habitats at risk. Potential cooperators and partners identified include BLM, FS, USGS, U.S. Fish and Wildlife Service (USFWS), National Park Service (NPS), Agricultural Research Service (ARS), Natural Resources Conservation Service (NRCS), Environmental Protection
Agency (EPA), non-governmental organizations (e.g., The Nature Conservancy), universities, agricultural experiment stations, and Native American tribes, among others.

The geographic domain pertaining to the Plan includes portions of Oregon and Washington east of the Cascade Range, and the parts of Idaho and Montana that are drained by the Columbia and Snake Rivers. In effect, all of Idaho except its extreme southeastern corner is included, as is the northwestern corner of Montana west of the continental divide and north of Butte. The Plan is designed to address information needs of all Department of Interior agencies (i.e., BLM, USFWS, NPS, Bureau of Indian Affairs, and Bureau of Reclamation). However, because (as stated above) issues relating to BLMadministered lands have not been well addressed in research strategies proposed by the FS, special attention is afforded to the lower-precipitation (1.6-4.7 in./yr; 4-12 $\mathrm{cm} / \mathrm{yr}$ ), lower-elevation lands that comprise rangelands in the interior Columbia River Basin, upper Klamath Basin, and northem Great Basin (hereafter collectively referred to as "the Basin"). Ultimately, however, effectiveness of research and management on public lands in the region will hinge upon strategic, landscape-scale collaboration with FS research, and upon coordinated effort among DOI bureaus to address common research interests.

\section{Implementation of the Interior Columbia Basin Ecosystem Management Plan on DOI Lands: Step-down Process, Socioeconomic Considerations}

The focus of future management and research is to promote sustainable ecosystems through maintenance, protection, or restoration of habitats. Sustainable ecosystems maintain a characteristic diversity of major functional groups, productivity, soil fertility, and rates of geochemical cycling, over the normal cycle of disturbance events (Chapin et al. 1996). Management decisions (e.g., determination of stocking rates) for any particular area will continue to be made locally through the land-use planning process for each BLM resource area, wildlife refuge, or national park. Information from multiple scales will be integrated to aid decision-making through a step-down process, such that commitments of actions to meet broad-scale objectives occur only after local conditions are considered (USDA and USDI 2000a). Three tiers of more focused analyses include subbasin review [a mid-scale assessment: 800,000 - to 
$1,000,000$-acre $(300,000$ to $400,000 \mathrm{ha})$ drainage areas] ecosystem analysis at the watershed scale $[10,000$ to 100,000 -acre $(4,000$ to $40,000 \mathrm{ha})$ drainage areas, usually watersheds or subwatersheds], and site-specific analysis (the level of most management activities, typically resulting in a National Environmental Policy Act [NEPA] process). These three levels of analysis will provide the primary means for setting landscape and project goals and objectives.

At the fine-scale level of individual allotments, it may be challenging to implement significant change in livestock grazing practices. Many ranchers' families have grazed livestock in the region for several generations, although as ranchers grow older, more operators leave the profession than enter it (Haynes and Horne 1997). In the Basin, BLM permittees manage operations that are generally more profitable and significantly larger than are those of non-permittees (Haynes and Horne 1997). Dependency of the livestock industry on forage from BLM and FS lands averages $7 \%$ across the Basin, ranging from $1 \%$ to $12 \%$ among economic subregions and from $\sim 0$ to $40 \%$ among individual counties (Frewig-Runyon 1995, Haynes and Horne 1997). Economic dependence of communities on industries such as livestock grazing, mining, and recreation is highest in areas that are geographically isolated and offer few opportunities for alternative employment (Haynes and Horne 1997). Because of lower beef cattle prices and higher production costs, the fee for grazing on public lands has stayed at the legal minimum of $\$ 1.35$ per AUM since 1996 (USDA and USDI 2000a). The number of cattle grazing on public lands is predicted to decline by about $1 \%$ per year for the next 20 years, as a result of herd reductions to avoid resource damage; declining economic feasibility of livestock grazing; and implementation of recovery plans for federally listed species (Haynes and Horne 1997). Nonetheless, complete elimination of livestock grazing is neither projected nor recommended at the broad scale, because elimination of grazing disturbance may 1) increase incidence of wildfire in some systems (Young and Evans 1978), which is especially problematic in areas where fire is not desirable; 2) disrupt the economic and social needs of rural residents for federal resource products; and 3) depart from the existence of at least minimal levels of grazing in the Basin throughout time (Mack and Thompson 1982).

\section{General Overview of the Basin}

\section{Biophysical Background}

Volcanism, plate tectonics, glaciation, weathering, erosion, and sedimentation occurring over millions of years have provided the physical foundation for the evolution of the ecological relationships currently observed in the Basin. Furthermore, the physiographic environment dictates ecological potential, response to disturbances, and management options. Overlaid on this template is the inherent stochasticity in environmental (particularly climatic) conditions. For example, although all areas in the Basin experience irregularly occurring droughts, more arid ecosystems generally are affected most strongly by drought (Barry and Chorley 1982). Whereas succession and disturbance regimes on forested lands have been most dramatically altered by timber harvest, road development, and fire exclusion, disturbance regimes on arid lands have been altered most dramatically by the introduction of exotic plants, excessive livestock grazing, and fire suppression (Figure 5; Hann et al. 1997). Biophysical templates on rangelands in the West have changed more significantly than have templates on forests or mixed lands, largely as a result of agricultural development (Hann et al. 1997)

Establishment of shrubs and other perennial plants in arid and semiarid habitats may be episodic and dependent upon periods of above-average precipitation (Shaw and Haferkamp 1994). In the Basin, frequency of drought, favorable periods of precipitation for establishment (defined as precipitation $>110 \%$ of average for more than 2 years), and variability in precipitation all increase as aridity increases (MacMahon 1980, Osmond et al. 1990, Leonard et al. 1995). Because timing of wetter periods is unpredictable and because many of the Basin's rangelands receive low amounts (7.9-14.2 in.; $20-36 \mathrm{~cm}$ annual average) of precipitation overall, potential for restoration success clearly varies across the Basin (Miles and Karl 1995, Hann et al. 1997). Furthermore, especially in areas that normally experience high levels of inherent environmental stress, management-induced stresses may exacerbate the effects of harsh or variable climate on ecosystems. For example, Hann et al. (1997) suggest that recovery potential for native vegetation, soil integrity, and ecological processes decrease from areas of $>11.8 \mathrm{in}$. $(30 \mathrm{~cm})$ annual precipitation to areas between $9.8-11.8$ in. (25 to $30 \mathrm{~cm}$ ) annual precipitation to areas receiving $<9.8 \mathrm{in} .(25 \mathrm{~cm})$ annually. Soils that are naturally susceptible to erosion by wind or water, have high salinity, are sodic, or shrink or swell upon wetting and drying also appear 


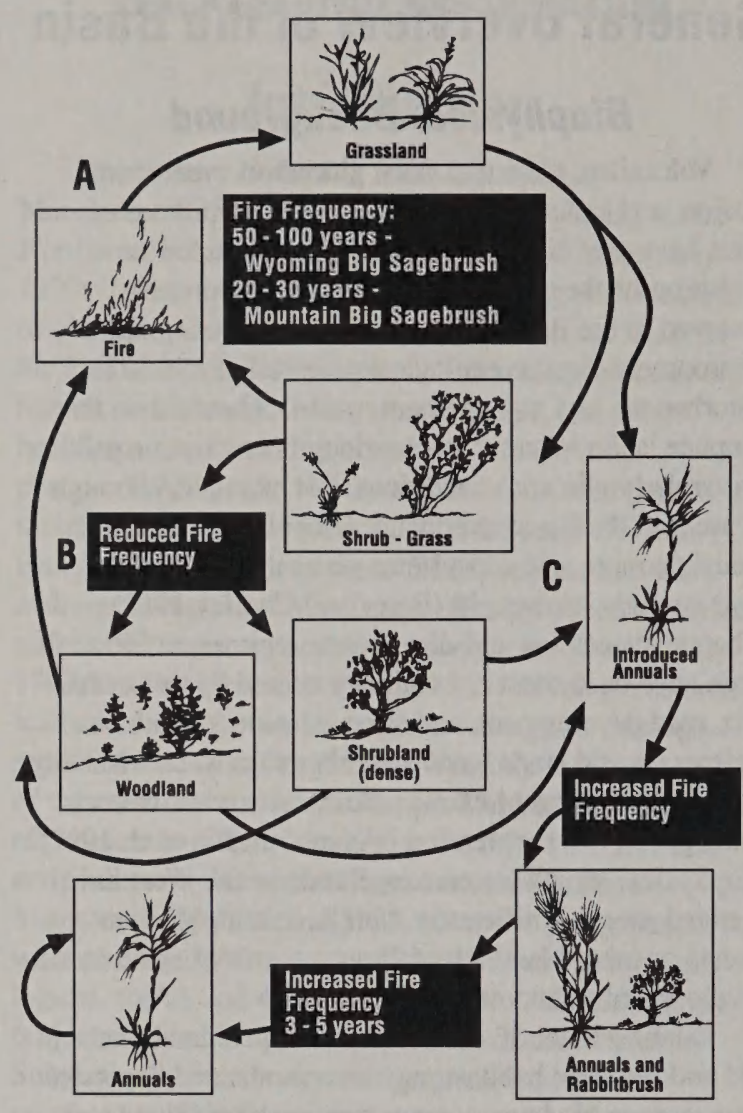

Fig. 5. General rangeland successional and disturbance processes (includes altered sagebrush steppe). There are three common pathways of succession in the sagebrush steppe. Pathway A represents succession from a grassland to a shrub-grass-dominated plant community, with fire acting to move the shrub-grass-community back to a grassland. This type of succession follows the climax model of plant succession. Pathway B represents succession of a shrubgrass-dominated plant community to either a woodland (dominated mostly by juniper) or a shrubland, and is caused by a reduction in fire occurrence. The dense shrub or woodland plant community can re-enter Pathway $A$ if native perennial understory plants are sufficient to establish themselves following a wildfire, or it could move into Pathway $C$ if the understory plants are mostly introduced annuals such as cheatgrass following a wildfire. Pathway $C$ represents succession of a shrub-grass or woodland-shrub-grass-dominated plant community to a community dominated by introduced annual grasses, characterized by an increase in fire occurrence. Once dominated by introduced annual grasses, the community tends to remain this way because of frequent fire and competition from the introduced annual grasses, which prevents shrubs and native perennial grasses from establishing. This type of succession follows the model of plant succession known as state and transition. Figure and legend adapted from Vavra et al. (1994). especially vulnerable to management-induced stress. Soil types of highest susceptibility occur in southeastern Oregon and across southern Idaho, and to a lesser extent in southern Washington.

Soils are determined primarily by climate, geologic parent material, vegetation, local topography, and the age of the soil (Brady 1974). Soils provide six valuable ecosystem services: 1 ) buffering and moderation of the hydrological cycle; 2) physical support of plants; 3) retention and delivery of nutrients to plants; 4) recycling of wastes and dead organic matter; 5) renewal of soil fertility; and 6) regulation of major element cycles (Daily et al. 1997). Soils in the Basin are generally young and thin, such that critical soil processes like nutrient cycling, infiltration, and percolation, occur in the top few inches to feet (centimeters to decimeters) of soil (Hann et al. 1997). Because precipitation during the growing season is generally low on DOI lands in the Basin, water-holding capacity of soils is critical in determining ecosystem response to various disturbances (Hann et al. 1997).

Soil productivity across the Basin is generally declining, due to improper implementation of vegetation management activities, road construction and maintenance, and excessive livestock grazing (Hann et al. 1997). While soil properties and function can be compromised in as little as one month of disturbance (Weltz et al. 1989), recovery of soils in the Basin from compaction has been estimated to require several decades to centuries (Knapp 1989; Hann et al. 1997), and regeneration of one inch of topsoil may require 200 to 1,000 years (Pimentel et al. 1993). For example, soil compaction due to heavy equipment, vehicles, pedestrian activity, and excessive livestock grazing often reduces the porosity, permeability, and hydrologic conductivity of soils, thereby increasing surface erosion (Hann et al. 1997). Erosion may also result from concentration of water in roads near riparian areas and from increased soil exposure such as loss of biological soil crusts (Jones et al. 2000a). Similarly, although fire can make nutrients more readily available to newly establishing plants, fire can also change surface soil characteristics, increase erosion rates, and can consume organic matter from soils. Soil material has been lost via erosion and through direct displacement of soils (e.g., for use in agriculture or as "fill dirt").

\section{Dominant Vegetation Groups}

Rangelands in the Basin are composed primarily of two vegetation groups, dry grass and dry shrub. From historical to current times, the geographical extent of dry grass habitats decreased from $9 \%$ to $4 \%$ of the 
Basin, largely due to habitat conversion on non-federal lands (Hann et al. 1997). Dry grass areas (e.g., fescue grasslands, fescue grasslands with conifers, wheatgrass grasslands) are the second-most vulnerable vegetation type to invasion by exotic plants, and are affected most notably by cheatgrass, yellow starthistle, spotted knapweed, and dalmatian toadflax. However, the degree to which these and other exotic plants (including seeded exotics such as wheatgrasses) affect ecosystems varies considerably across the Basin. Particularly within the upland herblands, native bunchgrasses have declined, while smaller-stature native grasses (e.g., Sandberg bluegrass) and exotic plants have increased (Hann et al. 1997). Before Euro-American settlement, fire-return intervals in dry grass habitats ranged from 5 to 75 years, and most fires were such that herbaceous vegetation returned after a fire (Figure 5; Hann et al. 1997). In contrast, most current fires produce a mix of lethal and non-lethal outcomes (i.e., burning of the upper vegetative layer of shrubs, trees, or both). These mixed-fire events historically occurred only where shrub or woodland cover types existed within dry grass areas, but now they occur more broadly, because of fire suppression (Hann et al. 1997). Future management of dry grass habitats will probably involve little to no use of prescribed fire and timber harvest, but will involve greater effort to control exotic plants.

Of the more than 150 million acres ( 60.7 million ha) of sagebrush-steppe habitat that occur in western North America, BLM manages $>45$ million acres (>18.2 million ha) - about 30\% - in nine western states (USDI BLM 2000). These dry shrub habitats have also declined from historical to current times, from occupying $30 \%$ to occupying $21 \%$ of the Basin. Again, this has occurred largely as a result of habitat conversion on non-federal lands (Hann et al. 1997). As in dry grass habitats, production of vegetation within dry shrub areas depends greatly on precipitation received during the fall-winter and winter-spring periods, the times of the year when most precipitation falls. Dry shrub areas receive less precipitation than do dry grass habitats, and the amount of precipitation varies more drastically across years in dry shrub habitats (Hann et al. 1997). As in dry grass areas, invasion of upland herblands and upland shrublands by exotic plants (especially cheatgrass, but also rush skeletonweed, medusahead, whitetop, and diffuse knapweed) has caused a change in dominance within dry shrub areas. As a result of fire exclusion, upland herbland areas have also been invaded by woody species such as sagebrush, and low sagebrush habitats have been encroached upon by western juniper in the northern
Klamath Basin (Figure 4; Hann et al. 1997). Future management of dry shrub habitats will probably involve little to no use of timber harvest, but will involve greater use of prescribed fire than in dry grass areas and greater effort to control exotic plants than in cool shrub habitats (Britton and Ralphs 1979, Hann et al. 1997).

\section{Background Information Specific to Each of the Plan's Major Research Themes}

\section{Rangeland Health}

Rangeland health has been defined as "the degree to which the integrity of the soil and the ecological processes of rangeland ecosystems are sustained" (National Research Council 1994). In sustainable ecosystems, the system is capable of retaining its characteristic vegetation and soils within predictable bounds of variation, given a natural disturbance regime (Chapin et al. 1996). More generally, ecosystem health can be defined as the capacity of rangeland, aquatic, and forest ecosystems to persist and perform as expected in a particular area (USDA and USDI 2000a).

\section{Exotic Plants}

The project area has been invaded by hundreds of exotic plants during the last 100 years (Mack 1986), and the spread of invasive plants claims approximately 4,600 acres (1,900 ha) of federal lands per day (USDI BLM 2000). As of the mid-1990s, approximately 862 exotic species of plants inhabited the area in Washington, Oregon, Idaho, Montana, and Wyoming (Rice 1994). Because many of these species are native to the Mediterranean region, they often thrive in the similar climate of the project area (i.e., wet, cool autumns and winters; and hot, dry summers; Mack 1986). Agriculture was the major means by which exotic plants initially entered the project area, although road networks, livestock grazing, wildlife, increased deposition of $\mathrm{CO}_{2}$ and nitrogen, and other disturbances to soil surfaces have facilitated their establishment and spread (Bazzaz 1986, Hann et al. 1997, Davis et al. 2000). Nonetheless, species such as cheatgrass, spotted knapweed, yellow starthistle, and leafy spurge have the ability to invade even relatively undisturbed sites such as wilderness areas and national parks (Svejcar and Tausch 1991, Asher 1994, Kindschy 1994). At a broad spatial scale, grasslands, riparian areas and some open forests are cover types that are more susceptible to exotic invasions than 
are montane areas, dense forests, and alkaline desert valley floors (Hann et al. 1997). The rapid spread and competitive nature of invasive exotic plants in the Basin deteriorate the structure, composition, and function of native plant and animal communities (Figure 2). These alterations to communities are observed as a) decline in aquatic and terrestrial habitats for wildlife; b) reduction of forage for grazing animals; $c$ ) potential increase in surface water runoff, sediment delivery, and soil erosion; d) decline in water quality; e) reduction in biological diversity; and f) changes in fire cycle and disturbance regime as they relate to succession (Figure 5; Hessburg et al. 1999).

Perhaps the most abundant invasive exotic plant in the Basin is cheatgrass (Hessburg et al. 1999). Introduced to the Basin in the 1880 s from Europe, probably via contaminated grain, cheatgrass reached its current distributional extent in the 1930s and has subsequently increased in density (Mack 1981). Ecotypic variation in cheatgrass has allowed it to colonize diverse habitats at elevations from 450 to $2,745 \mathrm{~m}$, and areas receiving between 15 to $56 \mathrm{~cm}$ precipitation annually (Bradley 1986 , Pyke and Novak 1994). Characteristics of cheatgrass that facilitate its establishment in native vegetation, particularly in disturbed areas, include high seed production, earlier germination than most native species, greater germination rate, tolerance to grazing, and rapid reestablishment after fire (Hulbert 1955, Mack 1981, D'Antonio and Vitousek 1992, Martens et al. 1994, Vallentine and Stevens 1994).

\section{Wildfire Suppression}

Across most of the Basin, wildfire suppression during the last 130 years has combined with other factors such as agriculture, excessive livestock grazing, and exotic plants to cause great changes in vegetation structure, density, and composition (Hessburg et al. 1999). Due to suppression, wildfires now generally occur with much less frequency (yet with greater intensity, size, and severity). However, invasion by exotic grasses has increased the frequency of wildfires in dry shrub and dry grass habitats (Figure 5; Hann et al. 1997). The consequences of fire suppression on rangelands include a) shifts of all vegetation types to agricultural lands; b) encroachment of woody species (e.g., juniper, sagebrush, ponderosa pine) into dry grass and cool shrub areas, resulting in reduction of herbaceous cover and species richness; c) increased density of sagebrush in dry shrub areas; d) increased fragmentation and loss of connectivity between habitat patches; e) increased erosion; f) lower biodiversity; and g) lower habitat value for wildlife species (Johnsen 1962, Young and Evans 1981, Hessburg et al. 1999).

\section{Roads}

Roads occupy only about $2 \%$ of the Basin's area, but because $39 \%$ of the Basin's roads are located in watersheds that are highly susceptible to erosion and sediment transport, water quality and hydrologic function in many streams have declined substantially (Lee et al. 1997). Roads often facilitate the spread of exotic weeds, reduce and fragment native habitats, serve as a barrier to many less vagile species, and increase human disturbance by providing easier access (Swanson and Dyrness 1975, Noss and Cooperrider 1994, Forman and Alexander 1998, Jones et al. 2000a, Trombulak and Frissell 2000). For example, most recreation use in the Basin is tied to roads and accessible water bodies (Haynes and Horne 1997, Lee et al. 1997). In rangelands, road construction has facilitated the expansion of woody species through indirectly assisting fire suppression (as fuel breaks) and livestock grazing (Hessburg et al. 1999). Although some road closures may occur in the Basin in the future (particularly in forests), implementation strategies assume that "the current minimal level of road construction on BLM lands will continue" (USDA and USDI 2000a:16-11). In fact, very little change in road density classes is expected during the first decade of implementation (USDA and USDI 2000a). Many roads on public lands were established through repeated use by early settlers and later land managers.

\section{Herbivory}

Herbivory by native grazers likely played a less significant role in Basin landscapes during the Pleistocene and early- to mid-Holocene than it does currently (Mack and Thompson 1982, Grayson 1993, Miller et al. 1994), as climatic changes and fires were the primary factors influencing vegetation historically (Hessburg et al. 1999). The introduction of domestic sheep, cattle, and horses by Euro-Americans led to higher grazing intensities, especially in the late 1800 s and early 1900s (Mack and Thompson 1982), creating adverse effects, especially in riparian areas, upland vegetative types, and ponderosa pine forests (Hessburg et al. 1999). In addition, human practices used with domestic livestock (e.g., artificial maintenance of livestock at consistently high levels, fences that prevent migration, supplemental feeding) have significantly altered the frequency, intensity, extent, and magnitude of grazing in semiarid communities (Archer and Smeins 1991). Nonetheless, many areas exist in the Basin in which removal of livestock alone is unlikely to improve ecological integrity, because transitions to altered vegetative states (e.g., encroaching junipers, areas of widespread cheatgrass and medusahead) have prevented the 
possibility of return to previous conditions (Archer and Smeins 1991, Laycock 1994, Miller et al. 1994). Because semiarid ecosystems generally do not exhibit succession to climax communities in the Clementsian sense, research is needed to improve our understanding of the conditions under which state transitions occur in diverse vegetation communities and the inputs of resources (i.e., active restoration treatments) needed to shift ecosystems from less desirable states to one of many other possible metastable configurations.

In general, excessive herbivory leading to new states or altered system trajectories has decreased the overall density of native grasses and increased the dominance of smaller-stature grasses and forbs (Hann et al. 1997). Continued stocking of livestock at near-normal levels during times of moderate to severe droughts may be the greatest cause of range deterioration and critical thresholds being crossed in upland areas (Jardine and Forsling 1922, Vallentine 1990). Determining how ecosystem patterns and processes in semiarid regions respond to bulk grazing by cattle, horses, and wapiti (elk) constitutes a major focus area of future research needs. Concentration of livestock in riparian areas remains an ongoing challenge.

Riparian areas have been particularly altered during the last 100 years, primarily due to improper livestock grazing practices (i.e., grazing during summer for too great a duration or in too great a number; Hann et al. 1997), but also due to impoundments for agriculture, historic mining, dams, channelization, insect and disease outbreaks, and introduction of exotic species. Although season, duration, livestock type and class, distribution, and stocking rates may all be manipulated to attempt recovery of riparian areas (Kauffman and Krueger 1984), most cases of successful riparian restoration have excluded livestock for two or more years. This period of exclusion often facilitates improvements due to improved future management (Hann et al. 1997). Livestock in riparian areas may affect water quality directly through deposition of fecal material in and near surface water, causing nutrient enrichment and contamination from bacterial and protozoan parasites, or by increasing temperatures, and suspended sediments (Behnke and Raleigh 1978, Platts 1979, Larsen 1996). Excessive livestock grazing may alter water quality indirectly by accelerating erosion, stream incision, and siltation; compacting soils and thus reducing infiltration; widening and shallowing the streambed; producing gradual stream channel trenching or braiding; altering timing and volume of water flows; and decreasing vigor and biomass and altering species composition and diversity of riparian vegetation
(Kauffman and Krueger 1984, Belsky et al. 1999). In addition to these changes, livestock can affect viability of riparian vertebrates by eliminating nesting substrates, altering habitat structure and composition, encouraging cowbird expansion, and increasing exotic plants (Wales 2001). Few studies exist on how landscape-level patterns in riparian vegetation affect viability of wildlife populations (Wales 2001).

\section{Expansion of Western Juniper}

Expansion of western juniper into mountain big sagebrush, low sagebrush, quaking aspen, and riparian communities has been proposed to stem from the addition of excessive livestock grazing and fire suppression to historic disturbance regimes in the Basin (Eddleman et al. 1994, Miller and Rose 1995). Excessive grazing pressure, particularly in the late 1800 s and early 1900 s, reduced fuels that could carry fire, and fire suppression further decreased frequency of fires in juniper habitats (Miller and Rose 1995, Hann et al. 1997). In contrast, before Euro-American settlement, distribution of juniper expanded during climatically wetter and cooler periods and contracted during warmer and drier periods via fire's often-lethal effect on juniper saplings (Miller and Wigand 1994, Hann et al. 1997). In some cases, increased densities of juniper in the above-mentioned communities can produce various effects on vegetative structure and composition and ecological processes, including a) decline in production or elimination of understory vegetation; $b$ ) reduced forage availability and quality of winter range for mule deer; $c$ ) potential decline in sagebrush-obligate species; d) potentially reduced rates of infiltration and increased runoff and soil erosion; and e) potential decline in biodiversity at very high juniper densities (Haugen 1993, Oregon Department of Fish and Wildlife 1993, Bates et al. 1994, Eddleman et al. 1994). As an example of the broad-scale magnitude of change in juniper habitats, Hann et al. (1997) estimated a $163 \%$ increase in extent of the juniper-sagebrush cover type from circa 1850 to 1991. Sagebrush, ponderosa pine, and lodgepole pine are examples of woody species that may similarly encroach upon dry grassland or increase their dominance in dry shrubland communities, often reducing herbaceous understory and biotic diversity (Eddleman et al. 1994, Miller and Rose 1995).

\section{Climate Change}

Although climatic changes must be viewed from the perspective of several temporal scales to adequately assess trend, mounting climatological data suggest that 
rapid shifts in climate (e.g., temperature, precipitation, seasonality, increased deposition of $\mathrm{CO}_{2}$ and nitrogen) are occurring in the United States and across the globe (Schneider 1990, Kittel et al. 1997). A reasonable body of theory has been put forward to predict biological responses to changes in climate (e.g., Peters and Darling 1985, McDonald and Brown 1992, Murphy and Weiss 1992), although few predictions regarding biological responses have been tested across broad spatial scales. Under presumed increases in temperature, populations are predicted to move up in elevation or latitude, or to experience local extirpations when migration upslope or to more northern habitats is not possible. As an example, Beever (1999) re-visited sites of historically recorded American pika populations in the hydrographic Great Basin, and found that more than one-fourth of the populations have suffered apparent extirpation during the latter part of the 20th century. Furthermore, most extirpations occurred at the lowest-elevation sites, although habitat area and proximity to roads also appeared to contribute to greater extinction risk.

\section{Restoration Across DOI Lands Definitions}

One of the overarching goals of research and resulting management on federal lands is to restore and maintain ecological integrity and ecosystem health over the long term. ICBEMP efforts have defined restoration in the manner of the Society for Ecological Restoration: "Ecological restoration is the process of assisting the recovery and management of ecological integrity." Restoration may involve a mix of active and passive approaches, and must consider the context (e.g., conditions in adjacent habitats, current climate) in which restoration projects occur. The Society defines ecological integrity as "a critical range of variability in biodiversity, ecological processes and structures, regional and historical context, and sustainable cultural practices." Ecological integrity has also been defined as "a measure of the presence of physical and biological processes, patterns, and functions" (USDA and USDI 2000a:2-11). National Academy of Sciences (1974) provides more explicit definitions of rehabilitation, reclamation, and restoration.

\section{Broad-scale Assessment of Conditions}

Nearly three-fifths (59\%) of FS- and BLM-administered lands in the Basin currently exhibit moderate (36\%) or high $(23 \%)$ degrees of departure from the historical range of variability (HRV; Morgan et al. 1994) in vegetation composition and disturbance regime, compared with only $7 \%$ of all lands that were classified as having no departure (Hessburg et al. 1999). Departure from HRV compares how vegetation composition, vegetation structure, and succession/disturbance regimes differ between current patches in a subwatershed landscape and the normal range and variability of these variables in historical landscape patches. However, BLM lands generally exhibit less departure from historical conditions than do privately owned lands. Ecological integrity, as used in the Supplemental Draft Environmental Impact Statement (USDA and USDI 2000a), is based on average trends of subwatershed composite HRV departure, road density, and conditions of aquatic habitat. Over half (51\%) of FSand BLM-administered lands in the Basin are estimated to have low ecological integrity currently, compared with 23\% that have high integrity (Figure 1; Quigley et al. 1996). Landscape health can be defined as "the best fit of the dynamic interaction of human land use, biodiversity, and ecosystem health that is in balance with the limitations of the biophysical system and inherent disturbance processes" (Hann et al. 1997, p. 918). Although no FS- or BLM-administered lands are believed to currently exhibit 'high' or 'very high' landscape health, $34 \%$ of these lands in the Basin have 'very low' health, compared with $49 \%$ exhibiting 'low' health and $17 \%$ exhibiting 'moderate' health (USDA and USDI 2000a).

\section{Issues of Particular Concern for Restoration}

Three fundamental research needs exist with respect to restoration: 1) understanding and defining restoration potential (i.e., existence of alternative states and thresholds); 2) setting goals; and 3) determining appropriate methods to achieve restoration goals.

At broad spatial scales, the most dramatic alteration to biological systems is the conversion, fragmentation, and degradation of habitats (Noss and Csuti 1994). Regarding conversion and degradation, criteria are not currently available to determine when the amount of land area remaining in any given ecosystem type threatens its existence as a functioning ecological entity (Flather and Sieg 2000). There is growing recognition that ecosystem behavior can change abruptly in response to a change in the environment-a pattern called a critical threshold. Ecosystem degradation, or loss of land within a particular successional stage, is one ecological change that has been suggested to exhibit threshold behavior (Fahrig 1998). Accordingly, understanding when ecosystems can sustainably withstand further area reductions, or when ecosystem processes are not reversible, will require knowledge of when critical thresholds are being approached at landscape scales 
(Flather and Sieg 2000). Because most research on landscape fragmentation has been performed in forested ecosystems, there is a critical need to complete studies in rangeland ecosystems (Flather and Sieg 2000). Research is needed to promote understanding of how landscape patterns such as fragmentation affect species population dynamics, dispersal, and diversity (Lubchenco et al. 1991). Remotely sensed satellite imagery can be used to quantify rangeland fragmentation and formulate hypotheses about specific agents of fragmentation such as roads, concentrations of exotic species, and intensive land uses (Flather and Sieg 2000).

The shrub-steppe region well illustrates the challenges associated with fragmentation and degradation. Extensive areas of shrub-steppe habitat (e.g., $\sim 60 \%$ of shrub-steppe in Washington) have been permanently converted to other uses such as agriculture and urban areas (Dobler et al. 1996). Furthermore, the best sites for healthy sagebrush communities (e.g., deep soils, and relatively mesic conditions) are also best for agricultural productivity. At the landscape scale, most of the remaining shrub-steppe habitat occurs in private ownership. Few areas of extensive high-quality sagebrush habitat remain, as brush control, intensive grazing, invasive species (e.g. Russian olive, cheatgrass, and other exotic annual grasses), altered fire regimes, seeding of crested wheatgrass, domestic predators (e.g., cats and dogs), and nest parasites (e.g. brown-headed cowbird) may all reduce habitat quality for different species (Altman and Holmes 2000). Analysis of habitat trends across the Basin suggests that three other issues are of high priority for seven mammal and birdsagebrush-obligate species. These issues include a) soil compaction, erosion, and loss of microbiotic crusts; b) continued degradation of wet meadow and riparian vegetation adjacent to springs, seeps, and streams; and c) adverse effects of human disturbance (Wisdom et al. 2000).

Given increasing competition among alternative land uses and the limited amount of the terrestrial landbase dedicated to strict resource protection, when there is choice over which areas to allocate to which protection status, the decision should be informed and in some sense optimal (Flather and Sieg 2000). However, rangeland ecologists do not yet know how to allocate limited conservation areas in a way that assures comprehensive protection of ecosystem types (Flather et al. 1997). Furthermore, we do not fully understand what degree of protection is required to sustain various ecosystem components, and what mechanisms determine whether protection of a given rangeland type will sustain viable populations of species in that type (Flather and Sieg 2000).
Biological soil crusts, composed of algae, bryophytes, microfungi, cyanobacteria, and bacteria growing near the soil surface, can comprise up to $80 \%$ of the living cover in an area (Belnap 1990, Eldridge and Greene 1994). Biotic crusts contribute to soil stability, nutrient cycling, and soil moisture, and their ecological importance is probably greatest in arid ecosystems that have low aboveground productivity (Hann et al. 1997). Microbiotic crusts contribute to soil structure and stability by binding soil particles within physical structures of the microphytes (Belnap and Gardner 1993, Danin and Yaalon 1980). The resulting microtopography creates greater surface roughness, which reduces water velocity, creates ponding, and enhances deposition of sediment (Brotherson et al. 1983). Crusts may exhibit competitive, mutualistic, or amensal (i.e., neutral) relationships with vascular plants, depending upon phenological stage of the organisms, climate, edaphic conditions, plant-animal interactions, and resource management (Graetz and Tongway 1986, Meyer 1986, Beymer and Klopatek 1992). Development of soil crusts may be compromised by any activity that disturbs the soil surface, such as off-road vehicle use, trampling by large animals, very frequent or severe fire, or recreational hiking. Cyanobacteria and algae are some of the first components to recover after disturbance, whereas bryophytes and lichens recover more slowly (Leonard et al. 1995, Rosentreter 1995). Much remains to be learned of the ecological functions of microbiotic crusts, including their roles in hydrology, nutrient cycling, energy flow, and biodiversity, their historic and potential future distributions, and their responses in the Basin to various types of disturbances.

Texture and chemistry of the soil surface are the main soil characteristics that influence potential for crust development (Hann et al. 1997). For example, fine-textured, mineral soils (e.g., calcareous gravelly loams and silt loams) tend to have more microbiotic crusts than do coarse-textured, well-drained rhyolitic soils. In addition, sites with inherently lower densities of herbaceous plants possess greater potential for crust development. As exotic annual grasses increase in abundance, they cover and shade the soil, thus reducing photosynthesis of crust components and leading to crust decline (Brotherson et al. 1983, Williams 1994). Biological crusts are fragile and vulnerable to disturbance when dry (and dormant, as during summer), but are more resilient to disturbances such as livestock grazing during their growing season, the cool, moist winter and late fall periods (Belnap 1993, USDA and USDI 2000b). Many details regarding restoration of soil crusts remain unknown, and knowledge of which com- 
ponent species of crusts in what proportions to expect on which soil types is fragmentary at best (Williams 1994).

The rapid expansion in the Basin of numerous exotic plant species, whose control can exact high costs, has led managers to adopt integrated weed management to restore native vegetation by releasing resident perennials from the competition of exotics or revegetating the native community. Integrated weed management involves combining several control techniques in a well-planned and coordinated manner to reduce impacts of exotic plants on public lands (USDA and USDI 2000a). Although most exotic plant species entered the Basin initially by way of agriculture, exotic plants may be spread by livestock, pack animals, wildlife, motor vehicles, seed mixtures, hay, wind, water, hikers, and other means. Limiting dispersal of weed seeds, minimizing disturbance to soils, and proper management of native vegetation are general techniques for preventing weed spread. Because exotic plants affect not only plant composition but also the structure, function, and disturbance regime of plant communities, establishment (or re-establishment) of native forbs, grasses, and shrubs is critical to preventing further degradation. Although techniques for re-establishing certain native grasses, sagebrush, and other shrubs exist, information is largely lacking on the restoration of native forbs. Other formidable impediments to restoration of native habitats are the high cost and low availability of native seeds; hence, it is often cheaper and easier to use nonnative species.

In addition to maintaining or re-establishing perennial plants, management options to control weeds include cultural control methods (e.g., management of livestock grazing and public use, prevention of soil disturbance); physical control methods (e.g., "grubbing," mowing, plowing, hand pulling, burning); biological control methods (e.g., introduction of species-specific herbivores); and chemical control methods (e.g., herbicides, fertilization of non-target species). In order of decreasing importance, priorities for control include 1) eradicating new introductions; 2) restricting expansion of large-scale infestations; 3 ) controlling large-scale infestations; 4) re-vegetating or establishing competitive grasses (probably the best long-term strategy); and 5) proper range management (USDA and USDI 2000a). Considerations important in selecting control techniques include cost; proximity to water (for chemical methods); specificity of herbicide or biological control agent, as it relates to potential to negatively impact non-target (native) species; and time to eradication, as it relates to potential for further degradation of the site. Research is needed to ascertain the effectiveness of multiple control techniques and the spatial application of these techniques in coordination with native plant restoration techniques. At a broader level, because the relative roles of fire and livestock grazing have been altered by climate change and exotic plant invasions, research is also needed to clarify the potential for restoration and the importance of various passive and active approaches within different vegetative communities.

\section{Aquatic-Terrestrial Interface}

Approximately $444,000 \mathrm{~km}(275,890 \mathrm{mi})$ of streams and up to 9,186 lakes occur in the Basin (Lee et al. 1997). Healthy watersheds provide numerous ecosystem services, including a) a high-quality, dependable supply of water; b) moderation of the effects of flooding, drought, and climate change; c) recharge of stream systems and groundwater aquifers; d) maintenance of diverse and productive vegetation that buffers sediment pulses, moderates stream temperatures through shading, and houses a diversity of watchable wildlife; and many others (Postel and Carpenter 1997, Williams et al. 1997). Whereas sources of disturbance in riparian areas historically included periodic floods and fires, beaver dams, as well as some browsing by deer, wapiti, and pronghorn antelope, recent disturbances leading to decreased riparian function have included livestock grazing, fire, timber harvest, conversion to crop and pastureland, road development, and dams, diversions, and pumping (Chamberlain et al. 1991, Platts 1991). Many of these disturbances have led to fragmentation of riparian habitat and, consequently, uncharacteristic isolation of aquatic organisms across the landscape. In addition, various forms of toxic pollutants, especially acid-mine drainage in streams, deposition of heavy-metal contaminated sediment in streams, lakes, and wetlands, and concentration of selenium salts in irrigation drainage, have compromised water quality and therefore biota in riparian systems. In addition to recent disturbance, past management activities such as homesteading and associated plowing, beaver trapping, in-stream dredging, overgrazing, and road building have left a legacy of altered channels by affecting rates at which sediment, water, and wood are transported through stream channels (Lee et al. 1997, Hessburg et al. 1999).

Across the Basin, key habitat trends identified by analysis of 120 stream re-surveys and 6,000 recent stream inventories include a) decreased extent and continuity of riparian and wetland vegetation in nonforest areas; b) decreased amount and diversity of riparian cover; c) decreased frequency of large trees and late seral vegetation; d) $80 \%$ decrease in riparian shrublands due to juniper invasion, conversion to riparian herblands, and 
increased abundance of exotic grasses and forbs (Hann et al. 1997, Hessburg et al. 1999). The surveys additionally found that, once variability in slope, lithology, and vegetation was accounted for, frequency of large pools alone and all pools combined decreased with increasing road density and management intensity (Lee et al. 1997).

However, stream habitat data are more available in forested regions than in rangelands, and are practically nonexistent in valley-bottom and agricultural areas, because stream inventories are generally motivated by concerns about fish habitat (Lee et al. 1997). Furthermore, most streamflow in the Basin originates from higher-elevation FS-administered lands (Lee et al. 1997), and Wissmar et al. (1994) believed that in eastern Oregon and Washington, most BLM-administered lands do not contribute significantly to streamflow. Even among forested systems, investigation of trends in riparian systems is compromised by the fact that no systematic or statistically based survey of conditions previously existed for federal or non-federal lands. Thus, conclusions drawn from available data may not be representative of the region of interest, and the lack of consistent protocols for data collection complicates analysis and interpretation of surveys across broad spatial scales.

Sixty-six percent of inventoried BLM-administered riparian areas in the western United States are either "non-functioning" or "functioning at risk" (USDI BLM 1994). The goals of BLM's Riparian-Wetland Initiative are to 1) restore and maintain existing riparian and wetland areas so that $75 \%$ are in "proper functioning condition" (i.e., adequate vegetation, landforms, or large woody debris is present to dissipate stream energy associated with high water flows); and 2) provide the widest variety of habitat diversity for wildlife, fish, and watershed protection (USDI BLM 1993).

Exchange of materials between aquatic and both adjacent terrestrial habitats and near-stream aquifers (e.g., the hyporheic zone) has been reduced by construction of drains, ditches, and dikes, as well as by clearing streams for boat passage (Lee et al. 1997). Similarly, connectivity of waterways has been compromised in part by the existence of at least 2,103 dams across the Basin (Lee et al. 1997). In streams with impaired water quality on BLM lands, impairment is most commonly caused by non-point pollution consisting of high levels of turbidity and sedimentation, and high temperatures (Lee et al. 1997). Although the ecological integrity of streams, lakes, and wetlands was significantly compromised by the $1920 \mathrm{~s}$, riparian areas have been the focus for some of the Basin's most successful restoration efforts to date (Lee et al. 1997). Improvement generally has resulted from enhanced management by livestock-grazing permittees working collaboratively with management agencies (Hann et al. 1997).

\section{Riparian Areas}

Riparian areas are the most biologically diverse habitats on federal lands, as the interface of aquatic and terrestrial habitats brings together a diversity of structural features, and provides contrast and a water source. Riparian areas provide food, cover, and water for over half of the terrestrial vertebrate species in the Basin, and up to three-quarters of species within a given area, such as the Blue Mountains, may use riparian areas disproportionately (Bull 1977, Thomas 1979, Raedeke 1989). Because riparian areas contain increased humidity, higher transpiration rates, greater shade, and increased air movement than surrounding (non-forested) upland habitats, they provide thermal cover and favorable microclimates that permit species to expend lower amounts of energy (Thomas 1979). Riparian shrubs and trees such as cottonwood, alder, and willow are important food sources for herbivorous mammals such as deer, wapiti, moose, beavers, hares, rabbits, and voles. Many species of amphibians, reptiles, birds, and mammals associate strongly with aspen-cottonwood riparian areas that contain both herbaceous and shrubby components. For example, within the Basin, 84 of the 132 species of breeding migratory birds use riparian areas for foraging or nesting (Saab and Rich 1997). Similarly, ecologists have only a superficial understanding of the distribution of and threats to amphibian taxa across this broad region that is often limited to generalized habitat relationships (Corn 1994). Riparian areas also act as corridors for dispersal or migration for many taxa, including carnivores, ungulates, birds, bats, and plants (Bull 1977, Gregory et al. 1991, Heinemeyer and Jones 1994, Vogel and Reese 1995). In addition to improper livestock grazing - the most important influence on riparian areas in Basin rangelands; (USDA and USDI 2000a)-riparian areas have been affected by conversion to agriculture, heavy recreational use, introduction of exotic plant and animal species, fire exclusion, historic mining, and dams.

\section{Wetlands}

Wetlands in the Basin include marshes, ponds, lakeshores, sloughs, wet meadows, and bogs, and range from permanent to ephemeral in their seasonal occurrence. Wetlands are defined by three fundamental characteristics: hydrophytic vegetation; hydric (i.e., becom- 
ing anaerobic) soils; and periodic to permanent inundation (Federal Interagency Committee for Wetland Delineation 1989). About $40 \%$ of historical wetlands have been lost from the Basin, primarily due to losses on private lands from past draining for pasture or cropland (Lee et al. 1997). The largest existing wetlands on DOI lands in the planning area occupy valley bottoms in the Upper Klamath Basin and northwestern Great Basin. Wetlands in the southern area of the Basin serve as critical links in migration routes for numerous waterbirds and shorebirds (Haig et al. 1998, Plissner et al. 2000), and contain many species of narrowly endemic fishes, amphibians, aquatic snails, and other aquatic species (Corn 1994, Lee et al. 1997). Wetlands depend on freshwater inflow from adjacent riparian areas to prevent increased mineralization (e.g., salts); thus, water quality in wetlands can be compromised by excessive "offtake" of water from source streams. Ephemeral ponds in arid lands are often heavily altered for the creation of guzzlers for livestock and upland game species. Within the Basin, lake conditions have been altered most strongly by residential development and recreational activities such as backpacking, horse packing, recreational vehicle use, and road and trail development (Lee et al. 1997). Recreation has led to disturbance or damage of beach and near-shore habitats, as well as the introduction of non-native plants (e.g., purple loosestrife, saltcedar, Russian olive) and animals (e.g., bullfrogs, non-native trout). These non-native species often become well established, and greatly influence the functional dynamics of existing native habitats.

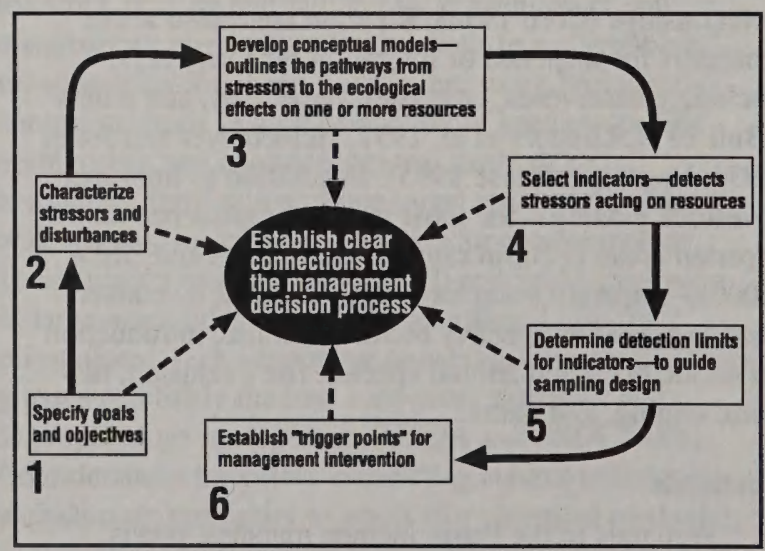

Fig. 6. A list of key issues to address sequentially in the design of a prospective monitoring program. In an adaptive management framework, monitoring is an ongoing, iterative process, refined over time as new understanding and insights are gained. Adapted from Noon et al. (1999).

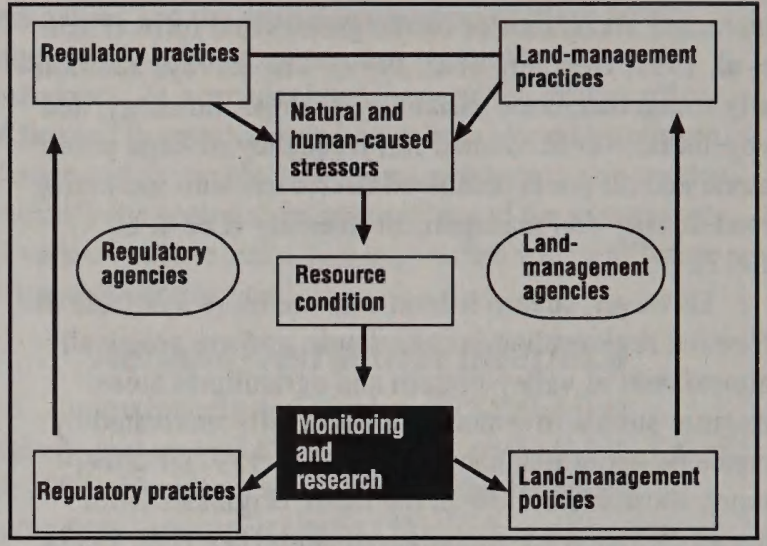

Fig. 7. Conceptual model demonstrating the relationship of arrangement of monitoring under an adaptive-management approach. The goal of monitoring is to provide feedback about status and trends in resource condition that will be useful for evaluating effects of management actions or regulatory practices. Adapted from Mulder and Palmer (1999).

\section{Special-status Fish Species}

Twenty-two of the 47 special-status fish species in the planning area occur in the Great Basin and Klamath Basin areas. These and other listed species on DOIadministered lands are affected most strongly by several factors, including water withdrawal or diversion; loss of connectivity and consequent disruption of metapopulation structure; degradation of habitat due to excessive livestock grazing, urbanization, and upstream silvicultural practices; and introduction of 55 non-native fish species across the Basin (Quigley et al. 1996, Lee et al. 1997, USDA and USDI 2000a). Data on distribution, life history, and habitat relationships are generally lacking for most narrow endemics, thus hindering the understanding necessary for their management and conservation (Lee et al. 1997). Although many key salmonid species inhabit DOI-administered aquatic habitats only along the Salmon River in Idaho, numerous salmonid strongholds occur on DOI lands (Figures 3 and 4). The role of these lands in regional maintenance of aquatic faunas, especially as corridors for migration, is critical. Furthermore, current distributions of redband trout and Yellowstone cutthroat trout overlap many BLM-administered lands in the Basin (Lee et al. 1997). Although the projected $1.9 \%$ annual growth of the human population across the Basin may undermine efforts to improve aquatic integrity, aquatic conservation strategies have highlighted the need for multi-scale approaches that acknowledge cumulative (i.e., synergistic) effects and metapopulation dynamics, and assume that federal lands will bear the responsibility for sustaining biological diver- 


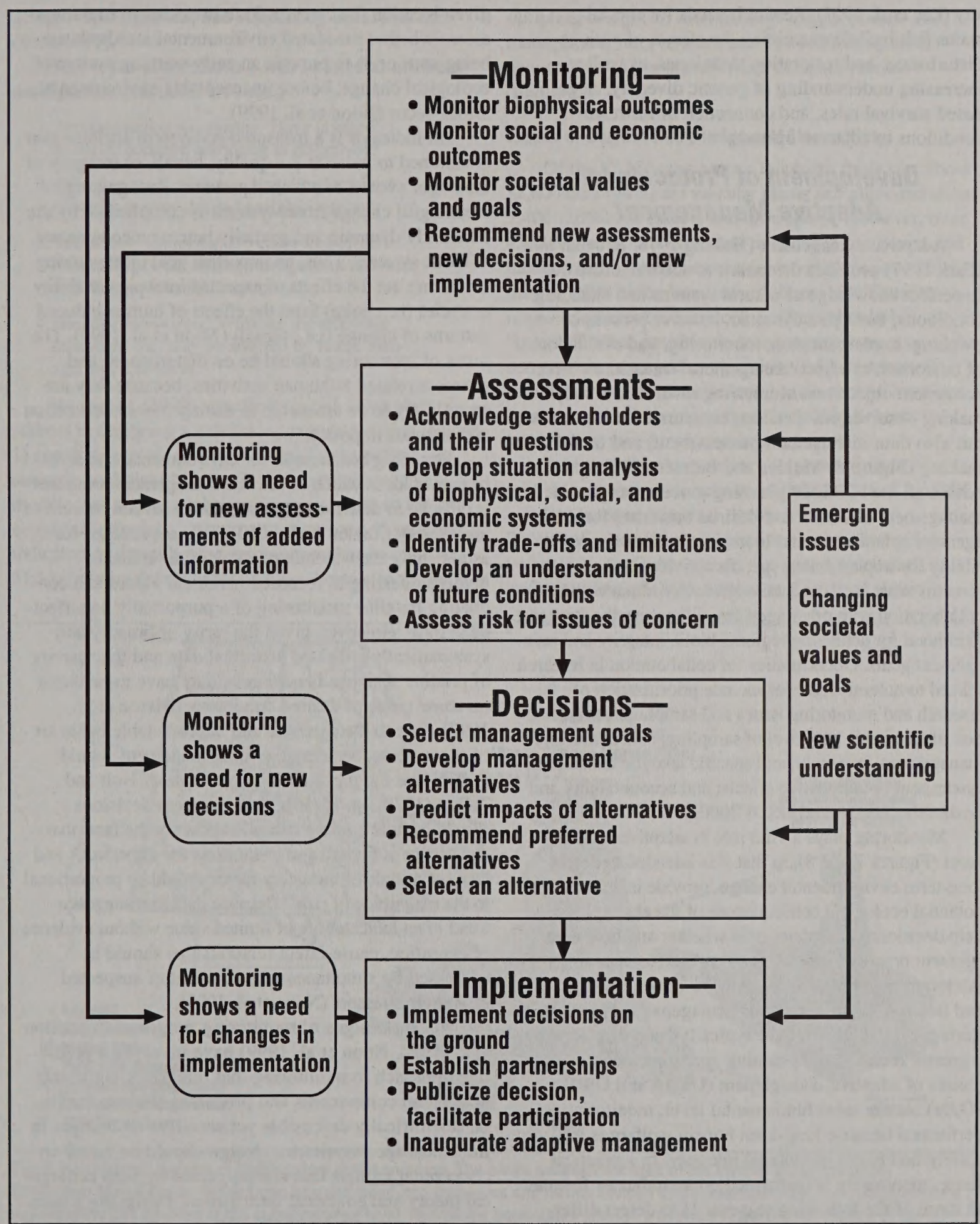

Fig. 8. Relationships among monitoring, assessments, decisions, and implementation in a general planning model for ecosystem management. Because the model is iterative, internal and external influences may initiate any step in the process, and the process is ongoing. Adapted from Quigley et al. (1996). 
sity (Lee et al. 1997). Research needs for specialstatus fish include examining the effects of various disturbances and restoration techniques, as well as increasing understanding of genetic diversity, stagebased survival rates, and connection of instream conditions to adjacent uplands.

\section{Development of Protocols for Adaptive Management}

Adaptive management (Holling 1978, Brunner and Clark 1997) provides the means to accommodate our imperfect knowledge of natural systems and changing conditions, through a dynamic, iterative process of planning, implementation, monitoring, and evaluation of outcomes, to adjust management strategies to meet ecosystem objectives. Monitoring involves not only making observations or taking measurements over time, but also data management, assessment, and decision making (Figure 6; Mulder and Palmer 1999).

Although the ICBEMP planning process has provided management direction and desired outcomes for DOI agencies at landscape and bioregional scales, the responsibility for implementing specific activities and analyses remains with local land managers. Coordination and collaboration with other agencies will ensure the strongest likelihood for achieving regional biotic integrity and management goals. Opportunities for collaboration in research related to natural resources include prioritization of research and monitoring issues and sampling areas; selection of frequency and level of sampling; data collection, management, inventory, and specific analytic techniques; assessment of cumulative effects; and accountability and credibility (USDA and USDI 2000a).

Monitoring plays a vital role in adaptive management (Figures 7 and 8), in that it is intended to detect long-term environmental change, provide insights to the potential ecological consequences of the change, and help decisionmakers determine whether and how management practices should be amended (Noon et al. 1999). Although monitoring is essential to critical evaluation and iterative improvement of management efforts, monitoring and evaluation have typically been displaced by a greater focus on the planning and implementation phases of adaptive management (USDA and USDI 2000a). At the most fundamental level, monitoring is performed because long-term human welfare is intimately tied to environmental integrity. In a practical sense, monitoring is performed on an indicator for one or more of the following reasons: 1) to detect differences in its value across an area at a given moment (i.e., status); 2) to detect changes in value over time at a given location (i.e., trend); 3) to provide information to assess whether mandated environmental standards are being met; or 4) to provide an early warning system of ecological change, before unacceptable environmental losses occur (Noon et al. 1999).

An indicator is a measured ecosystem attribute that is assumed to indicate the quality, health, or integrity of the larger system to which it pertains. Recognizing meaningful change in ecosystems is complicated by the inherently dynamic and spatially heterogeneous nature of biotic systems. Thus, an important goal of monitoring is filtering out the effects of expected intrinsic variability or cycles (i.e., noise) from the effects of human-induced patterns of change (i.e., signal) (Noon et al. 1999). The focus of monitoring should be on disturbances and stressors related to human activities, because they are more likely to be amenable to management intervention and changes in policy.

Providing benchmarks for environmental standards or thresholds at which to activate management responses is difficult to determine a priori, due to several sources of uncertainty (Taylor et al. 2000). Two approaches for establishing the benchmark value of an indicator involve referring to recorded historical values and conducting baseline monitoring of a purportedly nonaffected system. However, given the rarity of broadly and systematically collected historical data and the scarcity of pristine systems, benchmarks may have to be based on some range of desired conditions (Bisson et al. 1997). Due to the dynamic and unpredictable behavior of ecosystems, benchmarks for management should incorporate the precautionary principle of Holt and Talbot (1978, pp. 15-16): "Management decisions should include a safety factor to allow for the facts that knowledge is limited and institutions are imperfect," and "the magnitude of the safety factor should be proportional to the magnitude of risk." Because data that suggest a trend in an indicator are of limited value without evidence of causation, cause-effect relationships should be addressed by simultaneous assessment of suspected ecosystem stressors (Noon et al. 1999).

Recent designs of monitoring programs (Thornton et al. 1994, Noon et al. 1999) have involved a predictive approach to monitoring that integrates numerous ecosystem components and processes (Figure 6). To be scientifically defensible yet sensitive to changes in the landscape, monitoring design should be based on conceptual models that are supported by both ecological theory and empirical information. Designing a monitoring program that can be implemented requires the identification of quantifiable questions and measurable indicators, as well as the development of monitoring 
design, field methods, and supporting infrastructure (Vora 1997).

Four types of monitoring will be used to evaluate management practices, including

1. Implementation monitoring: Have planned activities occurred according to objectives?

2. Effectiveness monitoring: Have implemented activities met the desired goals/objectives?

3. Validation monitoring: Do cause-and-effect relationships exist among management activities and changes in natural resources?

4. Baseline monitoring: What are the reference conditions that may be affected by future management activities?

Noon et al. (1999) specified a list of seven steps to address in designing a monitoring program, which include 1) specifying goals and objectives; 2 ) characterizing stressors and disturbances; 3 ) developing conceptual models that outline pathways from stressors to the ecological effects on one or more resources; 4) selecting indicators to detect how stressors are acting on resources; 5) determining detection limits for indicators to guide sampling design; 6) establishing "trigger points" for management intervention; and 7) establishing clear connections to the management decision process (Figure 6).

\section{Extent of Current Knowledge and Uncertainty}

Of the 17,186 taxa known to inhabit the Basin, about 12,800 taxa (74\%) are vascular plants and allies and about $3,400(20 \%)$ are insects and arthropods. However, over 43,800 species are estimated to occur in the Basin, and this number excludes most microscopic species, which may number in the hundreds of thousands. Thus, to improve efficiency, monitoring efforts should be "batched" when possible, to monitor numerous ecosystem components (e.g., soils, vegetation, and invertebrates) simultaneously. Systematic broad-scale surveys have not been completed for many taxa, including lichens, bryophytes, rare fungi, and invertebrates.

Additionally, there exists no systematic and reliable estimate of current condition and trend for DOI -administered ecosystems deemed 'rangelands'. Specifically, no mid-scale, consistent map of rangeland vegetation conditions exists, nor does a systematic understanding of the condition and trend of exotic

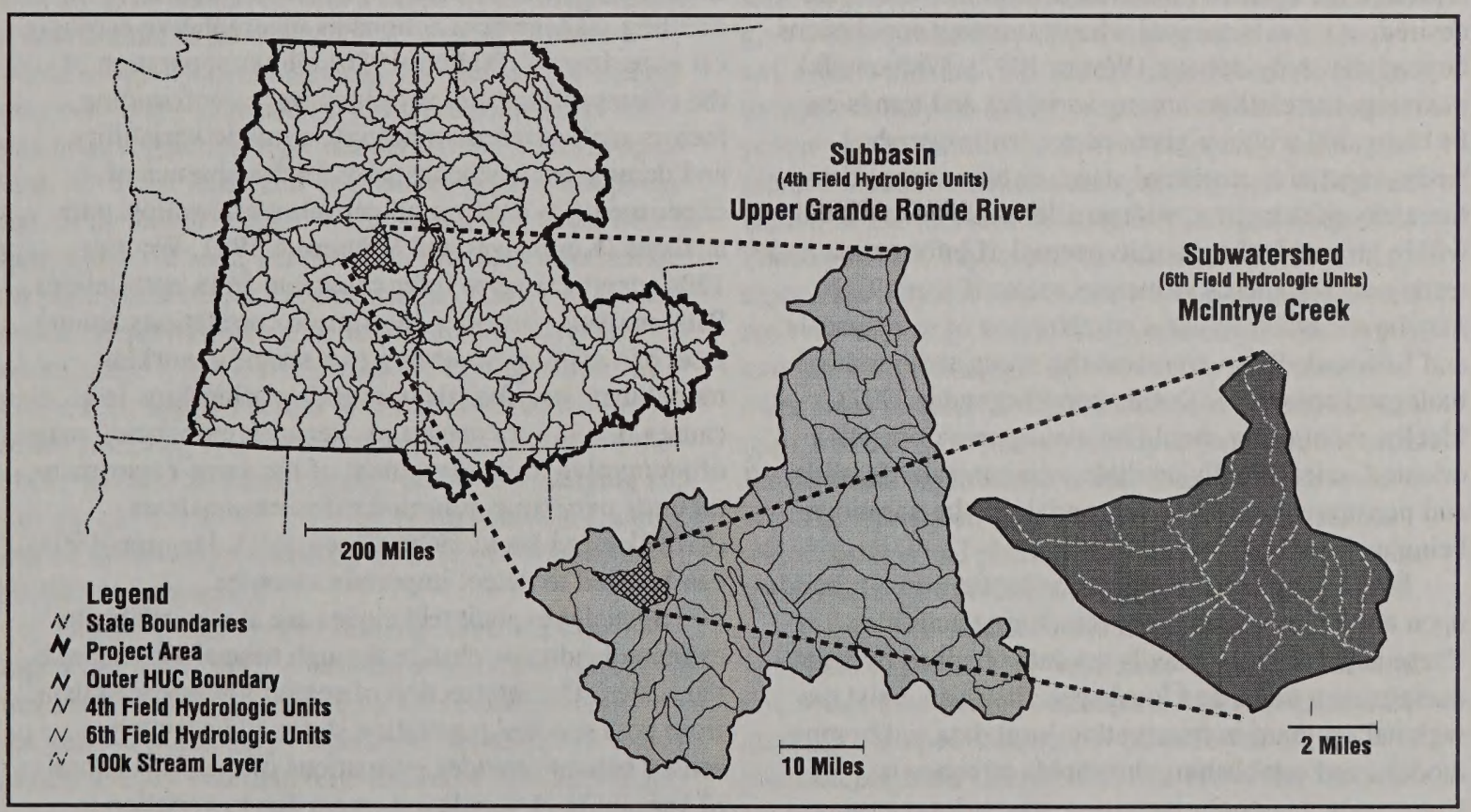

Fig. 9. Hierarchical division of hydrological drainage areas. The entire assessment area of the Interior Columbia Basin Ecosystem Management Project can be subdivided into subbasins and further divided into subwatersheds. The 1:100,000-scale hydrography can be seen at the subwatershed level. Hydrologic boundaries provide a useful framework with which to assess and monitor biological resources because 1) their classification is a well-established system used by numerous agencies and other research institutions; 2) their boundaries can generally be unequivocally defined and mapped; and 3) water is a critical landscape element for both biological systems and human civilizations. Adapted from Lee et al. (1997). 
plants across the Intermountain West. Consistent mid-scale sampling and mapping of riparian conditions is also lacking, meaning that fine-scale examination of riparian areas will remain case studies not amenable to robust extrapolation. The lack of this systematic information will continue to present challenges for mid- and broad-scale assessments and monitoring, and will hinder the creation of a statistically reliable plan of effectiveness monitoring on rangelands. The usefulness of mid- and broad-scale sampling depends, however, upon the existence of a statistically valid fine-scale (plot-based) sampling strategy that addresses ecosystem attributes not detectable from remotely sensed imagery.

\section{Monitoring Across Several Spatial Scales}

Because ecosystem interactions operate within a hierarchy (Noss 1990), it is critical that monitoring and evaluation address questions and trends at various spatial scales. As managers and researchers focus their attention at broader spatial and temporal perspectives, scale will become an increasingly important issue for questions of community ecology and natural resource management (Allan et al. 1997, Hamer and Hill 2000, Schaefer et al. 2000). Sampling should be planned to represent the domain from which valid inferences are desired; caution is merited when extending conclusions beyond the study domain (Wester 1992). With careful planning, correlations among variables and trends can be compared within a given ecosystem, watershed, basin, vegetative structural stage, or cover type. Using a hierarchy of sampling, with smaller-scale units nested within larger blocks, permits accrual of information and testing of hypotheses at various scales (Figure 9). It may be necessary to use a combination of coarse-scale and fine-scale filters to assess the status and trends of biological resources (Dufrène and Legendre 1997). Ideally, monitoring should be management-objective oriented, scientifically credible, economically feasible, and performed at a scale appropriate to the questions being addressed.

Monitoring has the greatest potential when it builds upon and improves ongoing monitoring activities. These activities rely heavily on data obtained by local management units, and local specialists can assist the regional program in interpreting local data, calibrating models, and establishing thresholds of concern.

Conversely, regional monitoring affects local management units indirectly rather than directly, by providing a regionwide context for interpreting local-scale results. Nonetheless, scientific approaches developed for the regional program (e.g., monitoring design, indicator selection, methods of data analysis) can also be used in local-scale monitoring efforts.

\section{Reasons for Limited Success of Past Monitoring Efforts}

Because managers and the general public perceive monitoring costs to be high, monitoring has often been included only superficially in management strategies.

Thus, monitoring receives low priority and insufficient funding, and is implemented in a fragmentary manner. Furthermore, programs often try to measure too many variables, have vague objectives, fail to follow fundamental statistical principles of sampling and estimation, and are implemented ad hoc (Noon et al. 1999). Noon et al. (1999) suggested that the primary reasons for the failure of monitoring programs are a) minimal foundation in ecological theory or knowledge; b) little logic to justify selection of indicators; c) no necessary understanding of causation; d) trigger points not identified; and e) no connection to decision making.

\section{Aspects of Design and Analysis for Monitoring Strategies}

Both monitoring and management-oriented research, whether manipulative or observational, should be guided by clear, specific objectives. Treating management actions as manipulative ecological experiments (Walters 1986) allows separation of the effects of land-use activities from confounding factors such as geomorphology, climatic variability, and demographic stochasticity. In the absence of experiments to confirm all causal relationships, path analysis (Kingsolver and Schemske 1991, Wootton 1994) can be used to infer causation from correlations. Path analysis partitions the simple correlations among a set of variables according to a specific working model that describes their causal relationships (e.g., a causes $b, b$ in turn causes $c$ ). Because monitoring may often involve re-measurement of the same experimental units over time, repeated measures analysis (Crowder and Hand 1990, Green 1993, Huggins 1993) can be used to detect important changes.

Spatially explicit techniques are also available to examine landscape change through time at varying spatial scales. The intersection of spatially referenced data from both species' population status and remotely sensed habitat provides estimations of the proportions of variability in population status due to variation in habitat versus other factors. Changes in status and trend of habitat quality must be monitored at local through landscape scales to explain variability in population status at the scale of the individual, the local population, and the metapopulation (Noon 1999). Because variation 
in habitat availability and quality rarely accounts for all variation in population status, other potential drivers of change should be treated as covariates and added to models. Factors that are significantly correlated with population status can guide hypothesis testing in subsequent manipulative experiments.

When investigating an activity or management practice that has an unknown effect on resources of interest, it may preferable to relax alpha (i.e., significance level) in statistical tests to favor type I error over type II error (Toft and Shea 1983). This practice reduces the likelihood that an effect that is in fact present (e.g., clearcutting is increasing levels of surface erosion) goes undetected by observers. Because natural systems are complex and many factors can impinge upon ecosystem processes and components (Hilborn and Stearns 1982, Lidicker 1991), alternative explanations for observed phenomena should always be considered and explicitly tested whenever feasible. Although it is difficult to achieve adequate replication in factorial designs with more than two or three factors, several parametric and nonparametric multivariate techniques are available to account for multiple causes.

Stratification. If questions of many disciplines and taxa are to be addressed with a single monitoring scheme, it is important to determine the appropriate factor by which to stratify sampling areas. For example, sampling may be broadly stratified by soil series, ecological site, potential vegetation type, habitat type or GAP designation, life zone, dominant vegetative species, site potential, or by another factor. When sampling occurs over a heterogeneous area, stratification provides information on population characteristics within distinctive habitats, and suggests how to obtain total estimates over the entire range (Hayek and Buzas 1997). Algorithms in GIS can be applied across landscapes to randomly select sampling locations within blocks of each of the above factors. Selection among possible stratifying factors should reflect the question being addressed, and can be defined by examining sources of variability in preliminary sampling.

Given limited agency funding, there may be aspects of particularly charismatic species or communities that could be monitored by interested members of the general public (e.g., Operation HeadStart, Breeding Bird Surveys). Alternatively, naturalist activities (e.g., Breeding Bird Atlas) may be expanded to monitor a wider array of species or data on life-history variables. This technique may be used as one tool of a comprehensive strategy, with the understanding that assistance will be greatest near population centers and during economically prosperous periods. It is fundamentally important that monitoring be economically feasible, yet flexible enough to adapt to new information and new management philosophies. Existing plans with which new management direction must interface include the Healthy Rangelands Initiative, Inland Native Fish Strategy, PACFISH (1994), INFISH (1995), Biological Opinions (e.g., bull trout, steelhead, and chinook salmon), and USFWS recovery plans, especially for caribou and grizzly bears. Attempts should be made to look for common attributes and indicators that might relate to multiple management plans.

Replication. Temporal replication allows the quantification of the effects of extreme and variable climate and other elements that comprise environmental stochasticity. Spatial replication allows the assessment of variability across the landscape, produced by factors such as clinal variation and phenotypic plasticity. Both types of replication increase the likelihood that observed results reflect the normal range of natural variation in conditions.

Whenever possible, a priori power analyses (Cohen 1977) should be used to determine whether monitoring or a manipulative experiment could detect an effect of predicted magnitude for a given sample size. In general, sample sizes should be large enough to give a high probability of providing clear evidence of any effects that are of practical importance. Although exceptions may be likely, projects with low statistical power and low ability to deliver externally valid information should be undertaken sparingly and with a realization of the inherent limitations (Toft and Shea 1983, Peterman 1990, Taylor and Gerodette 1993). However, replication may not be possible when experimental units are very large (e.g., major lakes), and may be less important when experimenters do not wish to apply results to other areas (Wester 1992). Furthermore, several authors (e.g., Johnson 1999) have recently argued that the search for statistical significance is secondary in importance to direct interpretation of biological significance and the major patterns and phenomena that are directly revealed by convincing experimental design.

Even when replication is attempted, it remains important to assure that 'replicates' are truly independent, rather than being subsamples, repeated measures, spatially clumped samples, or other forms of pseudoreplication (Hurlbert 1984). However, because spatial and temporal axes are often correlated in ecological systems, it is critical that replicates constitute unbiased samples of the spatial and temporal scales and variables of interest (Peterson and Parker 1998). Consistency in data collection, sampling design, and analysis platforms across watersheds, management dis- 
tricts, and states is an excellent means to increase replication, and it allows statistically more powerful analyses, especially when multiple factors are involved. With respect to feasibility, there exists a trade-off between the number of treatment levels and experimental power: the greater the number of treatment levels for a given total sample size, the lower the statistical power.

Semivariograms (Hamlett et al. 1986, Cardina et al. 1997) may be used in the field or after preliminary sampling to determine the minimum sample size at which variability within treatments is minimized. Similarly, species effort curves (Hayek and Buzas 1997, Moreno and Halffter 2000, Patton et al. 2000) can suggest when sampling is adequate enough that further surveys will have little chance to detect new species. Techniques are also available (Hayek and Buzas 1997) to predict a sample size that will estimate an unknown variable (e.g., population density) with a given confidence within some range (e.g., within one standard deviation). Ideally, study design should address criteria of biological importance as well as statistical significance.

\section{Species and Habitats at Risk}

The BLM as well as FS, Departments of Defense and Energy, Bureau of Indian Affairs, and NPS have legal responsibilities and policy requirements to provide habitat for threatened, endangered, sensitive, proposed, and candidate (TESPC) species occurring on their lands. There are 235 plant and animal species federally listed as endangered or threatened in the western United States, and the USFWS has an increasing backlog of species proposed for listing. Management guidance relevant to TESPC species includes ecosystem analysis at the watershed scale and subbasin review guidelines; landscape consideration; direction for aquatic and terrestrial habitats; specific direction for aquatic and terrestrial TESPC areas; and guidelines for road management (USDA and USDI 2000a).

As a result of increasing numbers of listed species occurring on public lands, regional multi-species conservation strategies are being developed through the cooperation of federal, state, and local governments across the western United States. However, managing agencies lack sufficient knowledge to carry out conservation responsibilities for most threatened, endangered, and sensitive species. Land managers need a scientifically based understanding of 1) the historic abundance and distribution of species and their habitats; 2) natural environmental factors influencing them; 3 ) the effectiveness of conservation actions; and 4) acceptable levels of land uses in order to achieve healthy, resilient ecosystems capable of supporting viable populations of native plants and animals in adequate abundance (USDI BLM 2000). Thus, the highest research priorities for land managing agencies include 1) a comprehensive assessment of the condition of habitats and their spatial arrangement at landscape and regional levels; 2) determination of the adequacy of remaining habitats; 3 ) determination of the requirements and constraints for restoration of damaged habitats; and 4) assessment of the effects of noxious weeds, fire, grazing, and other disturbance processes on endangered habitats and species (USDI BLM 2000).

Whereas timber extraction and fire suppression have been the primary drivers of recent change in Basin forests, rangelands in the Basin have been altered as a result of grazing by livestock and feral horses, the introduction of exotic plant species, changes in the fire regime, and roads, and associated anthropogenic effects. Because of their lower elevations and consequent milder climates, Basin rangelands often comprise or are adjacent to areas of human settlement and activity. However, rangelands generally occur in areas of very dry climate, shallow soils, or cold climates with short growing seasons.

The primary disturbance agents of landscape pattern in rangelands include herbivory, fire, and exotic species, although succession/disturbance regimes differ among ridge, slope, toeslope, footslope, terrace, and plains landforms (Hann et al. 1997). For example, responses to grazing and potential for restoration of slope landforms to a native disturbance regime depend on the dominance and composition of exotic plants. In contrast, in toeslope and channel landforms, disturbance regimes have been altered by fire exclusion, dams, removal of beavers, construction of roads near the floodplain, and traditional grazing practices.

\section{Terrestrial Upland Vegetation (see Aquatic-Terrestrial Interface section for aquatic species)}

From historical to current periods, fragmentation has increased and connectivity within and among habitats has decreased, particularly in lower-elevation forests, shrub-steppe, and riparian habitats (Hessburg et al. 1999). Reduced connectivity among habitats can compromise dispersal, genetic exchange among populations, and rescue of locally extirpated populations (Hanski and Gilpin 1991, Saunders et al. 1991). Functional groups that may be particularly affected in the short term include wide-ranging species (i.e., species with large home ranges), species with poor dispersal abilities, species with low fecundity, habitat-obli- 
gate species (e.g., shrub-steppe birds), ground nesters, and interior species that avoid habitat edges (Wilcove 1985, van Dorp and Opdam 1987, Pimm et al. 1988, Noss and Csuti 1994). The greatest change in vegetation in the Basin has been the conversion of $37 \%$ of non-BLM, non-FS-administered lands to agricultural use (Hessburg et al. 1999).

\section{Terrestrial Species \\ (see Aquatic-Terrestrial Interface section for aquatic species)}

Although only 14,000 terrestrial plant and animal species were considered explicitly in the assessment of the Basin, 28 amphibian, 27 reptile, 362 bird, 132 mammal, 24,270 invertebrate, and approximately 19,000 plant species are estimated to occur in the Basin (Quigley et al. 1996, USDA and USDI 2000a). Flather and Sieg (2000) highlighted the need to develop standardized rangeland surveys for vertebrates other than birds and game animals, as well as for invertebrates and plants, to allow examination of spatial and temporal patterns of species richness, as well as trends in abundance. As of November 1999, federally listed species in the Basin included 16 threatened, 19 endangered, 3 proposed, and 10 candidate species (USDA and USDI 2000a). In addition, as of March 2000, 14 amphibian and reptile, 66 bird, 19 mammal, 23 invertebrate, and $>700$ plant species are listed as 'sensitive' by the FS, BLM, or both (USDA and USDI 2000a). Declines in plant and animal species have resulted from conversion of habitat to agriculture and urban development, overgrazing, recreation, high road densities, off-highway vehicles, fire suppression, mining, introduction of exotic plants and animals, and increased fire frequencies resulting from dense annual exotic grasses (Marcot et al. 1997). The area of source habitat has declined for most native species, and the degree of decline is generally consistent across the Basin (Marcot et al. 1997).

Of the 547 terrestrial vertebrate species in the Basin, Wisdom et al. (2000) identified 91 species "of conservation concern" based on rankings of The Nature Conservancy; management alternatives proposed for federal lands; public concern expressed through appeals of federal actions; and the ability to map their habitats across the Basin using about a $2 \mathrm{mi}^{2}\left(1-\mathrm{km}^{2}\right)$ pixel size. Wisdom et al. (2000) then subdivided 91 species of concern into 40 groups using hierarchical clustering analysis based on pairwise similarities in source habitats between species. Subsequently, cluster analysis was used to condense 37 of the 40 groups into 12 families based on terrestrial community types. The 12 families were believed to be the smallest set of groups that could be meaningfully used by managers and biologists to identify habitat requirements and species trends at the broadest scales of ecosystem management. Of the 12 families, the greatest declines in broad-scale habitat were projected for species dependent on native grasslands and open-canopy sagebrush, combinations of rangelands with early- or late-seral forests, and low-elevation old-forest habitats.

Bayesian belief network models provide an alternative to formal population viability analysis, and have been used to combine assessments of the quality and quantity of habitat with other environmental factors affecting populations of each species in order to project their Basin-wide distribution and abundance (Raphael et al. 2001). Bayesian belief models use conditional probabilities to predict the combined effects of multiple variables on landscape conditions for a given species. Environmental outcomes were defined in five classes that differed in abundance and connectivity of suitable habitat patches, and consequently, likelihood of regional extirpation. Population outcomes projected 100 years into the future for species dependent on old-forest conditions generally improved under all proposed management scenarios, whereas outcomes for rangeland species did not improve and often declined (Raphael et al. 2001). Declines in rangeland species were projected to occur as a result of slow rates of recovery, continued displacement of native plants by exotic plants facilitated by various human-associated disturbances, and crossed environmental thresholds (Raphael et al. 2001).

Preliminary validation analyses of the Bayesian belief models using independent data sets for species such as pronghorn antelope and sage grouse confirm that habitat amount is a fundamental determinant of species viability. Furthermore, other influences of habitat quality and connectivity, as well as non-habitat factors (e.g., road density, human population density) play secondary, but sometimes important, additive roles in decrementing broad-scale estimates of habitat (M. Wisdom, personal communication, April 2001).

\section{Ecological Roles and Trends of Endangerment, by Taxon}

Bryophytes (mosses, liverworts, and hornworts) combine with lichens and cyanobacteria to form microbiotic soil crusts, and serve as important sources of food and shelter for vertebrates and invertebrates. About $40 \%$ of the Basin's more than 800 species of bryophytes appear to be rare or endemic (Marcot et al. 1997). Modifications to the substrate or associated microclimate pose threats for terrestrial bryophytes, as do declines in water quality for aquatic and riparian 
bryophytes. As decomposers, fungi recycle nutrients within the ecosystem to make them available for other organisms. Fungi facilitate moisture and nutrient absorption by plants through mycorrhizal relationships with plant roots, and many species serve as important food sources for diverse animal species. Lichens, which consist of fungal and algal components, are important sources of food and organic matter in ecosystems. Modifications to lichens' substrates (e.g., rock, soil, wood) are the most serious known threat to the continued persistence of lichens, although lichens are sensitive to sulphur dioxide and other elements of air quality (Richardson 1992, Geiser et al. 1994, Rosentreter 1995, Marcot et al. 1997). Vascular plants (ferns, conifers, and flowering plants) provide the base of many food webs, protect soils against erosion, and provide shade and cover to animals and watercourses (Marcot et al. 1997).

Invertebrates include groups such as arthropods, mollusks, earthworms, protozoa, nematodes, and butterflies. Because invertebrates often have very fine-scale habitat requirements, estimates suggest that identified species represent only $1 \%$ to $15 \%$ of all $(\sim 24,270)$ species occupying the region (Marcot et al. 1997). Invertebrates play important roles in soil development, in pollination of crops and wild plants, as natural enemies of important pest species, and as vectors for numerous diseases, and may act as early indicators of ecosystem health (Ginsberg 1993, Samways 1993). Numerous factors may have contributed to declines observed in invertebrates, including use of pesticides; loss of litter and dead plant material; decline in forb abundance due to uncharacteristic grazing, range treatments, fire exclusion, and increased fire frequency; disturbance of wetlands, talus slopes, caves, springs, and other habitats; and habitat conversion (Marcot et al. 1997).

Except in riparian areas, amphibians are relatively uncommon in arid grasslands and shrublands of the Basin, instead inhabiting dry and moist forests (Corn 1994, Marcot et al. 1997). Amphibians bioturbate soils; control insects; serve as food for fishes, birds, and mammals; and indicate water quality and quantity (Marcot et al. 1997). Exact reasons for widespread amphibian declines have not been pinpointed, although potential contributors in the Basin include the reduction of riparian and other habitats, mining of talus and rock, climate changes, introductions of exotic fishes and bullfrogs, degraded water quality, irrigation, roads, pesticides, livestock effects on soils and water quality, chytrid fungi, and reduced invertebrate populations (Bury and Whelan 1984, Jennings and Hayes 1985, Leonard et al. 1993, Marcot et al. 1997). Habitats of reptiles in the Basin have been affected by the operations of large dams and associated regulated rivers; livestock grazing; exotic plant species; off-road vehicle use (that fragments habitat and causes direct mortality); fire suppression; and loss of wetlands. Additionally, capture for the pet trade may affect populations of some species such as horned lizards and black-collared lizards. Many birds in the Basin have experienced long-term declines due largely to habitat conversion, fragmentation, and degradation, and particularly in riparian, wetland, grassland, and shrub-steppe habitats (Marcot et al. 1997, Haig et al. 1998). A greater percentage of bird species (44\%; 128 of 362 species) have suffered the loss of $>10 \%$ of their habitat area within the Basin than have reptile species ( $41 \%$ of species with $>10 \%$ declines), amphibians (26\%), or mammals (25\%) (Marcot et al. 1997). However, species such as northern flicker, house wren, mountain bluebird, American robin, and gray flycatcher appear to be increasing, at least in part due to the expansion of western juniper (Collopy and Smith 1995).

More of the Basin's mammal species inhabit forested areas than other vegetation types, although rangelands also contain numerous characteristic mammal species. Species that have increased in the Basin include those that have been able to adapt to habitat changes, species that have been favored (though habitat manipulation and regulated harvest) as game animals, and meso-predators that have benefitted from control of larger predators (Marcot et al. 1997). Factors that have contributed to declines in mammals include loss and fragmentation of native habitats; altered prey or forage base; changes in vegetation structure and composition; rodent poisoning; soil compaction from uncharacteristic grazing; polluted waters; road building and roadkills; recreational shooting; disturbance of bat roosts; alteration of fire cycles; and past hunting by humans (Marcot et al. 1997, Verts and Carraway 1998, Wilson and Ruff 1999). Other factors that may affect viability of some species of mammals and birds include fire suppression; agricultural practices such as use of pesticides or high amounts of tilling; predator control and illegal killing; skiing resorts, snowmobiles, and disturbance associated with summer recreation; effect of fencing on dispersal and metapopulation structure; and loss of wetlands.

\section{Threatened, Endangered, and Candidate Species}

The Basin contains 6 candidate species of amphibians, 2 candidate reptile taxa, 19 imperiled bird taxa ( 3 threatened, 2 endangered, and 14 candidate taxa), 
and 19 imperiled mammal taxa ( 1 threatened, 1 endangered, and 17 candidate taxa). Populations of the endangered peregrine falcon have exhibited slow increases in density since the drastic declines due to pesticide use between 1946 and 1975. Two primary threats for persistence are contaminants and disturbance of nest sites. In addition, eggshell thinning continues to contribute to reduced reproductive fitness (Pagel 1995). The migratory whooping crane winters in areas outside the Basin. Efforts have been made to translocate birds and to cross-foster whooping crane chicks with sandhill crane parents (e.g., at Grays Lake NWR in Idaho), but recent breeding of whooping cranes within the Basin has been nearly nonexistent. Whooping cranes likely were never common in the Basin, especially after collectors nearly extirpated them for their plumage in the early 1900 s. Loss of wetlands, illegal shooting, collisions with power lines, and disease pose the greatest threat to the endangered crane. Because of their strong association with sage-steppe habitats that have declined significantly in recent decades, sage grouse and sharp-tailed grouse are being considered for listing across the region. Although it is tempting to assume that grouse will act as umbrellas under which other sagebrush-obligates will be conserved, each species requires a relatively unique management focus for its conservation (Altman and Holmes 2000). For example, sharp-tailed grouse are associated with deciduous trees and shrubs, where canopy cover $>15 \mathrm{~cm}$ occupies $15 \%$ to $35 \%$ of the site, and native forbs occupy $>10 \%$ of cover (Altman and Holmes 2000).

Gray wolves, currently considered federally endangered, were nearly exterminated from the Basin in the late 1800 s to early 1900 s due to shooting, poisoning, trapping, and reductions in wolves' native prey base (Laufer and Jenkins 1989, Fritts et al. 1994). Major threats to ongoing recovery and reintroduction efforts include continuing hunting and illegal killing by humans. An endangered population of less than 100 caribou occupies the Selkirk Mountains of Idaho and Washington. Population augmentations from the late 1980s forward have helped offset declines that occurred during 1954-1987 due to illegal killing. Major threats to this small population currently include habitat alteration due to timber harvest or wildfire, illegal killing, highway road-kill, and, to a lesser degree, disturbance by winter recreation. Four threatened vertebrate species from the Basin include the bald eagle, grizzly bear, northern spotted owl, and marbled murrelet, although the latter two species have distributions that only slightly overlap the Basin, on the east slope of the Cascade Range.

\section{Genetic Diversity}

Although geographic ranges of species fluctuate through time in response to influences such as predation, interspecific competition, glaciation, and climatic fluctuation, ranges of numerous species have exhibited sharp declines recently. Because directly measuring genetic markers to estimate genetic diversity carries a high cost, mapping and analyzing the contraction of species' ranges may provide a surrogate estimate of the loss of genetic variability (Soulé and Mills 1998).

Reliable interpretations of trends in geographic range size depend on research that establishes a robust link between range reduction and genetic diversity. Combining spatial statistics with geographical population analysis will be important for establishing the relative occupancy of a species' range, which must then be coupled to independent measures of genetic variation (Flather and Sieg 2000). 


\section{Research Program}

\section{Introduction}

The following list of research questions is designed to both support current management efforts and provide ideas for integrating emerging scientific understanding into future management. Questions are organized into five broad headings: rangeland health, restoration, the aquatic-terrestrial interface, monitoring and implementation protocols for adaptive management, and species and habitats at risk. Under each heading, questions are organized into several more specific categories. If this document is used to create a coordinated research strategy for the Intermountain West, the overarching themes of ecological integrity, changes in disturbance regimes, changes in landscape pattern and composition, and cumulative effects of past, current and future management may provide additional frameworks.

Each research question is accompanied by a brief background that provides rationale and possible approaches for addressing the question. The Plan primarily focuses on major issues that resource managers would face in implementing management with the Basin. Each question is preceded [in brackets] by a priority ranking of High, Medium, or Low, which was determined based on three questions: 1) How important is resolving this question to current and future management of DOI resources? 2) To what extent would current and future management suffer by not addressing this question? and 3) How feasible is implementation of research that would address the underlying hypothesis rigorously so as to contribute meaningfully to future management strategies and philosophies? Questions accompanied by the superscript, AD.MGMT are also appropriate for addressing monitoring and implementation protocols for adaptive management.

The Research Plan is a compilation of urgent and important research needs for DOI-administered lands in the Basin planning area. The Plan includes areas of research identified by ICBEMP documents (Quigley and Arbelbide 1997, USDA and USDI 2000a), agencies responsible for managing natural resources (USFWS 1998, USDI BLM 1999, USDI BLM 2000), and other sources relevant to management-oriented research (e.g., Soulé and Kohm 1989, Altman and Holmes 2000, USGS 2000). An important challenge for the Research Plan is to identify questions of broad-scale importance that are relevant to managers and researchers yet feasible to implement at local scales. Although research needs are presented here in the format of questions, research generally will address questions as testable, falsifiable hypotheses using inferential or Bayesian statistics. However, when questions are framed as hypotheses, it is important to distinguish between scientific hypotheses (about phenomena in nature) and statistical hypotheses (about properties of a population based on samples) (Connor and Simberloff 1986). Thus, because a primary goal of management research is an understanding of natural systems and maintenance of ecological integrity, a more qualitative description, catalogue, or result may be a more important outcome in some cases.

\section{Exotic Weeds}

\section{Rangeland Health}

i. $[\mathrm{H}]{ }^{\text {AD.MGMT }}$ What are the ranges of disturbance regimes and habitat, climate, and soil conditions that predispose communities to higher risk of invasion by exotic plants? In contrast, what physical and biological factors limit invading species? Stated another way, can abundance of individual invasive species such as cheatgrass be predictably modeled over ecosystem and landscape scales?

Potential factors in models include physical and chemical soil properties, fire frequency, current and historical grazing system (intensity, season, and frequency), potential vegetation type, precipitation, and proximity to roads. Accuracy and robustness of models must be tested with sets of empirical data independent of those used to parameterize the models. Sensitivity analyses (Burgman et al. 1993) can be used to determine factors that most strongly alter model outcomes. Greater attention should be given to these factors in subsequent monitoring and management.

ii. $[\mathrm{H}]$ What is the relationship between microbiotic soil crusts and exotic plants? Are there specific characteristics of crusts (e.g., minimum extent, stage of development, or presence of particular lichen, bryophyte, algal, or bacterial species) that drive responses of invaders?

Invasion of exotic annual grasses and the consequent increase in fire frequency (to $>40$ times historical frequencies) have produced dramatic changes in ecosystem structure in grasslands (Figure 4; Whisenant 1990), and are a major threat to continued persistence of microbiotic crusts. Whether intact soil crusts inhibit the establishment of cheatgrass and other exotic invasive species, the mechanism of inhibition, and the influence of land use, disturbance history, and soil properties on the crust-exotics relationship all merit further study (Vallentine and Stevens 1994, Hann et al. 1997). 


\section{Fire and its Effects on Ecosystem Sustainability}

i. $[\mathrm{H}]{ }^{\mathrm{ADMGMT}}$ When prescribed fire is used, what are its effects during the 1-15 years after a fire on the following ecosystem attributes and processes: a) species richness of plants; b) percent cover of grasses, shrubs, and forbs, plus their relative proportions; c) diversity of the small mammal, avian, and reptile communities; d) abundance of rare and habitat-specialist species; e) soil erosion, surface hardness, and soil moisture; $f$ ) microbiotic soil crusts; $g$ ) nutrient availability; $h$ ) rates of decomposition; i) abundance of invertebrates (e.g., thatch-building ants, a potential keystone)?

- Do effects of prescribed fire vary with post-fire treatment (natural colonization, regeneration from onsite surviving vegetation, planted exotic species such as crested wheatgrass, or assisted colonization with native species)?

- How do effects vary with the timing (i.e., season) of the prescription?

- When wildfires are allowed to burn, how do their effects compare with effects produced by prescribed fires in similar areas?

- In addition to the nature of the fire ignition, the timing and burning conditions under which the fire occurred, as well as post-fire management and precipitation all influence the effects that fires will exert on ecosystem components (M. Miller, personal communication, March 2001). Because prescribed fires often occur in spring or late fall, compared with wildfires, which occur most frequently during hot, dry summers, abiotic factors that may also influence results of fire should be explicitly included in analyses.

- Because fire frequency varied historically with landform (i.e., ridge, slope, toeslope), precipitation, soil type, vegetation type, among other factors, at what resolution should sampling occur to determine HRV in fire-return intervals? Are there conditions other than invasion of exotic plants that would cause desired fire frequencies to differ from HRV?

Wildfire has been a critical element of disturbance regimes in the Basin since at least the mid-Holocene. Data from several lines of evidence suggest that fire-return intervals in many semi-arid habitats of the Basin have shortened, due to the presence of exotic annual grasses. In contrast, fire-return intervals in some semi-arid habitats of the Basin have lengthened, a phenomenon that has been implicated in the encroachment of juniper and other conifers into higher elevation sagebrush communities and dry grasslands, often removing native understory species (Johnsen 1962, Young and Evans 1981). A major goal of post-fire rehabilitation in Basin rangelands consists of maintaining or enhancing health of native perennials, while limiting the establishment and spread of noxious weeds. Regarding vegetative diversity and composition, BLM now strongly encourages the use of native seed in post-fire revegetation efforts whenever possible (Richards et al. 1998).

Relationships between ambient conditions (e.g., wind speed, humidity), vegetative characteristics (e.g., moisture content, ratio of shrubs, forbs, and grasses, physiognomy, amount of fine fuels), fire characteristics (e.g., flaming residence time, surface and subsurface burn temperature, extent), damage or mortality of vegetation after fire, and post-fire recovery trajectories must be more firmly established. Models that incorporate critical elements of these factors can be tested and validated with field data. Furthermore, sensitivity analyses should be performed on models to determine the robustness of results to variability in key factors.

The response of vertebrates to fire varies greatly among species, depending upon the pre-fire condition of habitats, the extent and intensity of fire, and the species' natural history (Wales 2001). Although fire has been shown to directly affect vertebrate individuals through mortality or lost reproduction, most fire effects on terrestrial vertebrates are indirect, occurring through changes in food, habitat (e.g., cover, nesting sites), and competitors (Bendell 1974, Russell et al. 1999, Smith 2000). Because disturbances may combine synergistically to affect ecosystem structure and processes (Meffe and Carroll 1994, Steenhof et al. 1999), it is crucial that influences other than fire be explicitly considered in management planning. (See background of the previous question for additional information.)

ii. $[\mathrm{M}-\mathrm{H}]^{\mathrm{ADMGMT}}$ At sites with high potential for post-fire invasion by exotic grasses and forbs, what fire frequency, relative to $H R V$, provides the greatest long-term stability and ecosystem services?

Determining desired fire interval at sites highly vulnerable to invasion by exotic annual grasses requires a balanced perspective. On one hand, reducing fuel accumulations and volatility of vegetation reduces future risk of frequently reoccurring fires; however, early re-establishment of cheatgrass may preempt re-establishment of native perennials, thus increasing density of cheatgrass. Depending upon site characteristics, available funding, and intensity of fire management, other management strategies (e.g., mowing, disking, plowing, 
livestock grazing, herbicides, fire-resistant greenstrips) may be used in concert with prescribed fire to move disturbance regimes closer to HRV (Pellant 1999). In many vegetation types, the timing of prescribed fires may be critical, because land managers want to avoid letting fire escape designated boundaries, yet fires are sometimes difficult to ignite and keep burning (e.g., in low sagebrush communities with few fine fuels). The management challenge thus involves ascertaining how to maintain the beneficial effects of fire disturbance, while avoiding undesirable effects.

\section{Biological Soil Crusts}

Although much remains to be learned about the biology of microbiotic soil crusts, two of the more important areas of research for land managers concern their ecological roles and their response to disturbance.

i. $[\mathrm{H}]$ Which component species comprise crusts across soil types and topographic positions (i.e., with respect to landforms, aspects, and slope gradient) in semi-arid communities?

Sampling, description, and cataloging of soil crusts could be stratified by NRCS Ecological Site, because this system of vegetation classification is tied to soils, as are microbiotic crusts. In many districts and refuges in the Basin, managers have little information either on which species comprise crusts on lands under their jurisdiction or on how composition varies across the landscape.

ii. $[\mathrm{H}]{ }^{\text {ADMGMT }}$ At what intensity and during which season can livestock be grazed without harming the sustained functioning of soil crusts (e.g., soil stabilization and erosion reduction, nutrient cycling, mutualisms with vascular plants)? [Wicklow-Howard and Kaltenecker 1994]

Livestock can graze areas containing shrubs and microbiotic crusts when soils are moist without imposing much harm to crust components (Wicklow-Howard and Kaltenecker 1994), although crusts have been severely affected in many areas by dry-season livestock grazing. Damage to crusts has also been observed under continuous season-long grazing, short-duration grazing that provides intense physical impact to soil surfaces, and grazing that persists into late winter and early spring (Brotherson et al. 1983, Jeffries and Klopatec 1987, Marble and Harper 1989). Because cryptogamic crusts occur in regions with extreme and variable climates, it is crucial to examine crust response to disturbance across multiple years. A longer-term approach permits quantification of environmental stochasticity and its effect on various components of soil crusts, in either the presence or absence of other disturbances.

iii. [M] What is the relationship (i.e., linear, asymptotic, etc.) between cover of soil crusts and nutrient cycling; energy flow; establishment of native seedlings; water quality; and aboveground biodiversity?

Leonard et al. (1995) summarized existing current understanding of ecological roles of crusts and implications of crusts for rangeland management. Cryptogamic crusts in general increase soil stability, affect water infiltration, and may improve seed germination for various plant species. However, many details of the ecological roles of microbiotic crust species as soil stabilizers and nitrogen fixers are still being elucidated (Belnap 1994). Cryptogamic crusts are often most developed in salt desert scrub, low sagebrush, and big sagebrush vegetation types, occupying up to $80 \%$ of the living cover in some areas (Belnap 1990). Roles of crusts vary greatly among ecosystems. For example, the influence of crusts on infiltration and soil moisture depends on climate, soil type, disturbance history, age of the crust, state of wetness of the soil when rewetted, and other factors (Seyfried 1991, Williams 1993).

iv. $[\mathrm{H}]$ What is the availability of nitrogen fixed by microbiotic crusts, and what is its contribution to vascular plants and community structure and function (Snyder and Wullstein 1973, Belnap 1994, Evans and Ehleringer 1993)?

This question provides a specific example of one relationship listed in the broader question iii (above). Soils stabilized by crusts are known to have higher concentrations of organic material, nitrogen, calcium, potassium, magnesium, and available phosphorus (Harper and Pendleton 1993). Nitrogen fixation by crusts containing cyanobacteria is known to occur broadly in the Basin; however, the end fate of nitrogen fixed by crusts and its necessity to ecosystem function remain unknown.

\section{Biodiversity}

Assessment of status and trends. i. [H] ${ }^{\text {ADMGMT }}$ Are there plant or animal species that a) represent a particular use, ecosystem, or management concern (i.e., indicator species); b) exert disproportionate effects on ecosystem composition and function (i.e., keystone species); or c) are important functional components of more than one food web, plant-animal association, or ecosystem (i.e., link species; Soulé 
and Kohm 1989)? If such species do exist what factors limit the ability of trends in one species to predict dynamics of other species?

Because it is not feasible to monitor all resources across broad areas, various taxa can be monitored to reflect trends in composition, processes, and function of ecosystems. Although indiscriminate use of indicators is not recommended, some species possess attributes that may make them more likely to reflect the status of other species (e.g., species that act as keystone species; West 1993). Samson and Knopf (1993) recommend assessment of biodiversity by using species groups rather than by relying heavily on individual species. Consequently, ICBEMP evaluated relations of 12 'families' of species with key environmental correlates and key ecological functions (Wisdom et al. 2000). Of the 12 families, 2 contained species (all birds) that were associated exclusively with non-forested habitats, another 2 of the remaining 10 families contained species primarily associated with rangelands. Selected families that have undergone significant decline, have more stringent habitat requirements, and whose habitats encompass habitats for other families may be useful for developing multi-species research hypotheses and management strategies in the Basin. Viability may be estimated at coarse scales through analysis of factors such as habitat abundance, habitat quality and resiliency, and connectivity (Wisdom et al. 2000).

For example, does the trend in abundance and distribution of sage grouse correlate with trend in other sage-associated species (e.g., pygmy rabbit, sage thrasher, Brewer's sparrow, sage sparrow, sagebrush vole, loggerhead shrike)? Objective identification of keystones has been simplified by the recent formulation of the keystone species concept into an expression that quantitatively links species dynamics to ecosystem processes (Power et al. 1996).

ii. $[\mathrm{H}]^{\mathrm{AD} M \mathrm{MGM}}$ Are the abundance and diversity of bat species declining in the project area? If so, which factors contribute most strongly to this decline? Does gating caves or mines increase likelihood of persistence over long time scales?

In arid regions of western North America, bats dominate lists of candidate and sensitive species, in spite of relatively sparsely collected distributional data. In the Basin, very little information on bats is available; information is lacking on habitat associations, effects of vegetative alterations, effects of pesticides, and abundance, trends, and distribution of bats in the Basin (Marcot et al. 1997). Because bats use a variety of habi- tats (e.g., roosting, feeding, and breeding sites) throughout the year, they may be early signals of ecosystem degradation. Gating caves prohibits disturbance of roosting sites by human explorers, while still allowing nightly migrations by foraging individuals. Bats are not highly regarded in popular culture, and only recently have scientists and the general public begun to appreciate the ecological importance of bats (e.g., their role in insect pest control). Because of the association of bats with several types of habitats (e.g., caves, rock crevices, forests, springs), surveys for bats should be performed using a stratified sampling scheme, rather than with simple random or systematic sampling.

Response to disturbance. i. $[\mathrm{H}]$ Is it feasible and ecologically tenable to actively manage for locations of minimal livestock use? Alternatively, can grazing exclosures be used to maintain vertebrate diversity within mountain ranges and at larger scales? What quantity and size of exclosures are needed to achieve this objective?

Actively managing for minimal livestock use may involve herding, use of mineral blocks, or taking advantage of habitat-selection patterns of livestock (Cruz et al.1998, Vavra and Ganskopp 1998).

Livestock exclosures can be useful for investigating grazing because 1) they provide a matched-pairs design, eliminating potentially confounding edaphic and vegetative differences; 2 ) they allow the separation of effects attributable to climatic effects as opposed to livestock activity; and 3) when sufficiently large, they allow investigation of response to grazing removal across spatial scales (Bock and Bock 1993).

Maintenance of relatively undisturbed patches in disturbed landscapes may prevent local extirpation of species through subsequent recolonizations onto disturbed areas (Bock and Bock 1993, Perry and Amaranthus 1997). However, the persistence of species within an exclosure is not likely unless the exclosure is large enough to contain populations large enough to withstand environmental stochasticity. Thus, given their common use as the basic unit in landscape ecology and planning (Johnson and Patil 1998, Jones et al. 2000b), watersheds could be used to delineate source habitats. Ungrazed watersheds could be strategically located to maximize habitat diversity to provide for a maximum number of species and to contribute to regional ecological integrity. Small excluded watersheds could also provide an interesting comparison to other watersheds that receive light and heavy livestock use. However, because experimental units will be relatively large, the use of many subsamples is recommended to capture 
existing variability. Collection of data over several years would be most likely to produce robust results.

ii. $[\mathrm{H}]$ Which vertebrates have either benefited from or have been unaffected by cheatgrass-dominated areas? Which vertebrates avoid these areas? Does avoidance depend on the density of cheatgrass plants, extent of cheatgrass "ocean," or distance to areas with little or no cheatgrass that can act as colonizing sources?

In addition to altering fire-return intervals (Pellant 1996), cheatgrass can change vegetative composition by reducing native grasses and occupying previously bare ground in shrub interstices. Thus, cheatgrass can change availability of seeds of native grasses, microsite conditions (e.g., insolation, nutrient levels), and soil attributes. Examining how abundance of habitat specialists, endemics, and species needing open spaces (e.g., pygmy rabbit, longnose leopard lizard, sagebrush lizard, whiptail lizards, sage grouse, Columbian sharp-tailed grouse) changes over a gradient of increasing dominance of exotic plants would be useful. Although defining levels for some variables can be problematic, approaches involving island biogeography (e.g., patch size, distance to habitat 'mainlands') can provide insight for landscape-scale questions.

iii. $[\mathrm{H}]$ What level of accuracy do aerial censuses of wild horse populations possess, and how can actual population size be most reliably modeled across herd management areas? How do ecosystem components respond to imposition or removal of grazing by feral horses in different habitat types? What factors control habitat use by horses across seasons in western North America?

Herd management areas (HMAs) for horses occupy 46 million acres (18.6 million ha) of land in 186 areas across 10 states of the western United States. Monitoring of population size is critical for managers to both design and assess the effectiveness of population control efforts. Horses have the capacity to increase to high densities relative to forage resources (Coughenour 2000), and herds of feral horses have been observed to exhibit annual growth rates of $5 \%$ to $20 \%$ annually (Wolfe 1980). Bias in aerial censuses typically results in underestimates of population size, and can result from physiographic features or tree cover (e.g., pinyonjuniper habitat) that conceal individuals, large aggregations of bands, and other factors (Caughley 1974, Crane et al. 1997). Because horses occupy a unique place in both the American psyche and in management strategies, immunocontraception has been deemed the most preferred method of population regulation. Further research is needed to clarify how identity and strength of contraceptives used, as well as method and frequency of delivery, affect pregnancy rates.

Feral horses have been found to influence various components of terrestrial ecosystems (Turner 1987 , Reiner and Urness 1982, Beever and Brussard 2000, Beever et al., in press). In the Pryor Mountains of Montana and Wyoming (horse density $=0.0083$ animals/ha), however, Fahnestock and Detling (1999) found that herbivory by horses affected plant cover significantly less than did interannual variability in growing season precipitation. Understanding how herbivory by horses interacts with herbivory by cattle, across spatial and temporal axes, is also of interest. Very few data have been published on the response of semi-arid ecosystems to removal of grazing pressure by horses, and drastic reductions in herd sizes across many areas present a unique research opportunity. Habitat use by horses in Montana and Wyoming has been investigated through the use of field data (Miller 1980, McInnis 1985, Crane et al. 1997) and a spatially explicit simulation model (Coughenour 2000). However, GIS technology presents a new opportunity to investigate how factors such as visibility (i.e., viewshed) affect habitat use.

iv. [L] Does dominance of deer mouse increase in communities of small mammals (especially at low elevations) with increasing degrees of habitat alteration? By which mechanisms are rarer species lost from habitats dominated by this species?

The deer mouse is one of the most abundant and ubiquitous mammals in North America, and occurs in nearly every type of terrestrial habitat (Burt 1980). They are the primary known vector for hantavirus, and their extreme fecundity allows them to increase rapidly in newly colonized sites. Several studies have found that the deer mouse dominates small-mammal communities in disturbed systems (Martell 1983, Schulz and Leininger 1991, Bich et al. 1995). However, other than the fact that this species has broad physiological tolerances and great behavioral plasticity in the face of environmental variability, mechanisms by which the deer mouse come to dominate communities remains largely unknown. Simplification of small mammal communities due to increasing dominance of the deer mouse can inhibit natural rehabilitation of disturbed sites, as many plant species of semi-arid regions rely on caching and dispersal of seeds by desert-adapted rodents (e.g., heteromyids). 


\section{Restoration Across DOI Lands Landscape Ecology: Habitat Fragmentation, Connectivity, Boundary Effects}

Although habitat alteration and fragmentation comprise two of the most serious threats to ecological integrity and ecosystem services across the Basin, many effects of fragmentation and alteration remain poorly studied (especially cumulative and synergistic effects). In contrast to the large, contiguous land areas administered in the Basin by the FS, many DOI-administered lands exist in small or fragmented landscape patches. For example, BLM management needs in the western Pacific Northwest are strongly influenced by the 640 -acre (259-ha) ownership pattern that characterizes BLM land in that region (Richardson 1980). Even the most extensive and contiguous BLM landholdings (i.e., southwestern Idaho and southeastern Oregon) are mixed with or subdivided by private and other lands. With respect to national parks, Newmark (1987) demonstrated that even the largest parks in western North America were not large enough to avoid losses of mammal species over time, given species-area relationships. U.S. Fish and Wildlife Service refuges are similarly small and scattered across the Basin landscape, and are centered usually on distinctive local features in the landscape.

i. $[\mathrm{H}]{ }^{\text {AD.MGMT }}$ How does spatial pattern of land use affect movement or persistence of native vertebrates? For example, does concentrating activities such as grazing and future human developments away from movement corridors or source habitats promote viability of native vertebrates?

Distribution and abundance of most plant and animal species are heavily influenced by the spatial arrangement of suitable habitats across the landscape (Flather et al. 1992, Short and Turner 1994). This question indirectly addresses how altered habitats compare with natural barriers to dispersal (e.g., mountain ranges, rivers) in their permeability to species. Methods to examine movements are discussed in the section on corridors.

ii. $[\mathrm{M}-\mathrm{H}]$ Within sagebrush ecosystems, how do soil characteristics, nutrient and water flows, vertebrate and invertebrate assemblages, and sagebrush-obligate species vary across the landscape in areas of different patch size, habitat quality (i.e., composition and cover of exotic forbs, native grasses, native forbs), grazing history, current grazing system, and distance from sagebrush "mainland"? In a mosaic of varying land uses and vegetation types, how does rate of habitat change and conversion compare with historic rates of change and conversion? Do size and geometry of fragments and their interspersion across the landscape predict the spread of exotics, nutrient flow into and from ecosystem fragments, or abundance of species with large or specialized habitat requirements?

Federal lands in the Basin comprise 102.8 million acres (41.6 million ha), although road construction, spread of exotic grasses, and housing development resulting from human population growth will continue to reduce and fragment habitat, with consequences that ecologists do not yet fully understand. For most species, there exists relatively little understanding of nonlinear numerical and functional responses to habitat fragmentation or degradation due to factors such as invasive exotic grasses. Native shrubland (e.g., big sagebrush) habitats are one of four habitat types that have probably experienced the greatest degree of loss and fragmentation since the beginning of the 19th century. Particular losses have been observed in areas of, which may be the subspecies with the least resistance to disturbance, Wyoming big sagebrush. Although agricultural development and other factors have made native grasslands and sage-shrub habitats the most fragmented vegetative types in the Basin, all ICBEMP modeling of trends in habitat patches (i.e., fragmentation) was performed on forested ecosystems.

Patch characteristics (especially patch size) are known to influence abundance of several sage-steppe obligates, including sage sparrows (Rich 1980, Knick and Rotenberry 1995, Vander Haegen et al. 2000) and sage grouse (Washington Dept. of Fish and Wildlife 1995). For most species, understanding of landscape dynamics and patch use must be integrated with factors acting at smaller spatial scales. For sage grouse, for example, proximate factors that may interact with landscape-level factors to affect fitness include productivity, diversity, and vigor of native grasses and forbs, as well as relative nutritive value of various vegetative species in different phenological states.

This analysis requires investigation at watershed, landscape, or regional spatial scales (Figure 9), and either extensive field census of taxa that may indicate aspects of ecosystem integrity or analysis of already collected (standardized) empirical data. Measures of landscape structure, including concepts such as fractal dimension (a measure of patch size and shape complexity), contagion (the positive or negative association between patch types), and connectivity, could be applied to remotely sensed data (e.g., GAP, AVHRR imagery) to model patterns in broadly collected data on sagebrush taxa (Turner 1989, Knick and Rotenberry 2000). As an example, analyses of landscape-level changes in cover types and succession dynamics were performed for the Basin using 
the Columbia River Basin Successional Model (CRBSUM) and Vegetation Dynamics Development Tool (VDDT) models (Beukema and Kurz 1995). Because of the interaction of landscape and patch dynamics, field-collected data should be used to refine models produced by broad-scale data such as satellite imagery or aerial photos.

Maintaining or re-establishing connectivity among habitat patches is one restoration strategy that may prove useful in addressing habitat fragmentation, and may be achieved in numerous ways. First, designation of certain DOI-administered areas containing noteworthy resources as part of the National Landscape Conservation System (USDI BLM 2000) or changing the suite of activities permitted on selected lands may provide greater connectivity. If the designation will cause shifts in management, 'before-after' experiments with subsamples and appropriate control areas in various blocks (i.e., strata) can assess effectiveness of the designation in conserving local and regional resources. One example of an opportunity for landscape-scale management on federal and adjacent lands is the potential reduction in irrigated agriculture across the region in the future, a forecasted result of future water shortages (Haynes and Horne 1997). To meet municipal demands, amount of land in irrigated agricultural is projected to decrease for eight of nine economic analysis areas by the year 2040 (Haynes and Horne 1997). If lands that will no longer receive irrigation are arranged in dispersed and clumped patterns in areas of similar landform and vegetation, their contribution to ecological integrity can be compared. Clearly, socioeconomic studies are encouraged for assessing the costs and benefits to both private landowners and federal land agencies in collaborative management efforts.

Second, especially for wide-ranging species or species using multiple habitat types, coordinated management (e.g., attention to movement patterns or seasonally used habitats) may improve likelihood of persistence. Salwasser et al. (1987) highlighted the importance of cooperation among agencies in managing species that move across jurisdictional boundaries. Given increasingly fragmented landscapes, interagency collaboration can improve efficiency by unifying goals, facilitating data exchange, and improving management of particularly mobile taxa. A research application particularly important for rangelands is examining the relationship between attributes of adjacent mountains (e.g., vegetative cover and diversity, abundance of large trees) and either composition of animal species or stream characteristics in valleys. iii. [M - H] ADMGMT What level of connectivity do corridors of different width, length, or quality/type (e.g., natural remnants vs. fencelines vs. created corridors) provide for mobile organisms, if any?

Corridors between source populations or key resource areas may serve to rescue extirpated populations (Brown and Kodric-Brown 1977), and to facilitate exchange of species, genes, energy, and materials among recently fragmented areas. Use of corridors will vary across species, depending on the habitat structure and landscape context of the corridor, as well as the social structure, diet, foraging patterns, and home range of the target species (Harris 1984, Noss and Harris 1986, Lindenmayer and Nix 1993). Habitat connectivity for highly mobile organisms such as waterbirds differs from that of landbirds, in that disjunct wetlands can be "connected' habitat as the birds move among them both within and across seasons. Thus, understanding connectivity for these organisms requires a landscape perspective in order to fully address management and research needs.

Addressing this issue requires the acquisition and management of experimental corridors and observation of dispersal in disjunct areas and areas connected by different types of corridors. Mark-recapture and telemetry studies can be used to observe movements of more mobile species, while comparisons of genetic markers for organisms of differing vagility may be appropriate for investigating consequences of movements over longer time scales. Evidence from multiple lines of genetic markers will be the strongest indicator, although attention may focus on more rapidly evolving loci (e.g., mtDNA). For example, considering sage grouse as a model for other sage-obligate species, one can ask [M] what levels of genetic variability exist within and among populations across various spatial scales for populations of varying migration status?

iv. [M] ${ }^{A D M G M T}$ What determines the establishment of natural boundaries between ecosystems, and how can this knowledge be used to minimize the detrimental effects of anthropogenic fragmentation on ecosystem processes (Soulé and Kohm 1989)?

Potential determinants of natural boundaries include climatic (e.g., temperature, precipitation), vegetative, edaphic, hydrologic (e.g., watersheds), and geologic factors (Hann et al. 1997). Strongest determinants of boundaries should be ascertained for each type of disturbance. A crucial question to address includes determining how characteristics of the matrix surrounding a habitat patch influence the magnitude and extent of edge effects within the patch. 


\section{Wildlife Habitat}

i. $[\mathrm{H}]^{\text {AD.MGMT }}$ Does distribution of individual exotic animal species correlate with biotic or abiotic factors within subwatersheds or at larger scales? For example, do bullfrogs only colonize bodies of water above some threshold temperature or water depth, with low vegetative cover, year-round permanence, or having certain fish assemblages?

Bullfrogs, as well as many other vertebrates, have been introduced to many permanent waters of the Northwest, and now occupy many permanent ponds and streams in lowland areas (Bury and Whelan 1984, Jennings and Hayes 1985). Bullfrogs and other non-native vertebrates can radically alter community dynamics in areas they invade. Thus, understanding the factors controlling the distribution of non-natives may assist in efforts to restore affected communities, potentially suggesting priority areas for eradication of existing exotics or prevention of further spread. Results from the investigation could be used to create a model GIS coverage of distributions of bullfrogs and other invasive species. This spatially explicit data layer, in turn, might increase ability to predict distributions of other aquatic taxa and investigate causes of amphibian declines within the Basin. Because the effects of bullfrogs may be confounded by variability in conditions such as seasonality of standing water, presence of exotic fishes, and topography (Corn 1994, Kiesecker and Blaustein 1995, Adams 1999), including other variables when modeling bullfrogs and potentially affected taxa may elucidate multiple contributing factors (Lidicker 1991). For this analysis, the highest priority should be given to widely distributed species that may affect a broad array of taxa.

ii. [M] Are there areas where beavers occurred historically, have been extirpated, and could feasibly be re-introduced? After re-introduction, what is the effect on nutrient and sediment levels, channel characteristics, and riparian biodiversity?

Beavers comprised a significant factor in dynamics of aquatic systems historically, but have been removed from many stream systems because they fell riparian trees and their dens increase the extent of the floodplain, conflicting with other human land uses. Beaver dams can attenuate the magnitude of pulse flows, and thus change the frequency, duration, and intensity of disturbance in riparian habitats. Because of their influence on diverse ecological processes and riparian habitats, beavers have been termed keystone species in lotic systems. Beaver dams can influence movement patterns of fishes, re-colonization of stream reaches by invertebrates, and stream flows (Schlosser 1995). Imposition or removal of beaver dams may be used as models to observe hydrology associated with human-constructed dams, although issues of scale must be addressed. Experimental design to determine the effects of beaver dams might include replicated reintroductions of beavers into areas from which beavers were known historically, compared against similar control streams with no beavers. Various geomorphological, hydrological, and ecological variables should be collected before and after reintroductions, and could be used to characterize change over time.

A word of caution is in order. Because beavers can act as keystones and ecosystem engineers in riparian areas of semi-arid regions, careful attention should be given to stream type (Rosgen 1985, 1994), current channel characteristics, and their historic presence in proposed sites of reintroduction. Beaver dams have the potential to cause flooding, property damage, and loss of human and animal life both during and outside of normal periods of flooding. Very old, large beaver dams that may have been abandoned may require controlled removal or at least close supervision to ensure that they do not burst. It is not uncommon for railway lines, highways and buildings to be washed away and in some cases for people to die when a beaver dam breaks. Installing water-level control devices, such as 'beaver bafflers' are helpful in preventing sudden and unexpected dam breakages.

\section{Native Plant Communities in the Face of Encroachment by Exotics}

Two main foci of research regarding exotic species include 1) diagnosing and predicting the effect of exotics on vegetative structure, composition, and function; and 2) evaluating the effectiveness of existing and future treatment options across a range of ecological conditions and temporal and spatial scales. Research is needed to better define life history characteristics of numerous invasive plant species. For example, it is critical for control efforts to understand which life stages limit population growth for various invaders, so that unique characteristics of invaders can be attacked in a species-specific fashion at critical life stages.

Effects of invasive plants on native vegetation. $[\mathrm{H}-\mathrm{M}]$ What conditions represent thresholds for cheatgrass and other invasive species, beyond which ecological processes and function are compromised to 
the point that reseeding of native perennials (after control of exotics) is the only means to reestablish native communities?

Ecologists and resource managers are increasingly realizing that a state-transition paradigm better describes vegetative succession and response to disturbance than does the single-equilibrium climax paradigm (Archer and Smeins 1991, Laycock 1994, West and Young 2000). In the former model, natural perturbations, human-related disturbances, or a combination of both can cause shifts in systems to one of numerous alternative states. Unfortunately, understanding of which levels (e.g., intensity, duration, frequency) of disturbance constitute threshold-crossing events, and how factors combine, remains underdeveloped. Potential determinants of thresholds include density, species richness of exotics, and successional sequence of invaders (Pellant 1996). Threshold conditions will likely vary across the landscape, depending on ecological site, climate, management activities, disturbance regime, and plant and animal composition (Hann et al. 1997).

Framing questions about thresholds in terms of ecosystem processes may improve efficiency by elucidating dynamics of numerous ecosystem components simultaneously. For example, one might ask, across biophysical settings, what is the shape of the response curve of ecosystem services (Daily 1997) such as nutrient cycling, decomposition, carbon sequestration, and the hydrologic cycle to increasing densities of invasive plants? As a more specific example, do exotics alter pollination dynamics to the extent that native species are limited by a lack of animal pollinators? Axelrod (1960) estimated that two-thirds of all flowering plant species benefit from insects that visit their flowers; substantial declines since the late 1940s in abundance of honey bees may threaten productivity in agricultural and natural systems (Watanabe 1994, Nabhan and Buchmann 1997). As a final example, how do exotics change the composition and diversity of soil microorganisms, other than crust species, and how does this affect establishment and persistence of native species?

Restoration treatments. Again framing questions in terms of ecosystem processes, one might conversely ask what changes occur in ecosystem processes after physical, chemical, and biological control methods are employed for well-established and newly established infestations of invasive exotics? How do the changes vary as extent of control method (i.e., treated area) increases? The four questions below are examples that address restoration and its implementation across the Basin. i. $[\mathrm{H}]$ After fires of large spatial extent when native seeds cannot be collected or produced in sufficient amount to re-seed the entire burned area, what spatial arrangement of native and non-native reseeding creates greatest productivity and diversity of native species?

Effectiveness of restoration actions depend upon the nature of the disturbance(s), the abiotic conditions of the site (e.g., soil type, climate), which invasive plants are involved, and the spatial extent of the infestation. Marlette and Anderson (1986) observed little invasion by native perennial grasses into established crested wheatgrass stands. They concluded that most native perennials do not possess mechanisms for long-range dispersal, such that establishment declines exponentially with increasing distance from the parent plant. From results of simulated expansion from dispersed foci of revegetation, Moody and Mack (1988) concluded that small satellite patches possess greater potential for expansion than does a large central focus of revegetation. Potential spatial arrangements that can be compared include all lands mixed, core and buffer arrangement, interspersed patches, non-natives at areas of highest erosion potential, among others. Restoration efforts are most effective when site-specific conditions are considered within the framework of how they contribute to restoring connectivity and reducing fragmentation at larger spatial scales.

\section{ii. $[\mathrm{H}]$ In preparing seed mixes and restoration} plantings with native species, what mix provides an optimum compromise between the objectives of rapid soil stabilization, development of diverse native flora, and creation of soil nutrient and hydrological dynamics that are resistant to exotic species?

A high priority for restoration research is a better understanding of the factors affecting the establishment of native species. Of particular interest are finding native species that compete effectively against invasive exotics, understanding how exotic species alter the establishment process, and selecting native species for seed increase. Interspecific competitive interactions during and after establishment are also of interest, and finding native species that possess life histories and uptake patterns similar to cheatgrass and other exotics merits further research.

iii. [M - H] In areas of small spatial extent but relatively extensive degradation, does the use of seedlings (as opposed to seeds) improve rates of shrub establishment? 
In arid regions, plant establishment occurs slowly and is contingent upon a narrow range of climatic conditions (Williams 1977). Restoration of shrubs is important, because of their roles in substrate stabilization, creation of diverse microclimates, and development of a self-sustaining community that will require minimal future management. From research on efforts to restore sage-shrub habitat that underwent surface strip-mining, Parmenter et al. (1985) reported that use of seedlings (grown from seeds collected on adjacent areas) achieved higher levels of plant establishment than did cultivated seeds. High establishment success occurred in seedlings in the first planting, contrasting with the several successive plantings commonly required for seed establishment in restoration efforts.

iv. [M - H] In areas with unstable soils, do clumped plantings of seedlings exhibit greater ecological function (e.g., soil stabilization, nutrient cycling) than random or dispersed plantings?

Species of perennial grasses and forbs display a diversity of strategies to disperse seed propagules from parent plants. Especially in relatively windy areas, bunchgrasses and shrubs trap organic matter and spores of mycorrhizal fungi, and provide microclimate suitable for establishment of new individuals. In restoration of sage-shrub habitat in western Wyoming that underwent strip-mining for coal, plants established in clumps were more successful (in terms of both survivorship and production of new plants) than plants cultivated in regular or random spacing patterns (Parmenter et al. 1985).

\section{Soils}

i. $[\mathrm{H}]$ Will different components of crusts recover after 1, 2, 3, 5, 10, or even 20 years' removal of disturbance agents such as excessive grazing or severe fires? How does this vary with soil type? Can soils be efficiently and feasibly inoculated with crust components to facilitate the process?

Microbiotic crusts can be damaged temporarily by fire (Harper and Marble 1988, West 1990) and by continuous season-long or very intense, short-duration grazing (Brotherson et al. 1983, Johansen 1986, Jeffries and Klopatec 1987). Regrowth of crusts varies with disturbance history (Marble and Harper 1989) and current abundance of exotic annuals, but initial recovery of crusts after disturbances abate can be fairly rapid (several to 100 years). Cyanobacteria and algae comprise initial stages of recovery, followed by bryophytes and lichens in later successional stages of recovery (Rosentreter 1986, Belnap and Gardner 1993). Hann et al. (1997) noted a lack of research on response of microbiotic crusts to disturbances, particularly anthropogenic disturbances associated with land uses such as livestock grazing. Using knowledge of recovery trajectories and timing of various components, managers may be able to aid crust regrowth through subsurface inoculation of soils over small spatial areas. This question can be best addressed through an interdisciplinary group of soil scientists at numerous sites (with paired control sites), using repeated measures over time (Green 1993).

ii. $[\mathrm{H}]$ To what degree and extent has soil chemistry been altered in arid ecosystems? Are there any aboveground indicators that reliably signal areas with significantly altered soil chemistry? What factors affect the success of restoration, reclamation, and rehabilitation efforts that use various soil treatments?

Soil productivity across the Basin is generally declining, due to improper implementation of vegetation management activities, road construction and maintenance, and excessive livestock grazing (Hann et al. 1997). Although physical characteristics of soils such as bulk density, porosity, and water-holding capacity are known to affect rates of erosion and vegetation establishment, an understanding of how soil chemistry affects the structure, composition, and function of other ecosystem elements (Figure 2) is less developed.

The $\mathrm{C} / \mathrm{N}$ ratio is one critical aspect of soil chemistry, and is increasingly investigated as a target in restoration efforts. Addition of sucrose, a source of carbon, has been tested as a means to limit nitrogen availability to plant communities in grassland and shortgrass steppe habitats. Torok et al. (2000) found that degree of nitrogen immobilization can vary with soil moisture and organic matter. In red fescue grown from callus tissue, treatment with sucrose enhanced regeneration capacity and decreased frequency of albino plants (Zaghmut and Torello 1992). In abandoned croplands in the shortgrass steppe of Colorado, addition of $\mathrm{N}$ increased relative abundance of annual forbs and grasses (e.g., noxious weeds), whereas the addition of sucrose increased relative abundance of perennials (Paschke et al. 2000). Late-seral plant communities may be less effective than earlier-seral communities at capturing added $\mathrm{N}$, and sucrose additions may affect the rate and course of plant and soil redevelopment in as little as four years (Paschke et al. 2000). Should further experimentation corroborate this initial work, treatment methods that can be widely and economically applied should be sought. 
iii. [M] Have areas with a particular slope gradient and aspect (e.g., south-facing, steep slopes) suffered soil losses so severe that historical plant communities can no longer exist? Which techniques are most effective for restoring soils or mitigating soil losses in areas such as these, with varying levels of retrogression?

Increasing slope gradient can be one of the strongest predictors of high erosion rates in arid ecosystems (Wilcox and Wood 1989, Ludwig et al. 1995, Kim and Miller 1996). Due to physical forces involved, finer particles are washed downhill in disturbed areas, leaving soils remaining on slopes with a coarser texture. Vegetative cover or leaf litter on slopes can attenuate the force of incident precipitation and thus reduce soil loss (Wilcox and Wood 1989). However, steep slopes are commonly grazed by domestic sheep, which can reduce cover and thus increase erosion potential. Broad-scale re-creation of soils is not feasible, and numerous plant species cannot tolerate drastic changes in soil characteristics. This question should be addressed for soils possessing several types of parent material.

\section{Aquatic-Terrestrial Interface}

\section{Multi-scale Importance}

i. [H] How do aquatic habitats respond to disturbance events (fires, large floods, droughts) over short and longer time scales, and how does this level of resiliency compare with the response to altered frequency and magnitude of disturbances caused by anthropogenic influences such as roads, exotic species, livestock grazing, water diversions, dams, and gravel mining?

Structure and function of riparian areas often depend upon the frequency, magnitude, and duration of disturbance by extreme hydrological events and upon the way in which these events affect geomorphic and hydrologic processes. Research design may focus on three types of studies: a) field surveys that measure the impact of historical events such as fires and large floods; b) intensive, opportunistic surveys during and immediately after rare disturbance events; and c) use of human influences to assess response of aquatic systems to changed disturbance regimes (Lee et al. 1997). Because the role of disturbance in shaping riparian and aquatic systems varies with climate region and from naturally stable to highly variable systems, broader inference will be gained from replication across watersheds and dominant natural gradients. Especially in complex and variable aquatic systems, understanding long-term responses to disturbance over scales relevant to disturbance regimes of the Intermountain West is critical. Approaches such as retrospective analysis, fast-system analogues, simulation models, and space-for-time substitution may be used to complement long-term research (Fleming 1999).

In some stream systems, legacies of past climate change strongly affect stream geomorphology and current stream functioning and can result in a natural tendency towards stream incision or degradation. Human-related impacts can greatly exacerbate both the magnitude and rate of change (degradation) in these stream systems. (Chambers et al. 1998, Miller et al. 2001). Thus, management strategies in riparian areas may be improved by incorporating an understanding of the effects of climate change processes as well as natural and anthropogenic disturbance.

ii. $[\mathrm{H}]{ }^{\mathrm{ADMMMT}}$ If sufficient data exist to estimate $H R V$ in intensity, frequency, and duration of flooding disturbance, do expected changes in recruitment of riparian trees, species composition of plants, channel morphology, and upland conditions occur when the disturbance regime is restored? If not, which conditions (e.g., lowered water table, altered composition of vegetation) most strongly inhibit potential for recovery?

In aquatic systems, disturbance events may differ in their magnitude, frequency, and duration, all of which diminish laterally away from the active channel (Gregory et al. 1991). Because irrigation and dams tend to attenuate pulse flows, heterogeneity in disturbance pattern has decreased from historic conditions. Removal of dams has been considered as one means to restore historic disturbance regimes and connectivity of aquatic habitats. However, the hydrogeomorphic and faunal responses to dam removal are largely unknown in this region. In addition, the importance of dams for agriculture and generation of hydroelectric power necessitates careful planning when considering dam removal. Field experiments during and after rare events can intensively and opportunistically examine changes during and following rare events. The nature of the changes can be compared with changes due to human impacts (e.g., construction of a new road, imposition of a dam or livestock grazing) to assess the resilience of aquatic ecosystems to disturbance.

Historically, wildfires were a natural and important part of the disturbance regime, and may have been the most pervasive disturbance agent across the landscape (Reeves et al. 1995). The pattern of wildfire frequency and intensity historically reflected variability in vegetative structure and cover types, climate, and topography, and aquatic populations were recolonized from connected neighboring populations after small-scale disturbances. In contrast, wildfires currently occur less fre- 
quently but with greater intensity than they did historically, due largely to fire suppression efforts. In addition, dams and diversions often prevent population recolonization. Wildfires can directly affect water chemistry, and can indirectly affect hydrologic regime, erosion, debris flows, and riparian cover (McMahon and deCalista 1990, Bozek and Young 1994).

iii. $[\mathrm{H}]$ At scales from the stream reach or wetland to the landscape, how have historic landscape processes been altered by anthropogenic disturbances (e.g., land and water uses), and what effects do the change in physical processes have on aquatic habitat and populations?

Connectivity among aquatic habitats occurs naturally in contiguous lotic systems, but also occurs in lentic systems through climatic cycles and active dispersal of vagile organisms. Ecologists and managers have increasingly been investigating aquatic integrity and riparian function at larger scales (Hynes 1975). In particular, watersheds have often been proposed as the unit of analysis for investigating pattern and process in ecosystems (Johnson and Patil 1998, Jones et al. 2000b, Kepner et al. 2000). This approach emphasizes the fundamental connection between stream, riparian (or wetland), and adjacent upland habitats, and provides the broad context within which smaller-scale investigations can be realized. A key interaction to consider is the manner in which roads, fuel treatments, grazing, diversions, impoundments, and channelization have affected stream temperature, stream sedimentation, channel structure (e.g., incision) and complexity, as well as connectivity of aquatic habitat. The use of replicated aquatic units with controls is essential to remove effects of climate and intrinsic stochasticity, which can confound investigations of disturbance in semi-arid regions (Hastings and Turner 1965, Herbel 1979, Branson 1985). Addressing this question robustly requires an interdisciplinary team of hydrologists, aquatic ecologists, landscape ecologists, modeling experts, and managers of spatially explicit data.

Grazing presents an example of a disturbance that has changed from nomadic wild grazers in pre-European times to current conditions. Riparian zones often receive heavier use by livestock than do upland zones, because they have flatter terrain, abundant water and shade, and more succulent vegetation (Platts 1991). Platts (1991) reviewed effects of grazing on streambanks, the water column, and the stream channel, and evaluated the compatibility of seven major grazing strategies with fishery needs. High priority should be assigned to improving our understanding of riparian condition, and research should involve a multi-disciplinary approach that includes hydrologists, geomorphologists, modelers, and vertebrate biologists. Designing a grazing system requires consideration not only of grazing intensity (i.e., utilization level), duration, season, frequency of rotation, and grazer identity (sheep vs. cattle), but also of the spatial arrangement of grazing pressure across the landscape.

iv. $[\mathrm{H}]{ }^{\text {ADMGMT }}$ How do water quality and aquatic diversity vary across DOI-administered lands with respect to changes in road density, canopy cover and composition, sedimentation, and grazing system?

In this context, diversity includes genetic variability within species (e.g., evolutionarily significant units), composition of various functional groups (e.g., macroinvertebrate shredders, macroinvertebrate scrapers, algae, microinvertebrates, fishes), and community diversity. Extensive sampling for the ICBEMP has produced broad-scale maps documenting the status and distribution of aquatic species, especially salmonids, for the Basin. However, algae, microinvertebrates, and macroinvertebrates, the basic biotic components of most aquatic habitats, are poorly known from the Basin. Furthermore, point samples of invertebrates may reflect only conditions in the immediate vicinity, and thus correlate poorly with particular land uses.

Due to the influence of topographic and geomorphologic factors on aquatic diversity (Gregory et al. 1991), experiments are needed to separate effects of land-use activities from confounding factors (e.g., geomorphology, stream profile). Thus, more direct links can be established between landscape conditions and biological responses. For example, field experiments within and between watersheds can use sites of restoration and development activities as experimental replicates to manipulate levels of the factors of interest (e.g., grazing system, canopy cover, abundance of exotics). Corresponding invertebrate sampling should occur at sampled locations along gradients of human influence.

v. [L - M] What disturbance factors cause departures in correlation between upstream and downstream conditions in streams?

Hynes (1975) underscored the importance of a landscape perspective for understanding structure and function of stream ecosystems. Geomorphic processes, fluvial landforms, succession of plant communities, and production of nutritional resources all combine to define riparian conditions (Gregory et al. 1991). Although geomorphologic and vegetative conditions can vary among different reaches of the same stream, it is unclear to what extent human land uses combine with 
endogenous sources of variability in stream ecosystems. In the Basin, most stream inventories have been performed in high-elevation, constrained reaches, while low-elevation rangelands have been greatly undersampled (Lee et al. 1997). Integrating information from upper reaches of the same stream or from lower-order streams may aid interpretation of stream surveys performed on DOI-administered lands.

\section{Spring Locations}

i. $[\mathrm{H}]$ What are the composition, abundance, and trend of spring-dwelling biotas? How do soils and nearby communities (e.g., invertebrates, plants, large mammals, birds, granivorous mammals) respond to changes in spring management?

Many spring-dwelling animal species in arid and semi-arid regions have restricted distributions, due to the disjunct distribution of springs. Such taxa include ostracods, springsnails, butterflies, and diverse aquatic insects. Systematic, broad-scale surveys of springs in the western United States, in addition to detecting high levels of endemism in spring communities, have found springs to be highly altered by recreation, impoundment for irrigation or livestock grazing, and large-animal use (Hamlin 1996, Külköylüoglu and Vinyard 2000). The influences of domestic cattle and feral horses are greatest immediately adjacent to springs, and decrease asymptotically with increasing distance from the spring (Valentine 1947). Spring networks provide a naturally replicated system, in which the effects of uncapping springs or changes in grazing management can be experimentally investigated.

\section{Wetland, Riparian, and Upland Communities}

i. $[\mathrm{H}]{ }^{\mathrm{AD} M \mathrm{MGMT}}$ What levels of shoreline disturbance by humans or livestock cause loss of fitness in wetland animal species? Does minimizing disturbance during periods of reproduction mitigate effects on fitness?

Lee et al. (1997) cite shoreline disturbance as one of numerous factors contributing to declines in wetland species. For many nesting shorebirds, periods of reproduction are when species are most vulnerable to anthropogenic influences. Seasonally restricted access to breeding and nesting areas has been successful in bolstering population sizes for some species. Similarly, some fishes require specific site conditions to complete reproduction. Examples of taxa on which to focus investigation include resident and migratory birds, endemic fishes, aquatic invertebrates, and introduced species. Comparing reproductive success of several species or groups representa- tive of key ecosystem processes at several human-excluded and control areas over two to five years should address this question adequately. A smaller-scale approach to addressing the question would ask: In areas where humans are allowed access to only portions of wetlands, how much time do vertebrate species spend in human-limited areas? (Also see question v. in this section for further discussion on thresholds.)

\section{ii. $[\mathrm{H}]$ To what degree have ephemeral wetlands} been converted to other uses within the region?

In many areas of the Basin, water is a limiting resource, and ephemeral wetlands may play critical roles at landscape scales in water and energy budgets of native wildlife. Recent research (Clausnitzer 2000) suggests that some ephemeral wetlands within the Basin possess many hydrologic and edaphic similarities to vernal pools of California, which have been afforded high levels of protection there. Exotic bullfrogs, exotic fishes, and predaceous aquatic insects tend to occur in relatively deep, structurally simple, more permanent ponds that have become more common in western North America (Hayes and Jennings 1986, Roth and Jackson 1987). Because these exotics often cannot persist in more ephemeral water bodies, ephemeral water sources may become increasingly important for sustaining populations of amphibians through time. Alterations to ephemeral wetlands may affect aquatic invertebrates, aquatic birds, amphibian breeding, and, by reducing springtime forb production, pronghorn antelope and sage grouse. Increased salinization of either ephemeral or permanent wetlands may dramatically reduce their value to native vertebrates (Rubega and Robinson 1996). Effects of livestock grazing on ephemeral water sources in the region have largely not been quantified. Experimental manipulation of ephemeral wetlands, via digging out and re-filling of replicated seasonal wetlands, could be used in concert with comparison of unaltered and excavated areas to rigorously address effects of alteration and attempted restoration.

iii. [M] Which factors limit the success of vegetation reestablishment at aquatic-terrestrial interfaces experiencing trampling, eutrophication, or salinization?

A knowledge base for streamside revegetation already exists, but improved understanding of external validity (numerous conditions) would assist in applicability of revegetation techniques. Many plant species are specialized to tolerate conditions unique to the aquatic-terrestrial interface, and cannot immediately colonize sites that have suffered compaction or altered balance of nutrients. 
In addition to the disturbances of trampling, eutro phication, and salinization, various characteristics of the hydrological regime such as the intensity, duration, and frequency of pulse flows in riparian zones, as well as the discharge level throughout the year, can affect the recruitment of vegetation. Furthermore, in many streams, legacies of past geomorphologic activity (e.g., natural geologic processes, historic mining) in the stream, as well as anthropogenic disturbances upstream and upland can constrain potential options for recovery. This question can be addressed either through multivariate analysis of sites with varying recolonization success or through one- or two-factor experimental manipulation of conditions known to be important in plant establishment.

iv. [M] At what concentrations of salinity, total dissolved solids, toxic pollutants, and dissolved oxygen will populations of fishes, birds, and aquatic invertebrates start to decline (i.e., experience compromised reproductive success)? Can exceeding these thresholds be reliably avoided through manipulation of water levels using existing systems of water management?

Due to withdrawals for irrigation, mining, road construction, farming, livestock grazing, and shoreline recreation, numerous characteristics of water quality have been altered significantly from historic conditions, especially in low-elevation water bodies (Rubega and Robinson 1996, Lee et al. 1997). Many fishes in the southern portion of the Basin are relatively narrow endemics, and do not have broad tolerances for changes in salinity, dissolved solids, and dissolved oxygen. For example, Lahontan cutthroat trout die at high water temperatures or in the presence of high levels of total dissolved solids (Dickerson 1997). Often, loss of links in aquatic food webs can lead to a cascade of further extirpations. For many species, tolerance levels can be established in laboratories; however, it is most important to determine the synergistic effects of simultaneous stressors on organisms. Tolerance levels of many species to toxic pollutants have not been established, and environmental scientists often have only a superficial understanding of synergistic effects of multiple stressors on organisms.

This question assumes the existence of thresholds, above which organisms respond fundamentally differently to biotic or abiotic stressors than they do at conditions below the threshold. However, not all organisms respond in a distinctly binary manner, as implied by a threshold, but rather in a graded, continuous fashion. Furthermore, intrinsic variability in ecosystems complicates the ability to evaluate stressors using a precise, static threshold. Three types of variability include sto- chastic variation, successional trends after natural disturbance, and cyclic variation (Noon et al. 1999). Therefore, active management may be recommended when monitoring produces repeated observations of indicator variables out of the normal (or historic) range of values, rather than simply when a threshold is crossed. Accordingly, the goal of research relating to thresholds is a better understanding of ecosystem processes and ecological resilience.

v. [M] AD.MGMT Similar to questions related to upland exotic plants, what are the conditions most favorable for establishment of "aquatic nuisance species" (e.g., zebra mussel and other mussels, crustaceans, cordgrasses)? What detection, monitoring, prevention, and control techniques should be employed?

Answers to these two questions may help prioritize how to distribute funding and management effort among many areas, which control method or methods to employ, and when. Although animal invasions are most likely in the Columbia River and its immediate tributaries, species such as whitetop and tamarisk have broad distributions and can drastically alter hydrological conditions in waterways across the more arid rangelands of the Basin. Given rates of spread of aquatic nuisance species and the consequent ecological disruption observed in other ecoregions, proactive management strategies should prove to be fiscally prudent. Altered hydrologic regimes, changes in water quality due to various land uses, and changes in riparian vegetation due to overgrazing may all facilitate the establishment and spread of nuisance species.

vi. [M] ${ }^{\text {AD.MGMT }}$ If it is socially and biologically feasible to eradicate introduced fishes, do ecosystem and regional integrity benefit more from efforts in fewer medium- to large-sized aquatic habitats or in more numerous small-sized habitats? Does this action increase fitness of native fishes, amphibians, or aquatic insects?

In western North America, numerous exotic fishes have been introduced into permanent waters (Moyle 1986), and in lowland areas bullfrogs now occupy many permanent ponds and streams (Bury and Whelan 1984). Introductions of bullfrogs and fish have been implicated in declines of native amphibians (Leonard et al. 1993) as well as native fishes (Williams et al. 1989, Nehlsen et al. 1991, Fisher and Shaffer 1996).

However, numerous factors mediate the effects of exotic species on biotic diversity, and these factors may interact in complex or correlated fashion to produce faunal change (Winter and Hughes 1995, Adams 2000). 
National parks in the western United States have generally stopped introducing fishes, and abundance of planted species has often declined in park water bodies. Biological integrity and not just species diversity is increasingly recognized as an important characteristic of ecosystem health. Thus, determining the effects of habitat size on manipulation of ratios of native to non-native species is but one of many factors that can be investigated to maximize ecological benefits of control efforts. Logistical difficulties may preclude restoration of very large water bodies. However, experimental design could employ a paired design across patch sizes, with fish removals in half of the units. Within financial constraints, replicates should be located in several broad environmental strata (e.g., GAP vegetation types, ecological reporting units) if broad applicability is desired.

vii. [L] To what extent is regional integrity and persistence of species affected by stocking events of native fishes?

Native fishes are stocked periodically in water bodies across the region, yet there has been no definitive assessment of their effects on target species and other components of aquatic systems. To achieve the most definitive answer, manipulations of stocking rates should ideally be done for one species at a time in replicated water bodies, and over the course of several years to account for environmental stochasticity.

\section{Development of Monitoring and Implementation Protocols for Adaptive Management}

\section{Overarching Issues}

i. $[\mathrm{H}]$ What is the minimum set of variables that can be used to reliably detect disturbance or departure from historic range of variability within a given soil-vegetation type, elevation band, and aspect? For example, for what range of values can an easily monitored (on-site, fine-scale) variable such as penetration resistance (hardness) of soil surfaces be used as a proxy to detect changes in other ecosystem components? Which components are and are not predicted by the proxy?

Multivariate characterization of disturbance has become an increasingly common focus of ecologists during the last two decades. Often, variables of interest are difficult, if not logistically impossible, to collect across broad spatial scales. As an alternative, proxies are often used to represent ecosystem components or processes. Descriptors of spatial elements and configuration can be used to clarify patterns and processes in ecosystems, especially when used in concert with site-specific nonspatial variables. Iterative testing and fine-tuning of potential suites of disturbance indicators will help managers and researchers balance between conciseness (for logistical concerns of implementation) and capturing processes that drive ecosystem function.

A set of range condition indicators has been developed (Pellant et al. 2000), and is being field-tested at selected locations across the western United States. Similarly, Hann et al. (in press) derived a variable to estimate disturbance departure from the historical landscape mosaic and succession-disturbance regimes produced by the cumulative effects of livestock grazing, timber management, invasions of exotic plants, agricultural conversions, and other human activities across broad areas. Levels of the variable reflect the composite degree of coarse-scale change in patch size, composition, and arrangement; timing and severity of tree die-off due to pest and pathogens; timing and intensity of ungulate grazing; composition of native versus non-native vegetation; and human activities and presence.

\section{Riparian Areas}

i. [M] In riparian systems, for purposes of prioritization, do point-or reach-specific management efforts (e.g., bank stabilization, eradication of exotic plants, change in grazing system) produce levels of restoration that vary across watersheds?

A fairly extensive literature exists regarding the distribution and interrelationships of aquatic biodiversity (e.g., fish, invertebrates) and physical habitats at the scale of stream reaches and individual habitat units. However, much less is known about the large-scale relationships and processes that influence structure, composition, and persistence of populations and communities. Thus, effective conservation and restoration of aquatic resources depend on a better understanding of the spatial and temporal distribution of habitats necessary to sustain functioning systems (Lee et al. 1997). Variables used to index restoration should reflect function and process in geomorphology, hydrology, vegetation, and resident animals (Figure 2). Meta-analysis (Fernandez-Duque and Valeggia 1994) or preliminary sampling could be used as a screen to determine which environmental factors may strongly influence restoration success. Subsequently, point-specific restoration should be implemented in differing levels of the factor at numerous replicates within a watershed. Once patterns in effectiveness of restoration can be established, future restoration may focus on areas providing the greatest improvement in aquatic function. 


\section{Wildlife}

i. $[\mathrm{H}-\mathrm{M}]$ Given that the region and the world are experiencing a relatively rapid period of climate change, what are the effects on stenotopic species, particularly temperature-sensitive species? Can population extirpations be predictably modeled? Are distributional ranges of species migrating up hillslopes and to more northerly latitudes? For species vulnerable to high temperatures or large fluctuations in temperature, are populations experiencing losses at the southern edges of the range or at lower elevations?

Although climatic changes must be viewed from the perspective of several temporal scales to adequately assess trend, mounting climatological data suggest that rapid shifts in climate (e.g., temperature, precipitation, seasonality) are occurring in the United States and across the globe (Schneider 1990, Kittel et al. 1997). A reasonable body of theory has been put forward to predict biological responses to changes in climate (e.g., Peters and Darling 1985, McDonald and Brown 1992, Murphy and Weiss 1992), although few predictions have been tested across broad spatial scales. Under presumed increases in temperature, populations are predicted to move up in elevation or latitude, or to be experience local extirpations when migration upslope or to more northern habitats is not possible. For aquatic habitats, high temperatures may result in at least temporary loss of water bodies, although water levels in the Basin can also be affected by drought. As an example, Beever (1999) re-visited sites of historically recorded pika populations in the hydrographic Great Basin, and found that more than one-fourth of the populations have suffered apparent extirpation during the latter part of the 20th century. Furthermore, most extirpations occurred at the lowest-elevation sites, although habitat area and proximity to roads also appeared to contribute to greater extinction risk. Finally, especially for less vagile species such as the meadow vole and northern pocket gopher, edges of species' ranges deserve conservation attention if management is to provide evolutionary and migratory potential for the future.

ii. $[\mathrm{M}-\mathrm{H}]$ For which vertebrate and invertebrate species do trends in habitat (Boyce et al. 1994, Hann et al. 1997, Marcot et al. 1997) not predict trends of population density?

Generally, vertebrate species with large home ranges are most severely affected by habitat loss and fragmentation (Lehmkuhl and Ruggiero 1991). Assessment of terrestrial species for ICBEMP primarily analyzed dynamics at broad spatial scales and relied on the assumption (i.e., working hypothesis) that amount, distribution, and trend of habitat reflect true population size, distribution, and trend of species at broad and finer scales (Marcot et al. 1997). However, many species will respond to changes in habitat at much finer spatial scales, depending on local biotic and abiotic conditions as well as on life-history characteristics of individual species. For example, significant road-kill mortality, nest parasitism, demography, population genetics, interspecific interactions, and disturbance dynamics are factors that can produce nonlinear relationships between habitat area and a species' distribution or abundance. Furthermore, broad-scale analyses of vegetation, by definition, cannot detect changes in finer-grained attributes of vegetation and habitat substrates. Early identification of species whose trends are not easily modeled by broad-scale changes in habitat may help avert future listing of threatened and endangered species. Wisdom et al. (2000) list 173 vertebrate species of conservation concern, based on extensive literature surveys and expert reviews of fauna in the Basin, which may be used as a starting point for future research on species at risk. This question can be investigated by incorporating existing information on sensitive species with replicated surveys in given habitat types to determine which species have incidence functions suggestive of finer-scaled habitat needs. (See also discussion on Bayesian belief models in the "Terrestrial Species" section of the Background.)

\section{Fisheries}

i. $[\mathrm{H}]$ As human settlement and demand for water in the Basin continues to increase, is there an upper limit on water diversion, above which the connection of streamside habitats to the water table is altered to the point that riparian vegetation no longer performs ecosystem functions (e.g., flood attenuation, sediment holding)?

Most recent controversy over land use in the western United States relates either directly (e.g., water supply, public health and recreation, road construction) or indirectly (e.g., special-status riparian obligates) to the hydrologic system. Water is a limited resource in the semiarid portions of the Basin, and its scarcity becomes more pronounced with increasing amounts of water allocated to human uses. Although many aquatic species in the semi-arid portions of the Basin possess physiological and behavioral traits adaptive for periodically low flows, human use of water has altered both the mean and the magnitude of variation in discharge. In addition to the effects on the functionality of riparian vegetation, the effects of reduced flows should also be assessed with respect to riparian-obligate vertebrates and invertebrates, geomorphological processes, and upland habitats. 
In some cases, a range of conditions will provide a more robust trigger for initiating management response than will a single threshold. Hydrologists, landscape ecologists, aquatic biologists, and geomorphologists can collectively address how various uses of water affect hydrologic characteristics such as stream temperature, turbidity, sedimentation, and channel roughness across the landscape (especially at the federal-private interface). Understanding how watersheds respond to incrementally increasing human use of water is critical for water quality planning and credibly defending policy in cases of litigation.

\section{ii. $[\mathrm{M}-\mathrm{H}]$ What are the effects of different} recreational uses of habitats (e.g., camping, fishing, hunting, mountain biking, off-highway vehicles, motorized boating)?

To manage and restore recreational areas, it is important to understand which aspects (e.g., camping adjacent to riparian areas) and intensities of recreation use are causing impacts (Stankey et al. 1985). Although studies on each recreational use have been performed individually and for some ecosystem attributes, ecologists do not know how these uses combine synergistically or how they affect ecological processes. This question is especially amenable to input from social scientists, to integrate recreational, aesthetic, and resource values into analyses.

\section{Soils}

Research questions regarding monitoring of soils are found in other sections of this Plan, in particular in the Restoration section. An additional question follows below.

i. $[\mathrm{H}]$ What are the effects of disturbances such as fire and livestock grazing on nutrient availability and its relationship to plant invasions? How do they change following restoration?

Nutrient dynamics are increasingly recognized as a determinant of system response to disturbance. Understanding how rates of nitrogen deposition vary across the Basin is an important first step to address this question.

\section{Testing Assumptions}

One function of monitoring and analysis is to provide tests of stated assumptions made by the Science Advisory Group (USDA and USDI 2000a). Assumptions are necessary to complete the vast array of broad-scale analyses included in the Assessment (Quigley and Arbelbide 1997). Stating assumptions clearly communicates what elements are known and unknown (e.g., Corn 1994), and provides an excellent mechanism for the fine-tuning of management, a central tenet of adaptive management (Holling 1978). Some assumptions that may merit verification on DOI-administered lands include the following:

i. $[\mathrm{H}]$ Is "the influence of management direction and the function of riparian areas ... essentially the same in forested and range areas" (USDA and USDI 2000b: 16-10)?

ii. [H] Is "the status and trends of salmonids and their habitats ... the most representative indicators of the responses in aquatic ecosystems related to federal land management" (USDA and USDI 2000b:16-16)? Alternatively, which aquatic species or assemblages best reflect health, integrity or resiliency of aquatic ecosystems in lower-elevation systems?

For the latter question, multivariate approaches to analyzing stream faunas are most likely to prove useful, including techniques such as PCA, cluster analysis, and reciprocal averaging. Intensity, scale, and methods of sampling also need to be outlined to ensure ability to apply conclusions at larger scales. In December 1999 , the Interagency Salmon Science Team identified roads and road type, geomorphology, land use type, and the distribution of age classes of upland and riparian vegetation as potential metrics.

iii. $[\mathrm{H}]$ Are levels of activities other than grazing unlikely to strongly influence riparian condition? Alternatively stated, is the assumption that "future riparian condition is viewed as the result of current condition, grazing levels, and riparian management direction that may influence grazing or other activity within the buffer but not the magnitude of that other activity" valid (emphasis added; USDA and USDI 2000b:16-16)? For example, does the amount of hiking, horseback riding, mountain biking, camping, or use of roads along streams affect stream condition?

iv. $[\mathrm{H}]$ To what degree do the soil property and climate indicators used in ICBEMP modeling of rangeland health predict conditions of structure, composition, and function of communities at the site level? What factors cause greatest departure from predictions suggested by indicators?

The soil indicators used include erodibility by water ( $\mathrm{K}$ factor), erodibility by wind (wind erodibility group), salinity, sodicity, and shrink-swell potential; climate indicators include three levels of annual precipitation, $<9.8 \mathrm{in}$., $9.8-11.8 \mathrm{in}$., and $>11.8 \mathrm{in}$. 
$(<25 \mathrm{~cm}, 25-30 \mathrm{~cm}$, and $>30 \mathrm{~cm})$. On-site validation or ground-truthing is needed.

\section{Habitats and Species at Risk Habitats at Risk}

Expansion of western juniper. i. $[\mathrm{H}]^{\mathrm{AD} \text { MGMT }}$ What is the relationship of wildlife populations to the (physical) structure of juniper habitats and recovery from fire?

Ecosystem processes occur very differently between open (i.e., containing shrub and herb layers) and closed (i.e., no shrub or herb layers) stands of juniper. Bird diversity appears to exhibit a bell-shaped response to increasing density of junipers (R. Miller, personal communication, January 2001), such that mid-successional stages form an important component of the landscape mosaic. The relationships between fauna and a) density and canopy cover of western juniper; b) understory composition; and c) vegetation structure are not well defined. Additional investigations of responses of wildlife populations to western juniper expansion and control would be useful (Hann et al. 1997). Prescribed fire is one of several techniques that managers can use to actively manage overall density or demographic parameters of juniper stands.

ii. $[\mathrm{H}]^{\mathrm{ADMGMT}}$ What are the thresholds that constrain successional pathways? For example, to what degree must loss of ladder fuels (i.e., range of cover of shrubs and forbs) occur before only mechanical treatments are useful in reducing juniper density? Similarly, what density of cheatgrass precludes the use of fire as a management tool?

Please see section entitled "Effects of invasive plants on native vegetation" for background information (p. 35).

iii. [M - $\mathrm{H}$, varying by location] ${ }^{\text {ADMGMT }}$ There is a need to establish a solid fire history and reconstruct the distribution of pre-EuroAmerican settlement stands.

Because historical conditions are known only at broad scales, data are often lacking to justify site-specific management actions that are challenged by various user groups (R. Miller, personal communication, January 2001). The goal is to determine fire frequencies and the mosaic of different successional stages in juniper-inhabited areas, especially areas with competing demands for resources. Although periodic fires occurring naturally often limit expansion of western juniper, recent $(<25 \mathrm{ybp})$ establishment of juniper stands has occurred even in research areas not influenced by fire suppression or livestock grazing (Soulé and Knapp 2000). iv. [M] ${ }^{A . M G M T}$ To what extent are hydrological processes affected by increased juniper densities or by restoration treatments to decrease juniper cover? How does this differ across soil types associated with different levels of precipitation?

Western juniper has expanded most extensively into mountain big sagebrush, low sagebrush, quaking aspen, and riparian communities. Especially at high densities, juniper trees intercept precipitation, and thus restrict precipitation input to the soil surface. At sites where western juniper is accompanied by only sparse understory vegetation, juniper has been implicated in reduced rates of infiltration and increased runoff and erosion. Nonetheless, most hydrological research on juniper has been performed in the southwestern United States, and more research is needed to clarify the role of western juniper in hydrological processes. Belsky (1996) challenged assertions that expansion of juniper has detrimental effects on streamflow, soil properties, and wildlife habitat. Tree growth in juniper results from nonlinear interactions between summer temperature, which oscillates with centennial-level frequency, and winter precipitation, which is dominated by shorter period, decadal-scale oscillations (Graumlich 1993). Thus, varying levels of precipitation will affect both tree growth and physical interactions between rain and soil. How surface and sub-surface hydrological regimes are affected by other changes in vegetation (e.g., increased density of sagebrush, reduction of bunchgrasses) and associated restoration also merits investigation.

Other Habitats at Risk. See questions on ephemeral wetlands and spring areas, which are relatively rare landscape elements that are relied upon by numerous wildlife species and are increasingly utilized by humans in semi-arid portions of the Basin. Other special habitat types that may be locally or regionally important to biotic integrity include caves, cliffs, talus, montane shrubs, and tree snags.

Sage-scrub habitats are one of three habitat types that have undergone the greatest extent of change in recent decades, and restoration efforts are complicated by low and variable amounts of precipitation in sage-scrub habitats. Sage grouse are increasingly used as a model to describe trends in sagebrush-steppe habitats and other sage-obligate species. Three sample questions about grouse are listed below, but also see questions in the Landscape Ecology section under the Restoration heading for a broad-scale perspective. 
i. $[\mathrm{H}]$ What is the relationship between disturbance regime and structure, composition, and function of vegetation in sage grouse habitat?

Sage grouse have evolved in semi-arid habitats that were periodically disturbed by factors such as volcanism, drought, fire, and floods, such that a mosaic of conditions existed across the landscape. For example, although effects of livestock grazing on numerous aspects of semi-arid vegetation are known, several details of the relationship can be clarified: a) how historic and current livestock grazing practices combine to affect vegetative structure, composition, and function; b) how other disturbances (e.g., exotic plants, mowing, prescribed fire) modify response of vegetation to grazing; and c) how response varies across the landscape.

Disturbance of lekking areas can lead to reduced reproductive success in sage grouse and other communally breeding species. Although other factors are involved, areas nearest population centers and major roadways tend to receive greatest use, and thus may also be predicted to experience higher levels of disturbance. Other potential disturbances that need further research to elucidate their effects on sagebrush obligates include oil and gas development (fragmentation, roads, noise, lights, etc.), fire regimes, and hunting. Intrinsic measures of habitat quality (e.g., composition and cover of native grasses and forbs, abundance of exotic annuals, shrub canopy height, abundance of key arthropods) should be included as covariates when assessing human influences on population trend.

ii. $[\mathrm{H}]$ In turn, how do demographic parameters of sage grouse and other sagebrush-obligates vary with vegetative characteristics (cover, species richness and diversity, production) across the region?

Again, some work has been done that relates fitness of individuals of sagebrush-obligate species with the amount of canopy cover, abundance of key forbs and bunchgrasses, arthropod abundance, sagebrush height, and other factors. Following females throughout the rearing process is essential to understanding fitness. An integrative approach that also simultaneously measures soil characteristics, invertebrate (especially ant) abundance, and perhaps small-mammal abundance may give insight into the mechanisms driving the response.

iii. [M-H] If nesting and lekking areas can be discriminated from randomly selected non-used sagebrush areas in each of several sagebrush types (using variables such as soil compaction, soil type, and shrub-forb-grass ratios in discriminant analyses), is re-seeding or prescribed burning of altered habitats a viable means to mimic conditions at nesting areas? In other words, to what extent do grouse and other sagebrush-obligates use restored lands for nesting and other functions?

\section{Species at Risk}

General themes. i. [H] For those species apparently negatively affected by high road densities, under what conditions do road closures improve habitat conditions and population trends of TESPC species (e.g., grizzly bears, wolves)? Does this effect vary across taxa (i.e., mammals vs. upland plants vs. aquatic species)?

Roads occupy only about $2 \%$ of the Basin's area, although the area affected ecologically by roads is considerably larger (Forman 2000, Trombulak and Frissell 2000). Furthermore, because $39 \%$ of the Basin's roads occur in watersheds highly susceptible to erosion and sediment transport, water quality and hydrologic function in many streams have declined substantially (Wisdom et al. 2000). Roads often facilitate the spread of exotic weeds, reduce and fragment native habitats, serve as a barrier to many less-vagile species, and increase human disturbance by providing access (Noss and Cooperrider 1994, Forman and Alexander 1998, Trombulak and Frissell 2000). In rangelands, road construction has facilitated the expansion of woody species through indirectly assisting fire suppression (as fuel breaks) and livestock grazing (Hessburg et al. 1999).

ii. $[\mathrm{H}]$ What are the status, trend, and connectivity of populations of nongame fishes? Is current richness and community structure influenced by streamside vegetative cover, degree of downcutting, water temperature, or some combination of these factors? In which ways should management of fine-scale and regional aquatic endemics differ from broad-scale efforts to create habitat conditions necessary to restore key salmonids ( 7 species; Figure 4)?

Twenty-two of the 47 special-status fishes in the planning area occur in the Great Basin and Klamath Basin areas (USDA and USDI 2000a), and these and other listed species are affected on DOI-administered lands most strongly by several factors. These factors include water withdrawal or diversion; loss of connectivity and consequent disruption of metapopulation structure; degradation of habitat due to excessive livestock grazing, urbanization, and upstream silvicultural practices; and introduction of 55 non-native fish species (USDA and USDI 2000a). Data on distribution, life history, habitat relationships, and responses to various types of disturbance are generally lacking for most narrow endemics, 
thus hindering understanding necessary for their management and conservation (Lee et al. 1997). For those species with sufficiently large population sizes, manipulative lab experiments may help refine understanding of their physiological tolerances and biotic relationships. For example, which mechanisms are these fishes most likely to use during drought conditions?

iii. $[\mathrm{H}]$ To determine areas needed for viable populations: 1) What is the minimum patch size used by threatened, endangered, sensitive, and candidate species for different life stages or functions (e.g., feeding, breeding, nesting)? 2) What are the range and frequency of dispersal distances moved by individuals of the species (via migration in animals or seed dispersal in plants), and how do natural and human-created barriers to dispersal affect these distances? If they are vastly different from suspected historic range of dispersal distances, does establishment of corridors improve connectivity among populations? 3) What effect do other conditions (e.g., sex ratios, mating system, age class distribution) have on $N_{e}$ (Nunney 1993)? 4) For particularly endangered species, are captive breeding programs, translocations, or other management strategies useful for increasing probability of persistence? (See question (ii.) of Landscape Ecology, under Restoration, for background information.)

iv. $[\mathrm{H}]$ What life-history, behavioral, morphological, or physiological characteristics of species predispose them to higher vulnerability to uncharacteristic disturbance?

Potential characteristics include low dispersal capability, intrinsic rarity, large body size, high degree of habitat specificity, low amount of behavioral plasticity, low fecundity, long generation times, and stenotopicity (possessing narrow tolerance ranges). Clearly, importance of individual factors will vary across taxa. However, research addressing this question may help predict which species will become endangered in the future. The 173 terrestrial species of conservation concern listed by Wisdom et al. (2000) provide one starting point for generating hypotheses about species' vulnerability to disturbance.

v. $[\mathrm{M}-\mathrm{H}]$ Which species on public lands are most and least commensal with conditions associated with human settlement (e.g., feral dogs and cats, increased trail use)?

Although the Basin contains only six major human population centers, hundreds of communities dot the Basin landscape. Furthermore, improvements in trans- portation have effectively spread the sphere of influence of human settlements, and population growth in the Basin is predicted to be above the national average (Hann et al. 1997). Understanding the degree of commensalism with humans for non-charismatic species will determine appropriate buffer widths and help refine patch occupancy models for each investigated species. Especially within taxonomic groups, it may be possible to lump species into categories of commensalism.

USFWS high-priority species or groups and their management needs, Regions 1 and 6 (USFWS 1998). i. $[\mathrm{H}]$ What are the status of upland shrubsteppe species and what common and species-specific influences are causing their declines? Additionally, what determines quality of nesting habitat, what are minimum area re-quirements, and what range of densities is needed for "source" populations? For species with limited dispersal distances, what are the population status and evolutionary distinctiveness of geographically disjunct populations?

It remains unclear how widespread alterations to vegetation composition and structure may affect species such as ground squirrels and their predators, loggerhead shrikes, Brewer's sparrows, sage sparrows, long-billed curlews, and upland sandpipers (Hann et al. 1997). In the Columbia Plateau of eastern Oregon and Washington, 16 landbird species have exhibited significant declines in population trends during recent (1980-1998) and/or long-term time periods (1966-1998) (Altman and Holmes 2000). One approach to ensure long-term maintenance of healthy shrub-steppe communities and populations is to monitor and manage for focal species that are highly associated with important ecosystem attributes or conditions (Altman and Holmes 2000, Vander Haegen et al. 2000). For landbirds, critical attributes can include soil type (for several species), cover of native bunchgrasses (for grasshopper sparrows), interspersion of tall shrubs with canopy openings (for loggerhead shrikes), and sagebrush cover (Brewer's sparrow) or height (sage thrasher) (Altman and Holmes 2000, Vander Haegen et al. 2000). Ideally, demographic data collected from multiple sites over several years can be used to assess trends and potential mechanisms of decline or expansion. This information should ultimately help shape grazing activities, land acquisition, recreational uses, and other land uses in interior shrub-steppe habitats.

ii. $[\mathrm{H}]$ For westslope and Yellowstone cutthroat trout species, what are the fine-scale distribution, population sizes and trends, genetic distinctiveness (as 
it relates to evolutionary and ecological significance; Waples 1991) for definable populations? Furthermore, how reproductively isolated is each population from other populations, subspecies and species, what is the distribution of habitat quality in which they reside, and what constitutes viable populations under the precautionary principle?

Using the populational (as opposed to the typological) focus, within-species or within-subspecies variability is equally or more important than differences among species and subspecies (Meffe and Carroll 1994). Connectivity in Basin streams has been drastically reduced from historic conditions, and many populations are more isolated. Concerns about hybridization and genetic swamping exist for several subspecies. Disagreement exists among fishery biologists about the evolutionary uniqueness of different populations and which differences merit distinct management.

iii. [M] What are the effects of human disturbance, fragmentation, and contaminants (through carrion feeding) on reproductive success, movement, and viability of wolverines, martens, and fishers? At what scale do populations exhibit genetic similarity and how does the availability of movement corridors affect this?

Viable populations of wolverines are believed to occur in the contiguous United States only in Idaho, Montana, and Wyoming, and threats to persistence, including overall human encroachment and habitat fragmentation due to development and logging, are occurring at ever-increasing rates (Buskirk et al. 1994, Lyon et al. 1994). Because these species occur at low densities, are primarily nocturnal, have inconspicuous mating behavior, leave little sign, and shun human activity, much remains to be learned of even their basic biology (Zielinski and Kucera 1995). Martens and fishers, other forest carnivores whose populations are similarly difficult to monitor, require relatively large habitat patches and sufficient prey base to persist. Genetic differentiation among populations and its connection to various landscape characteristics merits further study.

\section{Salmon issues [Interagency Salmon Science} Team, BLM, 12/1999]. i. [H] How do different management and restoration activities affect the extent, duration, magnitude, and frequency of peak-flow events in streams across different geophysical provinces?

Because change in the structure and composition of riparian vegetation is a likely mechanism for any changes in flow regime, vegetation should be monitored before and after changes in management (e.g., system of livestock grazing) are implemented. The existence of time lags in recovery from disturbance (Kondolf 1993) and potentially confounding factors underscore the importance of longer-term investigation.

ii. $[\mathrm{H}]$ To what degree and with what variability do different instream restoration techniques produce desired habitat conditions?

Addressing this question constitutes effectiveness monitoring, one of four types of monitoring used in the ICBEMP to meet management objectives and evaluate management practices. Spatial and temporal replication are crucial to understanding variability in streams characterized by pulse flows. Management efforts must recognize the importance of key processes and the biophysical and ecological contexts within which restoration occurs. Specific management actions that should be treated as experiments for restoring salmonid stocks include removal of (nonnative) brook trout, alteration of grazing system, habitat improvement (e.g., increased tree cover, channel modifications), reduction of negative influence of steelhead on other species (especially in hatcheries), control of predation by terns and cormorants, and removal or alteration of dam structures.

iii. [M] What is the range of survivorship values between life stages for salmon and trout species inhabiting waters of varying habitat condition (excellent, good, fair, poor)? How does the relationship between survival and habitat condition change as the scale of examination increases?

Understanding the effects of habitat condition on salmon and trout survival would allow the estimation of population levels under various management alternatives. Stage-transition models could produce life tables for each species, given survivorship values from egg to sac fry, sac fry to emergent fry, emergent fry to parr, and parr to smolt stages. Scale of investigation addresses the effects of connectivity, edge effects, and within-watershed dynamics, and therefore is an important element for the 'step-down' process.

iv. [M] What effects do spring livestock grazing and recreational fishing (i.e., trampling by cattle or anglers) have on salmon and trout redds?

This research would investigate direct trampling of eggs, indirect mortality of eggs resulting from sedimentation of graveled areas, and how these activities affect trends in returning adults. Control treatments are essential to remove confounding effects of interannual variation. Once grazing and recreational activities are quantified 
objectively, fish biologists can address this question through sampling within and across watersheds.

v. [M] What effect do logging trucks on non-paved roads have on water quality and salmonid reproductive success? Can roadside structures be used to attenuate energy of runoff without compromising travel?

Although road-derived sediment is known to directly affect salmon survival, details of extent and mechanisms of sediment transfer could be better understood to guide management. Structures to minimize road impacts that are inexpensive and persist through time with little to no maintenance would be a welcome tool in the effort to improve water quality of streams. Hydrologists are perhaps best equipped to describe the effects of roads on water quality, while fishery biologists can best assess responses of salmonids. Engineers (particularly hydrological or structural) may assist in design of cost-effective, efficient structures. Because roads exert strong influence directly and indirectly on aquatic habitats, it is crucial that their effects be minimized in the short term, while more permanent solutions are crafted for the long-term. Some studies suggest that road closures minimize some elements of erosion, but the extent to which this is true depends on soil type, precipitation levels, aspect, slope gradient, and other factors.

Research issues not captured in above research questions, for national wildlife refuges and fish hatcheries. There are 25 national wildlife refuges (NWRs) and 12 national fish hatcheries (NFHs) within the Basin. Research issues are summarized from USFWS (1998).

i. [H] What TESPC species occur on or adjacent to NWRs in the Basin, what are their status and trend, and which factors most strongly influence their distribution spatially and temporally (i.e., seasonally and across years)?

Example of species include Washington ground squirrel, microchiropteran bats (e.g., spotted bat), Ord's kangaroo rat, northern grasshopper mouse, tiger salamander, northern leopard frog, cinnamon teal, blue-winged teal, burrowing owl, bald eagle, long-billed curlew, snowy plover, sagebrush lizard, Ute Lady's tresses, numerous mollusks, and suckers. Examples of factors influencing distribution include presence of introduced species (e.g., predators, com-petitors, prey-base modifiers); livestock grazing; chemical contamination; degree of soil disturbance; water quality or quantity; insect abundance; fire regime; habitat conversion or alteration; and recreational use (hiking, camping, fishing, hunting, horseback riding, birdwatching). At many refuges in the region, distributions of imperiled species are poorly known, as is the effectiveness of different restoration strategies. In both the short and long term, spatially explicit data on vegetation, soils, roads, hydrology, and recreational use, combined with meta-analyses, can facilitate the determination of important factors in species' distributions and trends over time. Once factors are suspected to affect distribution, manipulative studies (translocations, re-introductions, or alterations of density) may be used to test hypotheses.

ii. $[\mathrm{H}]$ What are the landscape-level responses of ecosystems to management-driven changes in disturbance regimes (e.g., removal of livestock grazing, imposition of prescribed fire, increased wapiti herbivory, reduction of 'pest' insects)?

Although small-scale response to managementinduced alterations of disturbance regime is beginning to be understood, how such changes affect systems at landscape scales is less well understood. Potential variables of interest include trends in soils, vegetation composition (e.g., exotic plants, perennial native grasses) and structure, riparian condition, pronghorn antelope, bats, and sage grouse. Experimental design for fire and grazing, for example, would compare replicated and interspersed samples (blocked by habitat type, if necessary) in areas grazed by livestock, areas receiving prescribed fire, and areas experiencing neither (i.e., no grazing and naturally occurring fire).

iii. [M] In hatchery settings, what type of diet produces fish most similar to 'wild-type' individuals, with respect to appearance, behavior, and body composition?

Diet is known to contribute to reproductive success in fishes (Dunham et al. 2000) and other taxa. In the Interior Columbia Basin, concern exists that hatchery-raised steelhead may delay smoltification, resulting in potential interactions (e.g., predation, displacement, competition for food) between residual steelhead and listed species. Although both morphological (fish length and growth rate) and physiological factors may affect the onset of seaward migration, an integrative model that predicts the parr-smolt transformation has not been developed. Whereas many possible methods to manipulate growth in hatchery fish exist, most of these methods are not feasible for a production facility. Manipulation of feeding strategies during rearing may result in changes in growth that minimize steelhead residualism. Although little is known about the prevalence of disease in many hatchery-raised fish, disease is commonly a mechanism by which diet affects survival and reproduction. 


\section{Acknowledgments}

We would like to thank all participants from the June 1999 meeting that outlined the need for this research strategy and agreed upon the five research themes. Participants included Sandy Boyce from the USDA Forest Service Pacific Northwest Research Station, Mike Borman from the Oregon State University Rangeland Resources Department, and Bob Alverts, Mike Crouse, Geoff Middaugh, Clif Fanning, Dave Pacioretty, Mike Pellant, and Sherm Karl from the Bureau of Land Management. We also extend thanks to those who have provided feedback or critical review of the document, including R. Bruce Bury, Research

Zoologist, Ruth Jacobs, Information Specialist, Miranda Ruth, Student Assistant, USGS; Jeanne C. Chambers, Research Ecologist, USDA Forest Service; John Crawford, Professor, Oregon State University; Bob Alverts, OR-WA Research and Monitoring Coordinator; Sieling Chang, Rick Demmer, Fire Ecologist, Melanie Miller, Fire Ecologist, Don L. Smith, and John Swanson, Bureau of Land Management; as well as Miles Henstrom, Mike Wisdom, and Steve Wondzell of the ICBEMP Science Advisory Group, Becky

Gravenmier, ICBEMP Science Coordinator, and Thomas M. Quigley, ICBEMP Science Advisory Group Lead. 


\section{Literature Cited}

Adams, M.J. 1999. Correlated factors in amphibian decline: exotic species and habitat change in western Washington. Journal of Wildlife Management 63:1162-1171.

Adams, M.J. 2000. Pond permanence and the effects of exotic vertebrates on anurans. Ecological Applications 10:559-568.

Allan, D., D. Erickson, and J. Fay. 1997. The influence of catchment land use on stream integrity across multiple spatial scales. Freshwater Biology 37:149-161.

Altman, B., and A. Holmes. 2000. Conservation strategy for landbirds in the Columbia Plateau of eastern Oregon and Washington. Prepared for OregonWashington Partners in Flight. American Bird Conservancy, Boring, Oregon.

Archer, S., and F.E. Smeins. 1991. Ecosystem-level processes. Pages 109-140 in R.K. Heitschmidt and J.W. Stuth, editors. Grazing management: an ecological perspective. Timber Press, Portland, Oregon.

Asher, J. 1994. Crushing the wilderness spirit: alien plant invasions. Unpublished report, U.S. Department of Interior, Bureau of Land Management, Oregon State Office, Portland, Oregon.

Axelrod, D.I. 1960. The evolution of flowering plants. Pages 227-305 in S. Tax, editor. The evolution of life. University of Chicago Press, Chicago, Illinois.

Barry, R.G., and R.J. Chorley. 1982. Atmosphere, weather, and climate, 4 th ed. Methuen, London, England.

Bates, J., R. Miller, and T. Svjecar. 1994. Understory plant succession following cutting of western juniper (Juniperus occidentalis) woodland on Steens Mountain, Oregon. Pages 25-34 in Management of Great Basin rangelands, Annual Report, 1994; Special Report 935. Oregon State University, Agricultural Experiment Station; U.S. Department of Agriculture, Agricultural Research Service, Corvallis, Oregon.

Bazazz, F.A. 1986. Life history of colonizing plants: some demographic, genetic, and physiological features. Pages 96-110 in H.A. Mooney and J.A. Drake, editors. Ecology of biological invasions of North America and Hawaii. Springer-Verlag, New York, New York.

Beever, E.A. 1999. Species- and community-level responses to disturbance imposed by feral horse grazing and other management practices. Ph.D. Dissertation, University of Nevada, Reno, Nevada.
Beever, E.A., and P.F. Brussard. 2000. Examining ecological consequences of feral horse grazing using exclosures. Western North American Naturalist 60:236-254.

Beever, E.A., R.J. Tausch, and P.F. Brussard. Characterizing grazing disturbance in semi-arid ecosystems across broad spatial scales using ecosystem components. Ecological Applications (in press).

Behnke, R.J., and R.F. Raleigh. 1978. Grazing and the riparian zone: impact and management perspectives. Pages 184-189 in Strategies for protection and management of floodplain wetlands and other riparian ecosystems. U.S.D.A.- Forest Service General Technical Report RM-28. Rocky Mountain Research Station, Denver, Colorado.

Belnap, J. 1990. Microbiotic crusts: their role in past and present ecosystems. Park Science 10:3-4.

Belnap, J. 1993. Recovery rates of cryptobiotic crusts: inoculant use and assessment methods. Great Basin Naturalist 53:89-95.

Belnap, J. 1994. Potential role of cryptobiotic soil crusts in semi-arid rangelands. Pages $179-185$ in S.B. Monsen and S.G. Kitchen, editors. Proceedings: ecology and management of annual rangelands, 18-21 May 1992, Boise, Idaho. U.S.D.A.- Forest Service General Technical Report INT-313. Intermountain Research Station, Ogden, Utah.

Belnap, J., and J.S. Gardner. 1993. Soil microstructure in soils of the Colorado Plateau: the role of the cyanobacterium Microcoleus vaginatus. Great Basin Naturalist 53:40-47.

Belsky, A.J. 1996. Viewpoint: western juniper expansion: is it a threat to arid northwestern ecosystems? Journal of Range Management 49:53-59.

Belsky, A.J., A. Matzke, and S. Uselman. 1999. Survey of livestock influences on stream and riparian ecosystems in the western United States. Journal of Soil \& Water Conservation 54:419-431.

Bendell, J.F. 1974. Effects of fire on birds and mammals. Pages 73-138 in T.T. Kozlowski and C.E. Ahlgren, editors. Fire and ecosystems. Academic Press, New York, New York.

Beukema, S.J., and W.A. Kurz. 1995. Vegetation dynamics development tool user's guide, version 2.0 beta. ESSA Technologies Ltd., Vancouver, British Columbia, Canada.

Beymer, R.J., and J.M. Klopatek. 1992. Effects of grazing on cryptogamic crusts in pinyon-juniper woodlands in Grand Canyon National Park. American Midland Naturalist 127:139-148. 
Bich, B.S., J.L. Butler, and C.A. Schmidt. 1995. Effects of differential livestock use on key plant species and rodent populations within selected Oryzopsis hymenoides-Hilaria jamesii communities of Glen Canyon National Recreation Area. Southwestern Naturalist 40:281-287.

Bisson, P.A., G.H. Reeves, R.E. Bilby, and R.J. Naiman. 1997. Watershed management and desired future conditions. Pages 447--474 in D.J. Stouder, P.A. Bisson, and R.J. Naiman, editors. Pacific salmon and their ecosystems: status and future options. Chapman and Hall, New York, New York.

Bock, C.E., and J.H. Bock. 1993. Cover of perennial grasses in southeastern Arizona in relation to livestock grazing. Conservation Biology 7:371-377.

Boyce, M.S., J.S. Meyer, and L. Irwin. 1994. Habitat-based PVA for the northern spotted owl. In D.J. Fletcher and B.J.F. Manly, editors. Statistics in ecology and environmental monitoring. University of Otago Press, Dunedid, New Zealand. Otago Conference Series, volume 2 [not paginated].

Bozek, M.A., and M.K. Young. 1994. Fish mortality resulting from delayed effects of fire in the Greater Yellowstone Ecosystem. Great Basin Naturalist 54:91-95.

Bradley, A.F. 1986. Bromus tectorum. In W.C. Fischer, compiler. The fire effects information system [data base; not paginated]. U.S. Department of Agriculture, Forest Service, Intermountain Research Station, Intermountain Fire Sciences Laboratory, Missoula, Montana.

Brady, N.C. 1974. Nature and property of soils, 8th ed. Macmillan, New York, New York.

Branson, F.A. 1985. Vegetation changes on western rangeland. Range Monograph No. 2. Society for Range Management, Denver, Colorado.

Britton, C.M., and M.H. Ralphs. 1979. Use of fire as a management tool in sagebrush ecosystems. Pages 101-109 in The sagebrush ecosystem: a symposium. Logan, Utah.

Brotherson, J.D., S.R. Rushforth, and J.R. Johansen. 1983. Effects of long-term grazing on cryptogam crust cover in Navajo National Monument, Arizona. Journal of Range Management 35:579-581.

Brown, J.H., and A. Kodric-Brown. 1977. Turnover rates in insular biogeography: effect of immigration on extinction. Ecology 58:445-449.

Brunner, R.D., and T.W. Clark. 1997. A practice-based approach to ecosystem management. Conservation Biology 11:48-58.

Bull, E.L. 1977. Specialized habitat requirements of birds: snag management, old growth, and riparian habitat. Proceedings: nongame management in forests of the western United States, 7-9 February 1977, Portland, Oregon.

Burgman, M.A., S. Ferson, and H.R. Akçakaya. 1993. Risk assessment in conservation biology. Chapman and Hall, New York, New York.

Burt, W.H. 1980. A field guide to the mammals: North America north of Mexico. Peterson field guide series No. 5. Houghton Mifflin, New York, New York.

Bury, R.B., and J.A. Whelan. 1984. Ecology and management of the bullfrog. U.S. Fish and Wildlife Service Resource Publication 155.

Buskirk, S.W., A. Harestad, M. Raphael, and R.A. Powell, editors. 1994. Martens, sables, and fishers: biology and conservation. Comell University Press, Ithaca, New York.

Cardina, J., G.A. Johnshon, and D.H. Sparrow. 1997. The nature and consequence of weed spatial distribution. Weed Science 45:364-373.

Caughley, G. 1974. Bias in aerial survey. Journal of Wildlife Management 38:921-933.

Chamberlain, T.W., R.D. Harr, and F.H. Everest. 1991. Timber harvest, silviculture and watershed process. Pages 181-206 in W.R. Meehan, editor. Influences of forest and rangeland management on salmonid fishes and their habitat. Special Publication 19. American Fisheries Society, Bethesda, Maryland.

Chambers, J. C., K. Farleigh, R. J. Tausch, J. R. Miller, D. Germanoski, D. Martin, and C. Nowak. 1998. Understanding long- and short-term changes in vegetation and geomorphic processes: the key to riparian restoration. Pages 101-110 in D.F. Potts, editor. Proceedings: Rangeland Management and Water Resources. American Water Resources Association and Society for Range Management, 1998 May 27-29, Reno, Nevada.

Chapin III, F.S., M.S. Torn, and M. Tateno. 1996. Principles of ecosystem sustainability. American Naturalist 148:1016-1037.

Clausnitzer, D. 2000. Hydric soils in eastern Oregon temporary pools. Ph.D. Dissertation, Oregon State University, Corvallis, Oregon.

Cohen, J. 1977. Statistical power analysis for the behavioral sciences. Academic Press, New York, New York.

Collopy, M.W., and J.P. Smith. 1995. National status and trends report: the Pacific Northwest. U.S. Department of Interior, National Biological Service, Forest and Rangeland Ecosystem Science Center, Corvallis, Oregon. Draft.

Connor, E.F., and D. Simberloff. 1986. Competition, scientific method, and null models in ecology. American Scientist 74:155-162. 
Corn, P.S. 1994. What we know and don't know about amphibian declines in the West. Pages 59-67 in W. Covington and L. DeBano, technical coordinators. Sustainable ecological systems: implementing an ecological approach to land management. U.S.D.A.- Forest Service General Technical Report RM-247. Rocky Mountain Forest and Range Experiment Station, Fort Collins, Colorado.

Coughenour, M.B. 2000. Ecosystem modeling of the Pryor Mountain Wild Horse Range: executive summary. Pages 125-131 in F.J. Singer and K.A. Schoenecker, compilers. Managers' summary - ecological studies of the Pryor Mountain Wild Horse Range, 1992-1997. U.S. Geological Survey, Midcontinent Ecological Science Center, Fort Collins, Colorado.

Crane, K.K., M.A. Smith, and D. Reynolds. 1997. Habitat selection patterns of feral horses in southcentral Wyoming. Journal of Range Management 50:374-380.

Crowder, M.J., and D.J. Hand. 1990. Analysis of repeated measures. Chapman and Hall, London, England.

Cruz, R, D. Ganskopp, and M. Vavra. 1998. Modeling habitat preferences of cattle on eastern Oregon Rangelands. Pages 49-56 in Eastern Oregon Agricultural Research Center Annual Report, Agricultural Experiment Station Special Report 991. Oregon State University, Corvallis, Oregon.

D'Antonio, C.M, and P.M. Vitousek. 1992. Biological invasions by exotic grasses, the grass/fire cycle, and global change. Annual Review of Ecology and Systematics 23:63-87.

Daily, G.C., editor. 1997. Nature's services: societal dependence on natural ecosystems. Island Press, Covelo, California.

Daily, G.C., P.A. Matson, and P.M. Vitousek. 1997. Ecosystem services supplied by soil. Pages 113-132 in G.C. Daily, editor. Nature's services: societal dependence on natural ecosystems. Island Press, Covelo, California.

Danin, A., and D.H. Yaalon. 1980. Trapping of silt and clay by lichens and bryophytes in the desert environment of the Dead Sea region. In Bat Sheva seminar on approaches and methods in paleoclimatic research with emphasis on aridic areas. Jerusalem, Israel.

Davis, M.A., J.P. Grime, and K. Thompson. 2000.

Fluctuating resources in plant communities: a general theory of invasibility. Journal of Ecology 88:528-534.

Dickerson, B.R. 1997. The effects of high temperature and high levels of dissolved solids on the growth and survival of Lahontan cutthroat trout, Oncorhynchus clarki henshawi. M.S. Thesis, University of Nevada, Reno, Nevada.

Dobler, F.C., J. Eby, C. Perry, S. Richardson, and M. Vander Haegen. 1996. Status of Washington's shrub-steppe ecosystem: extent, ownership, and wildlife/vegetation relationships. Research report, Washington Department of Fish and Wildlife. Olympia, Washington.

Dufrène, M., and P. Legendre. 1997. Species assemblages and indicator species: the need for a flexible asymmetrical approach. Ecological Monographs 67:345-366.

Dunham, J.B., B.R. Dickerson, E. Beever, R.D. Duncan, and G.L. Vinyard. 2000. Effects of food limitation and emigration on self-thinning in experimental minnow cohorts. Journal of Animal Ecology 69:1-9.

Eddleman, L.E., R.F. Miller, P.M. Miller, and P.L. Dysart. 1994. Western juniper woodlands (of the Pacific Northwest): science assessment. URL accessed.

Eldridge, D.J., and R.S.B. Greene. 1994. Microbiotic soil crusts: a review of their roles in soil and ecological processes in the rangelands of Australia. Australian Journal of Soil Research 32:389-415.

Evans, R.D., and J.R. Ehleringer. 1993. A break in the nitrogen cycle in aridlands? Evidence from delta $15 \mathrm{~N}$ of soils. Oecologia 94:314-317.

Fahnestock, J.T., and J.K. Detling. 1999. The influence of herbivory on plant cover and species composition in the Pryor Mountain Wild Horse Range, USA. Plant Ecology 144:145-157.

Fahrig, L. 1998. When does fragmentation of breeding habitat affect population survival? Ecological Modelling 105:273-292.

Federal Interagency Committee for Wetland Delineation. 1989. Federal manual for identifying and delineating jurisdictional wetlands. Cooperative technical publication. U.S. Army Corps of Engineers, U.S. Environmental Protection Agency, U.S. Fish and Wildlife Service, and U.S.D.A. Soil Conservation Service, Washington, D.C.

Fernandez-Duque, E., and C. Valeggia. 1994. Meta-analysis: a valuable tool in conservation research. Conservation Biology 8:555-561.

Fisher, R.N., and H.B. Shaffer. 1996. The decline of amphibians in California's Great Central Valley. Conservation Biology 10:1387-1397.

Flather, C.H., S.J. Brady, and D.B. Inkley. 1992. Regional habitat appraisals of wildlife communities: a land- 
scape-level evaluation of a resource planning model using avian distribution data. Landscape Ecology 7:137-147.

Flather, C.H., K.R. Wilson, D.J. Dean, and W.C. McComb. 1997. Identifying gaps in conservation networks: of indicators and uncertainty in geographicbased analyses. Ecological Applications 7:531-542.

Flather, C.H., and C.H. Sieg. 2000. Applicability of Montreal Process Criterion 1 - conservation of biological diversity - to rangeland sustainability. International Journal of Sustainable Development and World Ecology 7:81-96.

Fleming, R.A. 1999. Statistical advantages in, and characteristics of, data from long-term research. The Forestry Chronicle 75:487-489.

Forman, R.T.T. 2000. Estimate of the area affected ecologically by the road system in the United States. Conservation Biology 14:31-35.

Forman, R.T.T., and L.E. Alexander. 1998. Roads and their major ecological effects. Annual Review of Ecology and Systematics 29:207-231.

Frewig-Runyon, L. 1995. Importance and dependency of the livestock industry on federal lands in the Columbia River Basin, 1995. Unpublished ICBEMP draft report, Boise, Idaho.

Fritts, S.H., E.E. Bangs, and J.F. Gore. 1994. The relationship of wolf recovery to habitat conservation and biodiversity in the northwestern United States. Landscape and Urban Planning 28:23-32.

Geiser, L.H., C.C. Derr, and K.L. Dillman. 1994. Air quality monitoring on the Tongass National Forest: methods and baselines using lichens. U.S.D.A.-Forest Service Technical Bulletin R10-TB-46. Alaska Region, Anchorage, Alaska.

Ginsberg, H.S. 1993. Invertebrate monitoring in the National Park System. Final report of a workshop: 1992 April 22-24. Technical report NPS-93/02, National Park Service Coastal Research Center University of Rhode Island, Narragansett, Rhode Island.

Graetz, R.D., and D.J. Tongway. 1986. Influence of grazing management on vegetation, soil structure and nutrient distribution and the infiltration of applied rainfall in a semi-arid chenopod shrubland. Australian Journal of Ecology 11:347-360.

Graumlich, L.J. 1993. A 1000-year record of temperature and precipitation in the Sierra Nevada. Quaternary Research 39:249-255.

Green, R.H. 1993. Application of repeated measures designs in environmental impact and monitoring studies. Australian Journal of Ecology 18:81-98.

Grayson, D.K. 1993. The desert's past: a natural prehis- tory of the Great Basin. Smithsonian Institution Press, Washington, D.C.

Gregory, S.V., F.J. Swanson, W.A. McKee, and K.W. Cummins. 1991. An ecosystem perspective of riparian zones. BioScience 41:540-551.

Haig, S.M., D.W. Mehlman, and L.W. Oring. 1998. Avian movements and wetland connectivity in landscape conservation. Conservation Biology 12:749-758.

Hamer, K. C., and J.K. Hill. 2000. Scale-dependent effects of habitat disturbance on species richness in tropical forests. Conservation Biology 14:1435-1440.

Hamlett, J.M., R. Horton, and N.A.C. Cressie. 1986. Resistant and exploratory techniques for use in semivariogram analyses. Soil Science Society of America Journal 50:868-875.

Hamlin, R.A. 1996. Conservation genetics of remnant springsnail, Pyrgulopsis wongi, populations in desert valleys of California and Nevada. M.S. Thesis, University of Nevada, Reno, Nevada.

Hann, W.J., J.L. Jones., M.G. Karl, P.F. Hessburg, R.E. Keane, D.G. Long, J.P. Menakis, C.H. McNicoll, S.G. Leonard, R.A. Gravenmier, and B.G. Smith. 1997. Landscape dynamics of the Basin. Pages 337-1055 in T.M. Quigley and S.J. Arbelbide, technical editors. 1997. An assessment of ecosystem components in the Interior Columbia Basin and portions of the Klamath and Great Basins. U.S.D.A.-Forest Service General Technical Report PNW-405. Pacific Northwest Research Station, Portland, Oregon.

Hann, W.J., M.J. Wisdom, and M.M. Rowland. Disturbance departure and fragmentation of natural systems in the Interior Columbia Basin. U.S.D.A.Forest Service Research Paper RP-545. Pacific Northwest Research Station, Portland, Oregon (in press).

Hanski, I., and M. Gilpin. 1991. Single species metapopulation dynamics: concepts, models, and observations. Biological Journal of the Linnean Society 42:3-16.

Harper, K.T., and J.R. Marble. 1988. A role for non-vascular plants in management of arid and semi-arid rangelands. Pages 135-169 in P.T. Tueller, editor. Vegetation science applications for rangeland analysis and management. Academic Publishers, Boston, Massachusetts.

Harper, K.T., and R.L. Pendleton. 1993. Cyanobacteria and cyanolichens: can they enhance availability of essential minerals for higher plants? Great Basin Naturalist 53:59-72. 
Harris, L.D. 1984. The fragmented forest: island bio-geographic theory and the preservation of biotic diversity. University of Chicago Press, Chicago, Illinois.

Hastings, J.R., and R.M. Turner. 1985. The changing mile: an ecological study of vegetation change with time in the lower mile of an arid and semi-arid region. University of Arizona Press, Tucson, Arizona.

Haugen, J. 1993. Proceedings of the western juniper forum; [Date of meeting unknown]; Bend, Oregon. Unpublished ICBEMP document, Walla Walla, Washington.

Hayek, L.C., and M.A. Buzas. 1997. Surveying natural populations. Columbia University Press, New York, New York.

Hayes, M.P., and M.R. Jennings. 1986. Decline of ranid frog species in western North America: are bullfrogs (Rana catesbiana) responsible? Journal of Herpetology 20:490-509.

Haynes, R.W., and A.L. Horne. 1997. Economic assessment of the Basin. Pages 1715-1869 in T.M. Quigley and S.J. Arbelbide, technical editors. 1997. An assessment of ecosystem components in the Interior Columbia Basin and portions of the Klamath and Great Basins. U.S.D.A.-Forest Service General Technical Report PNW-405. Pacific Northwest Research Station, Portland, Oregon.

Heinemeyer, K.S., and J.L. Jones. 1994. Fisher biology and management: a literature review and adaptive management strategy. U.S.D.A.-Forest Service Northern Region, Missoula, Montana.

Hemstrom, M., T. Spies, C. Palmer, R. Kiester, J. Teply, P. McDonald, and R. Warbington. 1999. Late-successional and old-growth forest effectiveness monitoring plan for the Northwest Forest Plan. U.S.D.A.-Forest Service General Technical Report PNW-438. Pacific Northwest Research Station, Portland, Oregon.

Herbel, C.H. 1979. Utilization of grass- and shrublands of the southwestern United States. Pages 161-203 in B.H. Walker, editor. Management of semi-arid ecosystems. Elsevier, New York, New York.

Hessburg, P.F., B.G. Smith, B.G. Smith, S.D. Kreiter, C.A. Miller, R.B. Salter, C.H. McNicoll, and W. J. Hann. 1999. Historical and current forest and range landscapes in the interior Columbia River Basin and portions of the Klamath and Great Basins. Part I: Linking vegetation patterns and landscape vulnerability to potential insect and pathogen disturbances. General Technical Report PNW-GTR-458, U.S.D.A.Forest Service Pacific Northwest Research Station, Portland, Oregon.
Hilborn, R., and S.C. Stearns. 1982. On inference in ecology and evolutionary biology: the problem of multiple causes. Acta Biotheoretica 31:145-164.

Holling, C.S. 1978. Adaptive environmental assessment and management. John Wiley and Sons, New York, New York.

Holt, S.J., and L.M. Talbot. 1978. New principles for the conservation of wild living resources. Wildlife Monographs 59.

Huggins, R.M. 1993. A robust approach to the analysis of repeated measures. Biometrics 49:715-720.

Hulbert, L.C. 1955. Ecological studies of Bromus tectorum and other annual bromegrasses. Ecological Monographs 25:181-213.

Hurlbert, S.H. 1984. Pseudoreplication and the design of ecological field experiments. Ecological Monographs 54:187-211.

Hynes, H.B.N. 1975. The stream and its valley. Verhandlungen, Internationale Vereinigung für Theoretische und Augewandte Limnologie 19:1-15.

(INFISH), Inland Native Fish Strategy. 1995.

Environmental Assessment: decision Notice and Finding of No Significant Impact. Interim Strategies for managing fish-producing watersheds in eastern Oregon and Washington, Idaho, western Montana and portions of Nevada. [Place of publication unknown]: U.S. Department of Agriculture, Forest Service, Intermountain, Northern, and Pacific Northwest Regions. [irregular pagination].

Jardine, J.T., and C.L. Forsling. 1922. Range and cattle management during drought. U.S. Department of Agriculture Bulletin 1031, Washington, D.C.

Jeffries, D.L., and J.M. Klopatec. 1987. Effects of grazing in the vegetation of the blackbrush association. Journal of Range Management 40:390-392.

Jennings, M.R., and M.P. Hayes. 1985. Pre-1900 overharvest of California red-legged frogs (Rana aurora draytonii): the inducement for bullfrog (Rana catesbiana) introduction. Herpetologica 41:94-103.

Johansen, J.R. 1986. Importance of cryptogamic soil crusts to arid rangelands: implications for short-duration grazing. Pages 58-64 in J. Tiedeman, editor. Short-duration grazing. Washington State University, Pullman, Washington.

Johnsen, T.N. 1962. One-seed juniper invasion of northern Arizona grasslands. Ecological Monographs 32:187-207.

Johnson, D.H. 1999. The insignificance of statistical significance testing. Journal of Wildlife Management 63:763-772.

Johnson, G.D., and G.P. Patil. 1998. Quantitative multiresolution characterization of landscape patterns for 
assessing the status of ecosystem health in watershed management areas. Ecosystem Health 4:177-187.

Jones, J.A., F.J. Swanson, B.C. Wemple, and K.U. Snyder. 2000a. Effects of roads on hydrology, geomorphology, and disturbance patches in stream networks. Conservation Biology 14:76-85.

Jones, K. B., D.T. Heggem, T.G. Wade, A.C. Neale, D.W. Ebert, M.S. Nash, M.H. Mehaffey, K.A. Hermann, A.R. Selle, S. Augustine, I.A. Goodman, J. Pedersen, D. Bolgrien, J.M. Viger, D. Chiang, C.J. Lin, Y. Zhong, J. Baker, and R.D. Van Remortel. 2000b. Assessing landscape condition relative to water resources in the western United States: a strategic approach. Environmental Monitoring and Assessment 64:227-245.

Kauffman, J.B., and W.C. Krueger. 1984. Livestock impacts on riparian ecosystems and streamside management implications ... a review. Journal of Range Management 37:430-438

Kepner, W.G., C.J. Watts, C.M. Edmonds, J.K. Maingi, S.E. Marsh, G. Luna. 2000. A landscape approach for detecting and evaluating change in a semi-arid environment. Environmental Monitoring \& Assessment 64:179-195.

Kiesecker, J.M., and A.R. Blaustein. 1995. Synergism between UV-B radiation and a pathogen magnifies amphibian embryo mortality in nature. Proceedings of the National Academy of Sciences of the United States of America 92:11049-11052.

Kim, K.H., and W.P. Miller. 1996. Effect of rainfall electrolyte concentration and slope on infiltration and erosion. Soil Technology 9:173-185.

Kindschy, R.R. 1994. Pristine vegetation of the Jordan Crater kipukas: 1978-91. Pages 85-88 in S.B. Monsen, and S.G. Kitchen, compilers. Proceedings - ecology and management of annual rangelands. General Technical Report INT-313, U.S.D.A.-Forest Service, Ogden, Utah.

Kingsolver, J.G., and D.W. Schemske. 1991. Path analysis of selection. Trends in Ecology and Evolution 6: 276-280.

Kittel, T.G.F., J.A. Royle, C. Daly, N.A. Rosenbloom, W.P. Gibson, H.H. Fisher, D.S. Schimel, L.M. Berliner, and VEMAP2 Participants. 1997. A gridded historical (1895-1993) bioclimate dataset for the conterminous United States. In Proceedings of the 10th Conference on Applied Climatology, 20-24 October 1997, Reno, Nevada. American Meteorological Society, Boston, Massachusetts.

Knapp, P.A. 1989. Natural recovery of compacted soils in semi-arid Montana. Physical Geography 10:165-175.
Knick, S.T., and J.T. Rotenberry. 1995. Landscape characteristics of fragmented shrubsteppe habitats and breeding passerine birds. Conservation Biology 9:1059-1071.

Knick, S.T., and J.T. Rotenberry. 2000. Ghosts of habitats past: contribution of landscape change to current habitats used by shrubland birds. Ecology 81:220-227.

Kondolf, G.M. 1993. Lag in stream channel adjustment to livestock exclosure, White Mountains, California. Restoration Ecology 1:226-230.

Külköylüoglu, O., and G.L. Vinyard. 2000. Distribution and ecology of freshwater Ostracoda (Crustacea) collected from springs of Nevada, Idaho, and Oregon: a preliminary study. Western North American Naturalist 60:291-303.

Larsen, R. 1996. Survival and transport of fecal pathogens in grazed watersheds. In M. George, technical coordinator. Livestock management in grazed watersheds: a review of practices that protect water quality. University of California, Agricultural Issues Center, Davis, California. 42 pgs.

Laufer, J.R., and P.T. Jenkins. 1989. Historical and present status of the grey wolf in the Cascade Mountains of Washington. The Northwest Environmental Journal 5:313-327.

Laycock, W.A. 1994. Implications of grazing v. no grazing on today's rangelands. Pages $250-280$ in M. Vavra, W.A. Laycock, and R.D. Pieper, editors. Ecological implications of livestock herbivory in the West. Society for Range Management, Denver, Colorado.

Lee, D.C., J.R. Sedell, B.E. Rieman, R.F. Thurow, and J.E. Williams. 1997. Broadscale assessment of aquatic species and habitats. Pages 1057-1496 in T.M. Quigley and S.J. Arbelbide, technical editors. 1997. An assessment of ecosystem components in the Interior Columbia Basin and portions of the Klamath and Great Basins. U.S.D.A.-Forest Service General Technical Report PNW-405. Pacific Northwest Research Station, Portland, Oregon.

Lehmkuhl, J.F., and L.F. Ruggiero. 1991. Forest fragmentation in the Pacific Northwest and its potential effects on wildlife. Pages 35-46 in L.F. Ruggiero, K.B. Aubry, A.B. Carey, and M.H. Huff, technical coordinators. Wildlife and vegetation of unmanaged Douglas-fir forests. U.S.D.A.-Forest Service General Technical Report RM-285. Pacific Northwest Research Station, Portland, Oregon.

Leonard, S.G., R. Rosentreter, and M.G. Karl. 1995. Microbiotic crusts: ecological roles and implica- 
tions for rangeland management. Unpublished ICBEMP report, Boise, Idaho.

Leonard, W.P., H.A. Brown, L.L.C. Jones, K.R. McAllister, and R.M. Storm. 1993. Amphibians of Washington and Oregon. Seattle Audubon Society, Seattle, Washington.

Lidicker, W.Z.J. 1991. In defense of a multifactor perspective in population ecology. Journal of Mammalogy 72:631-635.

Lindenmayer, D.B., and H.A. Nix. 1993. Ecological principles for the design of wildlife corridors. Conservation Biology 7:327-630.

Lubchenco, J., A.M. Olson, L.B. Brubaker, S.R. Carpenter, M.M. Holland, S.P. Hubbell, S.A. Levin, J.A. MacMahon, P.A. Matson, J.M. Melillo, H.A. Mooney, C.H. Peterson, H.R. Pulliam, L.A. Real, P.J. Regal, and P.G. Risser. 1991. The sustainable biosphere initiative: an ecological research agenda. Ecology 72:371-412.

Ludwig, B., J. Boiffin, J. Chadoeuf, and A.V. Auzet. 1995. Hydrological structure and erosion damage caused by concentrated flow in cultivated catchments. Catena 25:227-252.

Lyon, L.J., K.B. Aubry, W.J. Zielinski, S.W. Buskirk, and L.F. Ruggiero. 1994. The scientific basis for conserving forest carnivores: considerations for management. Pages 128-137 in L.F. Ruggiero, K.B. Aubry, S.W. Buskirk, L.J. Lyon, and W.J. Zielinski, editors. The scientific basis for conserving forest carnivores: American marten, fisher, lynx, and wolverine in the western United States. U.S.D.A.-Forest Service General Technical Report RM-254. Rocky Mountain Forest and Range Experiment Station, Fort Collins, Colorado.

Mack, R.N. 1981. Invasion of Bromus tectorum L. into western North America: an ecological chronicle. Agro-Ecosystems 7:145-165.

Mack, R.N. 1986. Alien plant invasion into the Intermountain West: a case history. Pages 191-213 in H.A. Mooney and J.A. Drake, editors. Ecology of biological invasions of North America and Hawaii. Springer-Verlag, New York, New York.

Mack, R.N., and J.N. Thompson. 1982. Evolution in steppe with few large, hooved mammals. American Naturalist 119:757-773.

MacMahon, J.A. 1980. Ecosystems over time: succession and other types of change. In R. Waring, editor. Forests: fresh perspectives from ecosystem analyses. Proceedings of the Oregon State University Biological Colloquium, 26-27 April 1979. Corvallis, Oregon.
Marble, J.R. and K.T. Harper. 1989. Effect of timing and grazing on soil-surface cryptogamic communities in a Great Basin low-shrub desert: a preliminary report. Great Basin Naturalist 49:104-107.

Marcot, B.G., M.A. Castellano, J.A. Christy, L.K. Croft, J.F. Lehmkuhl, R.H. Naney, R.E. Rosentreter, R.E. Sandquist, and E. Zieroth. 1997. Terrestrial ecology assessment. Pages 1497-713 in T.M. Quigley, and S.J. Arbelbide, technical editors. An assessment of ecosystem components in the Interior Columbia Basin and portions of the Klamath and Great Basins. U.S.D.A.-Forest Service General Technical Report PNW-405. Pacific Northwest Research Station, Portland, Oregon.

Marlette, G.M., and J.E. Anderson. 1986. Seed banks and propagule dispersal in crested-wheatgrass stands. Journal of Applied Ecology 23:161-175.

Martell, A.M. 1983. Changes in small mammal communities after logging in north-central Ontario. Canadian Journal of Zoology 61:970-980.

Martens, E., D. Palmquist, and J.A. Young. 1994. Temperature profiles for germination of cheatgrass versus native perennial bunchgrasses. Pages 238-243 in Monsen, S.B. and S.G. Kitchen, compilers. Proceedings-ecology and management of annual rangelands. 18-21 May 1992; Boise, Idaho. U.S.D.A.-Forest Service, Intermountain Research Station General Technical Report INT-313, Ogden, Utah.

McDonald, K.A., and J.H. Brown. 1992. Using montane mammals to model extinctions due to global change. Conservation Biology 6:409-415.

McInnis, M.L. 1985. Ecological relationships among feral horses, cattle, and pronghorn in southeastern Oregon. Ph.D. Dissertation, Oregon State University, Corvallis, Oregon.

McMahon, T.E. and D.S. deCalista. 1990. Effects of fire on fish and wildlife. Pages 233-250 in J.D. Walstad, S.R. Radosevich, and D.V. Sandberg, editors. Natural and prescribed fire in Pacific Northwest forests. Oregon State University Press, Corvallis, Oregon.

Meffe, G.K., and R.C. Carroll. 1994. The species in conservation. Pages 50-77 in G.K. Meffe and R.C. Carroll, editors. Principles of conservation biology. Sinauer Associates, Sunderland, Massachusetts.

Meyer, S.E. 1986. The ecology of gypsophile endemism in the eastern Mojave Desert. Ecology 67:1303-1313. 
Miles, T.G., and M.G. Karl. 1995. Introduced forage grasses in the interior Columbia basin: science assessment. Unpublished ICBEMP report, Walla Walla, Washington.

Miller, J., D. Germanoski, K. Waltman, R. Tausch, and J. Chambers. 2001. Influence of late Holocene processes and landforms on modern channel dynamics in upland watersheds of central Nevada. Geomorphology 38:373-391.

Miller, R. 1980. The ecology of feral horses in Wyoming's Red Desert. Ph.D. Dissertation, University of Wyoming, Laramie, Wyoming.

Miller, R.F., and R.A. Rose. 1995. Historic expansion of Juniperus occidentalis (western juniper) in southeastern Oregon. Great Basin Naturalist 55:37-45.

Miller, R.F., T.J. Svejcar, and N.E. West. 1994. Implications of livestock grazing in the Intermountain sagebrush region: plant composition. Pages 101-146 in M. Vavra, W.A. Laycock, and R.D. Pieper, editors. Ecological implications of livestock herbivory in the West. Society for Range Management, Denver, Colorado.

Miller, R.F., and P.E. Wigand. 1994. Holocene changes in semi-arid pinyon-juniper woodlands. BioScience 44:465-474.

Moody, M.E., and R.N. Mack. 1988. Controlling the spread of plant invasions: the importance of nascent foci. Journal of Applied Ecology 25:1009-1021.

Moreno, C.E., and G. Halffter. 2000. Assessing the completeness of bat biodiversity inventories using species accumulation curves. Journal of Applied Ecology 37:149-158.

Morgan, P., G.H. Aplet, J.B. Haufler, H.C. Humphries, M.M. Moore, and W.D. Wilson. 1994. Historical range of variability: a useful tool for evaluating ecosystem change. Pages 87-111 in N. Sampson and D.L. Adams, editors. Assessing forest ecosystem health in the inland west. New York: Food Products Press.

Moyle, P.B. 1986. Fish introductions into North America: patterns and ecological impact. Pages $27-43$ in H. Mooney and J. Drake, editors. Ecology of biological invasions of North America and Hawaii. Springer-Verlag, New York, New York.

Mulder, B.S., and C.J. Palmer. 1999. Introduction to effectiveness monitoring. Pages 1-20 in B.S. Mulder, B.R. Noon, T.A. Spies, M.G. Raphael, C.J. Palmer, A.R. Olsen, G.H. Reeves, and H.H. Welsh, technical coordinators. The strategy and design of the effectiveness monitoring program for the Northwest Forest Plan. U.S.D.A.-Forest Service
General Technical Report PNW-437. Pacific Northwest Research Station, Portland, Oregon.

Murphy, D.D., and S.B. Weiss. 1992. Effects of climate change on biological diversity in western North America: species losses and mechanisms. Pages 355-368 in R.L. Peters and T.E. Lovejoy, editors. Global warming and biological diversity. Yale University Press, New Haven, Connecticut.

Nabhan, G.P., and S.L. Buchmann. 1997. Services provided by pollinators. Pages $133-150$ in G.C. Daily, editor. Nature's services: societal dependence on natural ecosystems. Island Press, Covelo, California.

National Academy of Sciences (NAS). 1974.

Rehabilitation of western coal lands. J.B. Lippencott, Boston, Massachusetts.

National Research Council. 1994. Rangeland health new methods to classify, inventory, and monitor rangelands. National Academy Press, Washington, D.C.

Nehlsen, W., J.E. Williams, and J.A. Lichatowich. 1991. Pacific salmon at the crossroads: stocks at risk from California, Oregon, Idaho, and Washington. Fisheries 16(2):4-21.

Newmark, W.D. 1987. A land-bridge island perspective on mammalian extinctions in western North American parks. Nature 325:430-432.

Noon, B.R. 1999. Scientific framework for effectiveness monitoring of the Northwest Forest Plan. Pages 49-68 in B.S. Mulder, B.R. Noon, T.A. Spies, M.G. Raphael, C.J. Palmer, A.R. Olsen, G.H. Reeves, and H.H. Welsh, Technical Coordinators. The strategy and design of the effectiveness monitoring program for the Northwest Forest Plan. U.S.D.A.-Forest Service General Technical Report PNW-437. Pacific Northwest Research Station, Portland, Oregon.

Noon, B.R., T.A. Spies, and M.G. Raphael. 1999. Conceptual basis for designing an effectiveness monitoring program. Pages $21-48$ in B.S. Mulder, B.R. Noon, T.A. Spies, M.G. Raphael, C.J. Palmer, A.R. Olsen, G.H. Reeves, and H.H. Welsh, Technical Coordinators. The strategy and design of the effectiveness monitoring program for the Northwest Forest Plan. U.S.D.A.-Forest Service General Technical Report PNW-437. Pacific Northwest Research Station, Portland, Oregon.

Noss, R.F. 1990. Indicators for monitoring biodiversity: a hierarchical approach. Conservation Biology 4:355-364.

Noss, R.F., and A.Y. Cooperrider. 1994. Saving nature's legacy: protecting and restoring biodiversity. Island Press, Covelo, California. 
Noss, R.F., and B. Csuti. 1994. Habitat fragmentation. Pages 237-264 in G.K. Meffe and C.R. Carroll, editors. Principles of conservation biology. Sinauer Associates, Sunderland, Massachusetts.

Noss, R.F., and L.D. Harris. 1986. Nodes, networks, and MUMs: preserving diversity at all scales. Environmental Management 10:299-309.

Nunney, L. 1993. The influence of mating system and overlapping generations on effective population size. Evolution 47:1329-1341.

Oregon Department of Fish and Wildlife. 1993. Juniper woodland management: an application of the fish and wildlife habitat mitigation policy. Oregon Department of Fish and Wildlife, Habitat Conservation Division, Portland, Oregon.

Osmond, C.B., L.F. Pitelka, and G.M. Hidy, editors. 1990. Plant biology of the Basin and Range. Ecological Studies 80. Springer-Verlag, New York, New York.

(PACFISH) U.S. Department of Agriculture, Forest Service and U.S. Department of Interior, Bureau of Land Management. 1994. Draft Environmental Assessment. Interim strategies for managing anadromous fish-producing watersheds on Federal lands in eastern Oregon and Washington, Idaho, and portions of California. Washington, DC: U.S. Department of Agriculture, Forest Service; U.S. Department of Interior, Bureau of Land Management. [irregular pagination].

Pagel, J.E. 1995. American peregrine falcon (Falco peregrinus anatum). In Status of species-Columbia River basin. Unpublished report. U.S.D.A.-Forest Service, Pacific Northwest Region, Portland, Oregon.

Parmenter, R.R., J.A. MacMahon, M.E. Waaland, M.M. Stuebe, P. Landres, and C.M. Crisafuli. 1985. Reclamation of surface coal mines in western Wyoming for wildlife habitat: a preliminary analysis. Reclamation and Revegetation Research 4:93-115.

Paschke, M.W., T. McClendon, and E.F. Redente. 2000. Nitrogen availability and old-field succession in a shortgrass steppe. Ecosystems 3:144-158.

Patton, T.M., W.A. Hubert, and F.J. Rahel. 2000. Effort needed to estimate species richness in small streams on the Great Plains in Wyoming. North American Journal of Fisheries Management 20:394-398.

Pellant, M. 1996. Cheatgrass: the invader that won the west. Unpublished ICBEMP report, Boise, Idaho.

Pellant, M. 1999. Fuels management in the Snake River Birds of Prey National Conservation Area (NCA). Presentation, Sagebrush Steppe Ecosystems: identifying issues and seeking practical solutions; Snake River Birds of Prey National Conservation Area Workshop. Boise, Idaho.
Pellant, M., P. Shaver, D.A. Pyke, and J.E. Herrick. 2000. Interpreting indicators of rangeland health, version 3. U.S. Department of the Interior, Bureau of Land Management, National Science and Technology Center, Technical Reference TR-1734-6, Denver, Colorado.

Perry, D.A., and M.P. Amaranthus. 1997. Disturbance, recovery, and stability. Pages 31-56 in K.A. Kohm and J.F. Franklin, editors. Creating a forestry for the 21st century: the science of ecosystem management. Island Press, Covelo, California.

Peterman, R.M. 1990. Statistical power analysis can improve fisheries research and management. Canadian Journal of Fisheries and Aquatic Science 47:2-15.

Peters, R.L., and J.D.S. Darling. 1985. The greenhouse effect and nature reserves. BioScience 35:707-717.

Peterson, D.L., and V.T. Parker, editors. 1998. Ecological scale: theory and applications. Columbia University Press, New York, New York.

Pimentel, D., J. Allen, A. Beers, L. Guinand, A. Hawkins, R. Linder, P. McLaughlin, B. Meer, D. Musonda, D. Perdue, S. Poisson, R. Salazar, S. Siebert, and K. Stoner. 1993. Soil erosion and agricultural productivity. Pages 277-292 in D. Pimentel, editor, World soil erosion and conservation. Cambridge University Press, Cambridge, England.

Pimm, S.L., H.L. Jones, and J. Diamond. 1988. On the risk of extinction. American Naturalist 132:757-785.

Platts, W.S. 1979. Livestock grazing and riparian/stream ecosystems. Pages 39-45 in Proceedings of the Forum on Grazing and Riparian/Stream Ecosystems. Trout Unlimited, Inc.

Platts, W.S. 1991. Livestock grazing. Pages 389-424 in Special Publication 19. American Fisheries Society, Bethesda, Maryland.

Plissner, J.H., L.W. Oring, and S.M. Haig. 2000. Space use of killdeer at a Great Basin breeding area. Journal of Wildlife Management 64:421-429.

Postel, S., and S. Carpenter. 1997. Freshwater ecosystem services. Pages 195-214 in G.C. Daily, editor. Nature's services: societal dependence on natural ecosystems. Island Press, Covelo, California.

Power, M.E., D. Tilman, J.A. Estes, B.A. Merge, W.J. Bond, L.S. Mills, G. Daily, J.C. Castilla, J. Lubchenco, and R.T. Paine. 1996. Challenges in the quest for keystones. BioScience 46:609-620.

Pyke, D. A. and S.J. Novak. 1994. Cheatgrass demography - Establishment attributes, recruitment, ecotypes, and genetic variability. Pages 12-21 in S.B. Monsen and S.G. Kitchen (compilers). Proceedings - ecology and management of annual rangelands; 
18-21 May 1992; Boise ID. U.S.D.A-Forest Service General Technical Report INT-313. Intermountain Research Station, Ogden, Utah.

Quigley, T.M., R.W. Haynes, and R.T. Graham, technical editors. 1996. Integrated scientific assessment for ecosystem management in the interior Columbia basin. U.S.D.A.-Forest Service General Technical Report PNW-382. Pacific Northwest Research Station, Portland, Oregon.

Quigley, T.M., and S.J. Arbelbide, technical editors. 1997. An assessment of ecosystem components in the Interior Columbia Basin and portions of the Klamath and Great Basins. U.S.D.A.-Forest Service General Technical Report PNW-405. Pacific Northwest Research Station, Portland, Oregon. 4 vols.

Raedeke, K., editor. 1989. Streamside management: riparian wildlife and forestry interactions. Contribution 59, Institute of Forest Resources, University of Washington, Seattle, Washington.

Raphael, M.G., M.J. Wisdom, M.M. Rowland, R.S. Holthausen, B.C. Wales, B.G. Marcot, and T.D. Rich. 2001. Status and trends of habitats of terrestrial vertebrates in relation to land management in the interior Columbia river basin. Forest Ecology and Management 55:1-25.

Reeves, G.H., L.E. Benda, K.M. Burnett, P.A. Bisson, and J.R. Sedell. 1995. A disturbance-based ecosystem approach to maintaining and restoring freshwater habitats of evolutionarily significant units of anadromous salmonids in the Pacific Northwest. Pages 334-349 in J. Nielson, editor. Evolution and the aquatic ecosystem: defining unique units in population conservation. American Fisheries Society, Bethesda, Maryland.

Reiner, R.J., and P.J. Urness. 1982. Effect of grazing horses managed as manipulators of big game winter range. Journal of Range Management 35:567-571.

Rice, P.M. 1994. Exotic plant species of the Columbia Basin. Unpublished ICBEMP report, Walla Walla, Washington.

Rich, T. 1980. Nest placement in sage thrashers, sage sparrows, and Brewer's sparrows. Wilson Bulletin 92:362-368.

Richards, R.T., J.C. Chambers, and C. Ross. 1998. Use of native plants on federal lands: policy and practice. Journal of Range Management 51:625-632.

Richardson, D.H.S. 1992. Pollution monitoring with lichens: naturalist's handbook. Richmond Publishing, Slough, England.
Richardson, E. 1980. BLM's billion-dollar checkerboard: managing the O\&C lands. Forest History Society, Santa Cruz, California.

Rosentreter, R. 1986. Compositional patterns within a rabbitbrush (Chrysothamnus) community of the Idaho Snake River plain. Pages 273-277 in E.D. McArthur and B.L. Welch, compilers.

Proceedings: symposium on the biology of Artemisia and Chrysothamnus, 9-13 July 1984. Provo, UT. U.S.D.A.-Forest Service General Technical Report INT-200. Intermountain Research Station, Ogden, Utah.

Rosentreter, R. 1995. Lichens. Unpublished ICBEMP report, Boise, Idaho.

Rosgen, D.L. 1985. A stream classification system. Pages 91-95 in Riparian ecosystems and their management. First North American Riparian Conference. U.S.D.A.-Forest Service General Technical Report RM-120. Rocky Mountain Research Station, Denver, Colorado.

Rosgen, D.L. 1994. A classification of natural rivers. Catena 22:169-199.

Roth, A.H., and J.F. Jackson. 1987. The effect of pool size on recruitment of predatory insects and on mortality in a larval anuran. Herpetologica 43:224-232.

Rubega, M.A., and J.A. Robinson. 1996. Water salinization and shorebirds: emerging issues. International Wader Studies 9:45-54.

Russell, K.R., D.H. Van Lear, and D.C. Guynn, Jr. 1999. Prescribed fire effects on herpetofauna: a review and management implications. Wildlife Society Bulletin 27:374-384.

Saab, V.A., and T.D. Rich. 1997. Large-scale conservation assessment for neotropical migratory land birds in the Interior Columbia River Basin. U.S.D.A.-Forest Service General Technical Report PNW-399. Pacific Northwest Research Station, Portland, Oregon.

Salwasser, H., C. Schonewald-Cox, and R. Baker. 1987. The role of interagency cooperation in managing for viable populations. Pages 159-173 in M. Soulé, editor. Viable populations for conservation. Cambridge University Press, New York, New York.

Samson, F.B., and F.L. Knopf. 1993. Managing biological diversity. Wildlife Society Bulletin 21:509-514.

Samways, M.J. 1993. A spatial and process subregional framework for insect and biodiversity conservation research and management. Pages 1-27 in K.J. Gaston K.J. Gaston, T.R. New, and MJ. Samway, editors. Perspectives on insect conservation. Intercept Limited, Andover, Hants, England. 
Saunders, D.A., R.J. Hobbs, and C.R. Margules. 1991. Biological consequences of ecosystem fragmentation: a review. Conservation Biology 5:18-32.

Schaefer, J.A., C.M. Bergman, and S.N. Luttich. 2000. Site fidelity of female caribou at multiple spatial scales. Landscape Ecology 15:731-739.

Schlosser, I.J. 1995. Dispersal, boundary processes, and trophic-level interactions in streams adjacent to beaver ponds. Ecology 76:908-925.

Schneider, S.H. 1990. The greenhouse effect: science and policy. Science 10:771-781.

Schulz, T.T., and W.C. Leininger. 1991. Nongame wildlife communities in grazed and ungrazed montane riparian sites. Great Basin Naturalist 51:286-292.

Seyfried, M.S. 1991. Infiltration patterns from simulated rainfall on a semi-arid rangeland soil. Soil Science Society of America Journal 55:1726-1734.

Shaw, N.L., and M.R. Haferkamp. 1994. Spiny hopsage seed germination and seedling establishment. Pages 252-256 in S.B. Monsen and S.G. Kitchen, compilers. Proceedings - ecology and management of annual rangelands; 18-21 May 1992; Boise, ID. U.S.D.A.-Forest Service General Technical Report INT-313. Intermountain Research Station, Ogden, Utah.

Short, J., and B. Turner. 1994. A test of the vegetation mosaic hypothesis: a hypothesis to explain the decline and extinction of Australian mammals. Conservation Biology 8:439-449.

Smith, J.K., editor. 2000. Wildland fire in ecosystems: effects of fire on fauna. U.S.D.A.-Forest Service General Technical Report RMRS-42. Rocky Mountain Research Station, Ogden, Utah

Snyder, J.M., and L.H. Wullstein. 1973. The role of desert cryptograms in nitrogen fixation. American Midland Naturalist 90:257-265.

Soulé, M.E., and K.A. Kohm. 1989. Research priorities for conservation biology. Critical Issues Series No. 1. Island Press, Washington, D.C.

Soulé, M.E., and L.S. Mills. 1998. No need to isolate genetics. Science 282:1658-1659.

Soule, P.T., and P.A. Knapp. 2000. Juniperus occidentalis (western juniper) establishment history on two minimally disturbed research natural areas in central Oregon. Western North American Naturalist 60:26-33.

Stankey, G.H., D.N. Cole, R.C. Lucas, M.E. Petersen, and S. Frissell. 1985. The limits of acceptable change (LAC) system for wilderness planning. U.S.D.A.Forest Service General Technical Report INT-176. Intermountain Research Station, Ogden, Utah.
Steenhof, K., M.N. Kochert, L.B. Carpenter, and R.N. Lehman. 1999. Long-term prairie falcon population changes in relation to prey abundance, weather, land uses, and habitat conditions. Condor 101:28-41.

Svejcar, T., and R. Tausch. 1991. Anaho Island, Nevada: a relict area dominated by annual invader species. Rangelands 13:322-236.

Swanson, F.J., and C.T. Dyrness. 1975. Impact of clear-cutting and road construction on soil erosion by landslides in the western Cascade Range, Oregon. Geology 3:393-396.

Taylor, B.L., and T. Gerodette. 1993. The uses of statistical power in conservation biology: the vaquita and northern spotted owl. Conservation Biology 4:489-500.

Taylor, B.L., P.R. Wade, D.P. DeMaster, and J. Barlow. 2000. Incorporating uncertainty into management models for marine mammals. Conservation Biology $14: 1243-1252$.

Thomas, J.W., technical editor. 1979. Wildlife habitats in managed forests of the Blue Mountains of Oregon and Washington. U.S. Department of Agriculture, Forest Service, with U.S. Department of the Interior, Bureau of Land Management, and the Wildlife Management Institute, Washington, D.C.

Thornton, K.W., G.E. Saul, and D.E. Hyatt. 1994. Environmental monitoring and assessment program assessment framework. Environmental Protection Agency Report EPA/620/R-94/016. Office of Research and Development, Environmental Monitoring and Assessment Program, Research and Assessment Center, Research Triangle Park, North Carolina.

Toft, C., and P. Shea. 1983. Detecting community-wide patterns: estimating power strengthens statistical inference. American Naturalist 122:618-625.

Torok, K., T. Szili-Kovacs, M. Halassy, T. Toth, Z. Hayek, M.W. Paschke, and L.J. Wardell. 2000. Immobilization of soil nitrogen as a possible method for the restoration of sandy grassland. Applied Vegetation Science 3:7-14.

Trombulak, S.C., and C.A. Frissell. 2000. Review of ecological effects of roads on terrestrial and aquatic communities. Conservation Biology 14:18-30.

Turner, M.G. 1987. Effects of grazing by feral horses, clipping, trampling, and burning on a Georgia salt marsh. Estuaries 10:54-60.

Turner, M.G. 1989. Landscape ecology: the effect of pattern on process. Annual Review of Ecology and Systematics 20:171-197. 
U.S. Department of Agriculture (USDA) and U.S. Department of the Interior (USDI). 2000a. Interior Columbia Basin Supplemental Draft Environmental Impact Statement. Vol. 1. BLM/OR/WA/PT00/019+1792. U.S. Department of Agriculture, Forest Service, U.S. Department of Inteior, Bureau of Land Managment, Portland, Oregon (irregular pagination).

U.S. Department of Agriculture (USDA) and U.S. Department of the Interior (USDI). 2000b. Interior Columbia Basin Supplemental Draft Environmental Impact Statement. Vol. 2. BLM/OR/WA/PT00/019+1792. U.S. Department of Agriculture, Forest Service, U.S. Department of Inteior, Bureau of Land Managment, Portland, Oregon (irregular pagination).

U.S. Department of the Interior (USDI), Bureau of Land Management (BLM). 1993. Riparian area management: process for assessing proper functioning condition. Technical Reference TR 1737-9. Denver, Colorado.

U.S. Department of the Interior (USDI), Bureau of Land Management (BLM). 1994. Riparian area management: process for assessing proper functioning condition for lentic riparian-wetland areas. Technical Reference TR 1737-11. Denver, Colorado.

U.S. Department of the Interior (USDI), Bureau of Land Management (BLM). 1999. Research needs for salmon. Presented at Interagency Salmon Science Team meeting, Seattle, Washington (7-8 December 1999).

U.S. Department of the Interior (USDI), Bureau of Land Management (BLM). 2000. FY 2002 science priorities, current as of July 24,2000 . Washington, D.C.

U.S. Fish and Wildlife Service. 1998. Region 1 Bureau information (research) needs (BINs). Pacific Region regional office, Portland, Oregon.

U.S. Geological Survey. 2000. Species-at-Risk Program: high-priority species or groups and their management needs. Attachment 1 of Species at Risk Pre-Proposal Package (FY 2001), pages 4-5 and 16-19: Region 1 and Region 6 nominations.

Valentine, K.A. 1947. Distance from water as a factor in grazing capacity of rangeland. Journal of Forestry 45:749-754.

Vallentine, J.F. 1990. Grazing management. Academic Press, New York, New York.

Vallentine, J.F., and A.R. Stevens. 1994. Use of livestock to control cheatgrass - a review. Pages 202-206 in S.B. Monsen and S.G. Kitchen, compilers. Proceedings - ecology and management of annual rangelands, 18-21 May 1992, Boise, ID. U.S.D.A.Forest Service General Technical Report INT-313. Intermountain Research Station, Ogden, Utah.
Van Dorp, D. and P.F.M. Opdam. 1987. Effects of patch size, isolation, and regional abundance on forest bird communities. Landscape Ecology 1:59-73.

Vander Haegen, W.M., F.C. Dobler, and D.J. Pierce. 2000. Shrubsteppe bird response to habitat and landscape variables in eastern Washington, U.S.A. Conservation Biology 14:1145-1160.

Vavra, M., and D. Ganskopp. 1998. Grazing behavior in ungulates: current concepts and future challenges. Annals of Arid Zones 37:319-335.

Vavra, M., W.A. Laycock, and R.D. Pieper, editors. 1994. Ecological implications of livestock herbivory in the West. Society for Range Management, Denver, Colorado.

Verts, B.J., and L.N. Carraway. 1998. Land mammals of Oregon. University of California Press, Berkeley, California.

Vogel, C.A., and K.P. Reese. 1995. Mountain quail status report: a preliminary document to a conservation assessment for mountain quail. Unpublished report, Idaho Interagency Conservation/Prelisting Effort.

Vora, R.S. 1997. Developing programs to monitor ecosystem health and effectiveness of management practices on Lakes States National Forests, USA. Biological Conservation 80:289-302.

Wales, B.C. 2001. Effects of insects, disease, fire, grazing, and their management on terrestrial riparian vertebrates and habitat. Northwest Science 75:119-127.

Walters, C. 1986. Adaptive management of renewable resources. MacMillan Publishing Co., New York, New York.

Waples, R.S. 1991. Definition of "species" under the Endangered Species Act: application to Pacific salmon. NOAA Technical Memorandum NMFS F/NWC-194. National Marine Fisheries Service, Seattle, Washington.

Washington Department of Fish and Wildlife. 1995. Washington state recovery plan for the sage grouse. Game Division, Olympia, Washington.

Watanabe, M.E. 1994. Pollination worries rise as honey bees decline. Science 265:1170.

Weltz, N., M.K. Wood, and E.E. Parker. 1989. Flash grazing and trampling effects on infiltration rates and sediment yield on a selected New Mexico range site. Journal of Arid Environments 16:95-100.

West, N.E. 1990. Structure and function of soil microphytic crusts in wildland ecosystems of arid and semi-arid regions. Advanced Ecological Research 20:179-223.

West, N.E. 1993. Biodiversity of rangelands. Journal of Range Management 46:2-13. 
West, N.E., and J.A. Young. 2000. Intermountain valleys and lower mountain slopes. Pages 255-284 in M.G. Barbour and W.D. Billings, editors. North American terrestrial vegetation, 2nd ed. Cambridge University Press, Cambridge, United Kingdom.

Wester, D.B. 1992. Viewpoint: replication, randomization, and statistics in range research. Journal of Range Management 45:285-290.

Whisenant, S.G. 1990. Changing fire frequencies on Idaho's Snake River Plains: ecological and management implications. Pages 4-10 in E.S. McArthur, R.M. Romney, S.D. Smith, and P.T. Tueller, editors. Proceedings: symposium on cheatgrass invasion, shrub die-off, and other aspects of shrub biology and management. U.S.D.A.-Forest Service General Technical Report INT-276. Intermountain Research Station, Ogden, Utah.

Wicklow-Howard, M.C., and J. Kaltenecker. 1994. Fungi from the Owyhee region of southern Idaho and eastern Oregon. ICBEMP contract report prepared for the Eastside Ecosystem Management Project, Boise, Idaho.

Wilcove, D.S. 1985. Nest predation in forest tracts and the decline of migratory songbirds. Ecology 77:1211-1214.

Wilcox, B.P., and M.K. Wood. 1989. Factors influencing interrill erosion from semi-arid slopes in New Mexico (USA). Journal of Range Management 42:66-70.

Williams, J.D. 1993. Influence of microphytic crusts on selected soil physical and hydrologic properties in the Hartnet Draw, Capitol Reef National Park, Utah. Ph.D. Dissertation, Utah State University, Logan, Utah.

Williams, J.D. 1994. Microbiotic crusts: a review. Unpublished ICBEMP report, Boise, Idaho.

Williams, J.E., C.A. Wood, and M.P. Dombeck, editors. 1997. Watershed restoration: principles and practices. American Fisheries Society, Bethesda, Maryland.

Williams, J.E., J.E. Johnson, D.A. Hendrickson, S. Contreres-Balderas, J.D. Williams, M. NavarroMendoza, D.E. McAllister, and J.E. Deacon. 1989. Fishes of North America endangered, threatened, or of special concern: 1989. Fisheries 14(6):2-20.

Williams, O.B. 1977. Reproductive wastage in rangeland plants, with particular reference to the role of mammals. Pages 227-248 in Proceedings, 2nd U.S.-Australia Rangeland Panel. The impact of herbivores on arid and semi-arid rangelands. Perth, Western Australia, Australia.

Wilson, D.E., and S. Ruff. 1999. The Smithsonian book of North American mammals. Smithsonian Institution Press, Washington, D.C.
Winter, B.D., and R.M. Hughes. 1995. American Fisheries Society draft position statement on biodiversity. Fisheries 20(4):20-25.

Wisdom, M.J., R.S. Holthausen, B.C. Wales, C.D. Hargis, V.A. Saab, D.C. Lee, W.J. Hann, T.D. Rich, M.M. Rowland, W.J. Murphy, and M.R. Eames. 2000. Source habitats for terrestrial vertebrates of focus in the Interior Columbia Basin: broad-scale trends and management implications. U.S.D.A-Forest Service General Technical Report PNW-485. Pacific Northwest Research Station, Portland, Oregon.

Wissmar, R.C., J.E. Smith, B.A. McIntosh, H.W. Li, G.H. Reeves, and L.A. Brown. 1994. Ecological health of river basins in forested regions of eastern Oregon and Washington. U.S.D.A.-Forest Service General Technical Report PNW-326. Pacific Northwest Research Station, Portland, Oregon.

Wolfe, M.J., Jr. 1980. Feral horse demography: a preliminary report. Journal of Range Management 33:354-360.

Wootton, J.T. 1994. Predicting direct and indirect effects: an integrated approach using experiments and path analysis. Ecology 75:151-165.

Young, J.A., and R.A. Evans. 1978. Population dynamics after wildfires in sagebrush grasslands. Journal of Range Management 31:283-289.

Young, J.A., and R.A. Evans. 1981. Demography and fire history of a western juniper stand. Journal of Range Management 34:501-506.

Zaghmut, O.M.F., and W.A. Torello. 1992. Restoration of regeneration potential of long-term cultures of red fescue Festuca rubra L. by elevated sucrose levels. Plant Cell Reports 11:142-145.

Zielinski, W.J., and T.E. Kucera, technical editors. 1995. American marten, fisher, lynx, and wolverine: survey methods for their detection. U.S.D.A.-Forest Service General Technical Report PSW-157. Pacific Southwest Research Station, Albany, California. 
$\bullet$

$\bullet$

- 


\section{APPENDICES}

\section{Appendix A}

Research needs identified by Department of Interior management agencies for the Interior Columbia River, Snake River, Klamath, and northern Great Basins, and sections of the Research Plan (Part 2) that address each need. Bolded sections address the specified need in greatest depth. Research needs for natural resources have not yet been received from the Bureau of Indian Affairs.

\begin{tabular}{|c|c|c|c|}
\hline Research Need & $\begin{array}{l}\text { tified as priority } \\
\text { for Fiscal Year(s) }\end{array}$ & $\begin{array}{l}\text { Page numbers } \\
\text { in Plan that } \\
\text { address need }\end{array}$ & Agency* \\
\hline Rangeland Health and Restoration & 1996-2002 & $28-30 ; 33-37$ & BLM \\
\hline Aquatic and riparian systems & $1997-2002$ & $35 ; 38-40 ; 42 ; 43 ; 45$ & BLM \\
\hline Prescribed fire & 2001,2002 & $29 ; 45 ; 49$ & BLM \\
\hline Wild horse and burro management & $1997-2002$ & $31-2$ & BLM \\
\hline Invasive plant issues & 1996-2002 & $28 ; 29-30 ; 31 ; 35 ; 42$ & BLM \\
\hline Declining and at-risk species & 2001,2002 & $30 ; 33 ; 38 ; 43 ; 45-46$ & BLM \\
\hline Water quality and hydrological issues & 2001,2002 & $30 ; 38 ; 40 ; 46 ; 48$ & BLM \\
\hline National Landscape Conservation System & 2002 & $33-2=$ & BLM \\
\hline Effects of western juniper expansion & 1997-1999 & 45 & BLM \\
\hline Vegetation Diversity Project & 1996-1999 & $28-29 ; 33 ; 35 ; 42-43 ; 46$ & BLM \\
\hline Paired Ecosystems (PE) Project: effects of climate change & 1996 & $43-1-2-10$ & BLM \\
\hline Re-GAP: GAP analysis regional land cover mapping & 2002 & 33 & BLM; USFWS \\
\hline $\begin{array}{l}\text { Improving management of fish, wildlife and habitats on } \\
\text { National Wildlife Refuges }\end{array}$ & 1995-2002 & $28 ; 35 ; 36 ; 49$ & USFWS \\
\hline $\begin{array}{l}\text { Production, management, and restoration of native fishes and other } \\
\text { aquatic species }\end{array}$ & 1995-2002 & $30 ; 35 ; 38-40 ; 43 ; 44 ; 46-49$ & USFWS \\
\hline $\begin{array}{l}\text { Analysis of the effect of physical and chemical environments on fish } \\
\text { and wildlife }\end{array}$ & 1995-2002 & $38 ; 40 ; 43 ; 46 ; 48$ & USFWS \\
\hline $\begin{array}{l}\text { Status of listed, proposed, candidate, and sensitive species } \\
\text { and their habitats }\end{array}$ & 1995-2002 & $30 ; 33-35^{* *}$ & USFWS \\
\hline $\begin{array}{l}\text { Management and restoration of terrestrial species and their ecosystems } \\
\text { Watershed-scale management of natural and anthropogenic factors that } \\
\text { contribute to reduced water quality or quantity (e.g., sediment } \\
\text { deposition in reservoirs) ["Ecology of western reservoirs"] }\end{array}$ & $\begin{array}{r}1995-2002 \\
2001-2002\end{array}$ & $\begin{array}{l}29-30 ; 49 \\
38 ; 40\end{array}$ & $\begin{array}{l}\text { USFWS } \\
\text { BOR }\end{array}$ \\
\hline $\begin{array}{l}\text { Diurnal and chronic long-term effects of water quality in Upper Klamath } \\
\text { Lake on early life cycle stages of endangered catostomid suckers }\end{array}$ & $1997-2002$ & $30 ; 38 ; 40 ; 43$ & BOR \\
\hline Habitat value of wetlands constructed for water treatment & $1997-2002$ & & BOR \\
\hline GIS analysis of sensitive species populations & $1997-2002$ & 46 & BOR \\
\hline Effects of visitor use on sensitive species & $1997-2002$ & $33 ; 40 ; 43 ; 46 ; 48$ & NPS \\
\hline Fishery and aquatic ecosystem research needs & $1997-2002$ & $35 ; 38-40 ; 42-43 ; 46-48$ & NPS \\
\hline A systems approach to management of noxious weeds & $1997-2002$ & $28 ; 29-30 ; 31 ; 35 ; 42$ & NPS \\
\hline Large mammal ecology (including predator-prey) & $1997-2002$ & $30 ; 33 ; 43 ; 46-47 ; 49$ & NPS \\
\hline Status and trends of species at risk, and implications of species declines & $1997-2002$ & $30 ; 33 ; 38 ; 43 ; 45-46$ & NPS \\
\hline Livestock grazing impacts on natural systems in National Parks & $1997-2002$ & $28 ; 30 ; 33 ; 35-37 ; 38-40$ & NPS \\
\hline Effects of air pollutants on Park resources & $1997-2002$ & 40 & NPS \\
\hline Visitor use and natural resource impacts at heavily visited National Parks & $1997-2002$ & $33 ; 40 ; 43 ; 46 ; 48$ & NPS \\
\hline Restoration of ecosystems in National Parks & $1997-2002$ & $33-37$ & NPS \\
\hline Effects of boundaries on ecological systems & $1997-2002$ & 33 & NPS \\
\hline Wildlife diseases & $1997-2002$ & 49 & NPS \\
\hline Inventory \& develop monitoring protocols for resources in desert ecosystems & $1997-2002$ & 44 & NPS \\
\hline
\end{tabular}

* Bureau of Land Management (BLM), U.S. Fish and Wildlife Service (USFWS), Bureau of Reclamation (BOR), National Park Service (NPS). **see 49 for specific organisms and threats. 


\section{Appendix B}

Allocation of scientist FTEs to address all questions in this research program with the Interior Columbia Basin and Snake River Plateau, by category.

\section{Assumptions:}

- Each scientist can manage 3-5 major projects simultaneously, 6-10 smaller projects, or an intermediate number of a combination of major and minor projects. In addition, a Scientist can participate in more projects if projects are collaborative and the scientist is not the PI for the project.

- Although many questions are framed as large, integrative questions, in some cases it may be necessary to address questions in intermediate steps. Thus, smaller projects that provide sufficient statistical power and appropriate spatial domain can be used to test hypotheses and validate causal relationships. Results are thus corroborated with continued investigation over time. This perspective fosters long-term research, which is sorely needed for high-priority issues of natural resource management.

- Although only scientists are listed in this Appendix, budgets should accommodate sufficient staff (e.g., GIS programmers, field technicians, data managers) to address questions in a scientifically robust manner. If this assumption is not met, then the number of scientists must be scaled back accordingly.

- The number of projects investigated and the level to which they are addressed will depend upon available funding, such that all questions may not be addressed.

- Although no scientist is assumed to work solely on Research Program projects, their duties would be dominated by this work. Otherwise, a greater number of scientists would be needed.

- The designation " + " denotes the scientist(s) that would be most appropriate to coordinate research within each category.

Number of support staff scientists and other researchers as needed to address each research category:

Title (specialization)

\section{A. Project Administration}

1 Project Leader

1 GIS Specialist

1 Data Manager/Statistician

1 Information Specialist

1 Administrative Assistant

\section{Range (Plant) Ecologist}

1-2 Soil Scientistsł

1-2 Vertebrate Biologists

1 Landscape Ecologist

1-2 Fire Ecologists

Collaboration by an Entomologist,

Plant Physiologist, and Mammalogist

2 Aquatic Ecologists $\ddagger$

1-2 Restoration Ecologists $\ddagger$

1-2 Landscape Ecologist

2 Ecologists

1-2 Soil Scientists
Level of expertise needed; \#FTE

No. of projects
GS-14; 1.0

GS-11; 1.0

GS-9; 1.0

GS- $9 ; 1.0$

GS-5; 1.0

\section{Rangeland Health}

GS- $12 ; 1.0$

GS- $13 ; 1.5$

GS- $13 ; 1.5$

GS-13; 0.5

GS-13; 1.5

GS-12; 0.1 each

\section{Restoration}

GS-13/14; 1.5

GS-13/14; 1.0

GS- $13 ; 1.0$

GS-12; 1.5

GS- $12 ; 1.5$
5 collaborating roles

2 major, 3 collaborating roles

3 major, 1 collaborating role

2 collaborating roles

2 large, 1 collaborating role

1 collaborating role
7 major roles

4 major roles

3 major, 3 collaborating roles

5 major, 1 collaborating role

5 major, 2 collaborating roles 
1 Vertebrate Biologist

1 Hydrologist

1 Range Ecologist

Collaboration by a Plant Physiologist/

Ecologist $(2 \mathrm{~m}, 1 \mathrm{c})$ and a Theoretical

Modeler (1m, 1c)

\section{Aquatic-terrestrial interface}

2-3 Aquatic Ecologists $\ddagger$

1 Landscape Ecologist

1 Hydrologist

1 Theoretical Modeler

Collaboration by an Invertebrate

Ecologist and a Vertebrate Ecologist
GS-12; 0.75

GS-12; 0.5

GS-12; 0.5

GS-12; 0.1 each
3 major, 1 collaborating role 2 major, 1 collaborating role 2 major, 1 collaborating role
GS-13/14; 2.5
4 large roles
2 major roles
2 major roles
GS-12; 0.5
GS-12; 0.5
GS-12; 0.1 each
1 collaborating role

\section{Development of monitoring and implementation protocols for adaptive management}

1 Ecologist $\ddagger$

1 Aquatic Ecologist

1 Soil Scientist

1 Landscape Ecologist

1 Vertebrate Biologist

1 Hydrologist

1 Plant Physiologist

1 Sociologist

1 Theoretical Modeler

\section{Species and habitats at risk}

4 Vertebrate Ecologists $\ddagger$

2 Aquatic Biologists $\ddagger$

1 Hydrologist

1 Plant Physiologist

1 Soil Scientist

1 Theoretical Modeler

1 Restoration Ecologist

1 Landscape Ecologist

1 Sociologist

1 Fire Ecologist

1 Ecologist
GS-13/14; 1.0

GS-12; 0.75

GS-12; 0.5

GS-12/13; 0.5

GS-12; 0.5

GS-12; 0.5

GS-12;0.5

GS-12;0.5

GS-12/13; 0.25

GS-13/14; 1.0; GS-12/13; 3.0

GS-13/14; 1.0 ; GS-12/13; 1.0

GS-12; 0.5

GS-12; 0.5

GS-12;0.5

GS-12; 0.5

GS-12; 0.5

GS-12; 0.5

GS-12; 0.5

GS-12; 0.25

GS-12; 0.25
2 major, 2 collaborating roles 3 major, 1 collaborating role 2 major, 2 collaborating roles 2 major, 1 collaborating role 2 major roles

2 major, 1 collaborating role 2 major roles several collaborating roles 1 major role

12 major roles

4 major roles

3 major roles

3 major roles

5 collaborating roles

2 major roles

2 major roles

1 major, 1 collaborating role several collaborating roles

1 major role

3 collaborating roles 


\section{APPENDIX C}

Estimated personnel needs (in FTEs) for each of five research categories over a ten-year period.

\begin{tabular}{|c|c|c|c|c|c|c|c|c|c|c|c|}
\hline Fiscal year & $\begin{array}{c}\text { FY } \\
2003\end{array}$ & $\begin{array}{c}\text { FY } \\
2004\end{array}$ & $\begin{array}{c}\text { FY } \\
2005\end{array}$ & $\begin{array}{c}F Y \\
2006\end{array}$ & $\begin{array}{c}\text { FY } \\
2007\end{array}$ & $\begin{array}{c}\text { FY } \\
2008\end{array}$ & $\begin{array}{c}\text { FY } \\
2009\end{array}$ & $\begin{array}{c}\text { FY } \\
2010\end{array}$ & $\begin{array}{c}\text { FY } \\
2011\end{array}$ & $\begin{array}{c}\text { FY } \\
2012\end{array}$ & $\begin{array}{l}\text { Total } \\
\text { Person } \\
\text { Years }\end{array}$ \\
\hline Project year & 1 & 2 & 3 & 4 & 5 & 6 & 7 & 8 & 9 & 10 & \\
\hline $\begin{array}{l}\text { Administration } \\
\text { Project leader } \\
\text { GIS Specialist } \\
\text { Data Manager } \\
\text { Information Specialist }\end{array}$ & $\begin{array}{l}1.0 \\
1.0 \\
1.0 \\
1.0\end{array}$ & $\begin{array}{l}1.0 \\
1.0 \\
1.0 \\
1.0\end{array}$ & $\begin{array}{l}1.0 \\
1.0 \\
1.0 \\
1.0\end{array}$ & $\begin{array}{l}1.0 \\
1.0 \\
1.0 \\
1.0\end{array}$ & $\begin{array}{l}1.0 \\
1.0 \\
1.0 \\
1.0\end{array}$ & $\begin{array}{l}1.0 \\
1.0 \\
1.0 \\
1.0\end{array}$ & $\begin{array}{l}1.0 \\
1.0 \\
1.0 \\
1.0\end{array}$ & $\begin{array}{l}1.0 \\
1.0 \\
1.0 \\
1.0\end{array}$ & $\begin{array}{l}1.0 \\
1.0 \\
1.0 \\
1.0\end{array}$ & $\begin{array}{l}1.0 \\
1.0 \\
1.0 \\
1.0\end{array}$ & $\begin{array}{l}10.0 \\
10.0 \\
10.0 \\
10.0\end{array}$ \\
\hline $\begin{array}{l}\text { Rangeland health } \\
\text { Research Scientists (GS-13) } \\
\text { Research Scientists (GS-12) } \\
\text { Technicians (field and lab) } \\
\text { Secretaries (GS-5) }\end{array}$ & $\begin{array}{l}4.5 \\
2.3 \\
8.0 \\
0.5\end{array}$ & $\begin{array}{l}4.5 \\
2.3 \\
8.0 \\
1.0\end{array}$ & $\begin{array}{l}3.5 \\
1.3 \\
8.0 \\
1.0\end{array}$ & $\begin{array}{l}3.5 \\
1.3 \\
8.0 \\
1.0\end{array}$ & $\begin{array}{l}3.5 \\
1.3 \\
8.0 \\
1.0\end{array}$ & $\begin{array}{l}3.5 \\
1.3 \\
8.0 \\
1.0\end{array}$ & $\begin{array}{l}3.0 \\
0.8 \\
8.0 \\
1.0\end{array}$ & $\begin{array}{l}3.0 \\
0.8 \\
8.0 \\
1.0\end{array}$ & $\begin{array}{l}2.5 \\
0.8 \\
8.0 \\
1.0\end{array}$ & $\begin{array}{l}3.5 \\
0.8 \\
0.0 \\
1.5\end{array}$ & $\begin{array}{l}35.0 \\
13.0 \\
72.0 \\
10.0\end{array}$ \\
\hline $\begin{array}{l}\text { Restoration } \\
\text { Research Scientists (GS-13) } \\
\text { Research Scientists (GS-12) } \\
\text { Technicians (field and lab) } \\
\text { Secretaries (GS-5) }\end{array}$ & $\begin{array}{c}4.5 \\
6.0 \\
15.8 \\
0.5\end{array}$ & $\begin{array}{c}4.5 \\
6.0 \\
15.8 \\
1.0\end{array}$ & $\begin{array}{c}3.5 \\
5.0 \\
12.8 \\
1.0\end{array}$ & $\begin{array}{c}3.5 \\
5.0 \\
12.8 \\
1.0\end{array}$ & $\begin{array}{c}3.5 \\
5.0 \\
12.8 \\
1.0\end{array}$ & $\begin{array}{c}3.5 \\
5.0 \\
12.8 \\
1.0\end{array}$ & $\begin{array}{c}3.0 \\
4.5 \\
11.3 \\
1.0\end{array}$ & $\begin{array}{c}3.0 \\
4.5 \\
11.3 \\
1.0\end{array}$ & $\begin{array}{l}2.5 \\
4.0 \\
9.8 \\
1.0\end{array}$ & $\begin{array}{c}3.5 \\
4.0 \\
11.3 \\
1.5\end{array}$ & $\begin{array}{c}35.0 \\
49.0 \\
126.0 \\
10.0\end{array}$ \\
\hline $\begin{array}{l}\text { Aquatic-terrestrial interface } \\
\text { Research Scientists (GS-13) } \\
\text { Research Scientists (GS-12) } \\
\text { Technicians (field and lab) } \\
\text { Secretaries (GS-5) }\end{array}$ & $\begin{array}{l}3.5 \\
2.4 \\
8.0 \\
0.5\end{array}$ & $\begin{array}{l}3.5 \\
2.4 \\
8.0 \\
1.0\end{array}$ & $\begin{array}{l}3.0 \\
1.8 \\
8.0 \\
1.0\end{array}$ & $\begin{array}{l}3.0 \\
1.8 \\
8.0 \\
1.0\end{array}$ & $\begin{array}{l}3.0 \\
1.8 \\
8.0 \\
1.0\end{array}$ & $\begin{array}{l}3.0 \\
1.8 \\
8.0 \\
1.0\end{array}$ & $\begin{array}{l}3.0 \\
1.5 \\
8.0 \\
1.0\end{array}$ & $\begin{array}{l}3.0 \\
1.5 \\
8.0 \\
1.0\end{array}$ & $\begin{array}{l}2.5 \\
1.5 \\
8.0 \\
1.0\end{array}$ & $\begin{array}{l}2.5 \\
1.5 \\
0.0 \\
1.5\end{array}$ & $\begin{array}{l}30.0 \\
18.0 \\
72.0 \\
10.0\end{array}$ \\
\hline $\begin{array}{l}\text { Monitoring/adaptive manage } \\
\text { Research Scientists (GS-13) } \\
\text { Research Scientists (GS-12) } \\
\text { Technicians (field and lab) } \\
\text { Secretaries (GS-5) }\end{array}$ & $\begin{array}{l}\text { nt } \\
1.0 \\
5.0 \\
8.3 \\
0.5\end{array}$ & $\begin{array}{l}1.0 \\
5.0 \\
8.3 \\
1.0\end{array}$ & $\begin{array}{l}1.0 \\
4.0 \\
8.3 \\
1.0\end{array}$ & $\begin{array}{l}1.0 \\
4.0 \\
8.3 \\
1.0\end{array}$ & $\begin{array}{l}1.0 \\
4.0 \\
8.3 \\
1.0\end{array}$ & $\begin{array}{l}1.0 \\
4.0 \\
8.3 \\
1.0\end{array}$ & $\begin{array}{l}1.0 \\
4.0 \\
8.3 \\
1.0\end{array}$ & $\begin{array}{l}1.0 \\
4.0 \\
8.3 \\
1.0\end{array}$ & $\begin{array}{l}1.0 \\
3.0 \\
8.3 \\
1.0\end{array}$ & $\begin{array}{l}1.0 \\
3.0 \\
0.0 \\
1.5\end{array}$ & $\begin{array}{l}10.0 \\
40.0 \\
75.0 \\
10.0\end{array}$ \\
\hline $\begin{array}{l}\text { Species and habitats at risk } \\
\text { Research Scientists (GS-13) } \\
\text { Research Scientists (GS-12) } \\
\text { Technicians (field and lab) } \\
\text { Secretaries (GS-5) }\end{array}$ & $\begin{array}{c}3.0 \\
10.0 \\
19.5 \\
1.0\end{array}$ & $\begin{array}{c}3.0 \\
10.0 \\
19.5 \\
1.5\end{array}$ & $\begin{array}{c}2.0 \\
8.0 \\
15.0 \\
1.5\end{array}$ & $\begin{array}{c}2.0 \\
8.0 \\
15.0 \\
1.5\end{array}$ & $\begin{array}{c}2.0 \\
8.0 \\
15.0 \\
1.5\end{array}$ & $\begin{array}{c}2.0 \\
8.0 \\
15.0 \\
1.5\end{array}$ & $\begin{array}{c}2.0 \\
8.0 \\
15.0 \\
1.5\end{array}$ & $\begin{array}{c}2.0 \\
8.0 \\
15.0 \\
1.5\end{array}$ & $\begin{array}{c}1.0 \\
6.0 \\
10.5 \\
1.5\end{array}$ & $\begin{array}{c}1.0 \\
6.0 \\
10.5 \\
2.0\end{array}$ & $\begin{array}{c}20.0 \\
80.0 \\
150.0 \\
15.0\end{array}$ \\
\hline
\end{tabular}

Total FTEs across all research categories

$\begin{array}{llllllllllll}\text { Research Scientists (GS-13) } & 16.5 & 16.5 & 13.0 & 13.0 & 13.0 & 13.0 & 12.0 & 12.0 & 9.5 & 11.5 & 130.0\end{array}$

$\begin{array}{lllllllllllll}\text { Research Scientists (GS-12) } & 25.7 & 25.7 & 20.1 & 20.1 & 20.1 & 20.1 & 18.8 & 18.8 & 15.3 & 15.3 & 200.0\end{array}$

$\begin{array}{llllllllllll}\text { Technicians } & 59.6 & 59.6 & 52.1 & 52.1 & 52.1 & 52.1 & 50.6 & 50.6 & 44.6 & 21.8 & 495.0\end{array}$

$\begin{array}{llllllllllll}\text { Secretarial support } & 3.0 & 5.5 & 5.5 & 5.5 & 5.5 & 5.5 & 5.5 & 5.5 & 5.5 & 8.0 & 55.0\end{array}$ 


\section{APPENDIX D}

Summary of estimated costs (in 1,000s of U.S. dollars) for completion of a 10-year study of Department of the Interior aridlands in the Interior Columbia River, Snake River, Klamath, and northern Great Basins. Totals listed pertain to a comprehensive research program that addresses all questions in this research Plan; costs would be accordingly reduced if only a portion of the questions were addressed.

\section{FY FY FY FY FY FY FY FY FY FY Totals

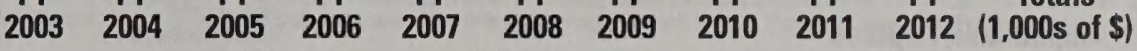

\section{Personnel}

Administration

$\begin{array}{ccccccccccc}299 & 317 & 336 & 356 & 366 & 387 & 398 & 420 & 432 & 456 & 3767 \\ 103 & 109 & 116 & 123 & 126 & 134 & 137 & 145 & 149 & 157 & \\ 61 & 65 & 69 & 73 & 75 & 79 & 81 & 86 & 88 & 93 & \\ 51 & 54 & 57 & 60 & 62 & 66 & 67 & 71 & 73 & 77 & \\ 51 & 54 & 57 & 60 & 62 & 66 & 67 & 71 & 73 & 77 & \\ 33 & 35 & 38 & 40 & 41 & 43 & 44 & 47 & 48 & 51 & \\ 1440 & 1528 & 1276 & 1352 & 1388 & 1469 & 1393 & 1472 & 1197 & 1531 & 14046 \\ 1886 & 2002 & 1660 & 1758 & 1805 & 1910 & 1835 & 1940 & 1621 & 1712 & 18129 \\ 2667 & 2826 & 2624 & 2778 & 2854 & 3022 & 3010 & 3186 & 2880 & 1483 & 27330 \\ 134 & 261 & 277 & 293 & 301 & 319 & 327 & 346 & 355 & 546 & 3161\end{array}$

Project Leader

GIS Specialist

Data Manager

Information Specialist

Administrative Assistant

Research Scientists (GS-13)

Research Scientists (GS-12)

Technicians

Secretarial support

\section{Travel}

Commercial

Vehicles (30)

Meals and lodging

$\begin{array}{ccccccccccc}20 & 20 & 20 & 20 & 20 & 20 & 25 & 25 & 25 & 30 & 225 \\ 90 & 148 & 148 & 148 & 148 & 148 & 148 & 148 & 148 & 110 & 1384 \\ 80 & 125 & 125 & 125 & 125 & 125 & 125 & 125 & 125 & 90 & 1170 \\ 150 & 150 & 75 & 80 & 85 & 90 & 95 & 95 & 95 & 60 & 975 \\ 13 & 17 & 17 & 17 & 20 & 17 & 17 & 17 & 20 & 25 & 180 \\ 6779 & 7394 & 6559 & 6927 & 7113 & 7507 & 7372 & 7774 & 6897 & 6043 & 70366\end{array}$

\section{Assumptions:}

1) Cost-of-living increases amount to $2.70 \%$ per annum.

2) Benefits add an additional $34 \%$ to all personnel costs.

3) Salaries incorporate a $7.68 \%$ locality payment.

4) Projects are assumed to begin in FY 2003, with all staff at Step 1.

5) All employees receive maximum step increases (e.g., no turnover in positions, no step freezes).

6) Each scientist requires 3 Field Technicians for 3-4 months per year, and maintains 1 Technician for data entry during the year. 


\section{APPEndix E}

List of taxa mentioned in the plan, listed in alphbetical order of common names. Retrieved February 20, 2002, from the Integrated Taxonomic Information System on-line database, http://www.itis/usda.gov.

\section{Common name}

\section{Vertebrates}

\section{Amphibians/Reptiles}

black-collared lizard
bullfrog
horned lizards
longnose leopard lizard
northern leopard frog
sagebrush lizard
tiger salamander
whiptail lizards

Birds

American robin bald eagle

blue-winged tea

Brewer's sparrow

brown-headed cowbird

burrowing ow

cinnamon teal

Columbian sharp-

tailed grouse

grasshopper sparrow

gray flycatche

house wren

loggerhead shrike

longer shrike

long-billed curlew

marbled murrelet

mountain bluebir

northern flicker
northern spotted owl

peregrine falcon

sage grouse

sage sparrow

sage thrasher

sandhill crane

sharp-tailed grouse

snowy plover

upland sandpiper

whooping crane

Fish

brook trout

bull trout

chinook salmon

redband trout

salmonids

steelhead

suckers

Yellowstone cutthroat trout

\section{Mammals}

$\begin{array}{ll}\text { American pika } & \text { Ochotona princeps } \\ \text { beaver } & \text { Castor canadensis } \\ \text { caribou } & \text { Rangifer tarandus caribou } \\ \text { deer mouse } & \text { Peromyscus maniculatus } \\ \text { fisher } & \text { Martes pennanti } \\ \text { grizzly bear } & \text { Ursus arctos horribilis } \\ \text { ground squirrel } & \text { Spermophilus spp. } \\ \text { horse } & \text { Equus caballus } \\ \text { marten } & \text { Martes americana } \\ \text { meadow vole } & \text { Microtus pennsylvanicus } \\ \text { microchiropteran bats } & \text { Microchiroptera } \\ \text { moose } & \text { Alces alces } \\ \text { mule deer } & \text { Odocoileus hemionus } \\ \text { northern grasshopper mouse } & \text { Onychomys leucogaster } \\ \text { northern pocket gopher } & \text { Thomomys talpoides } \\ \text { Ord's kangaroo rat } & \text { Dipodomys ordii } \\ \text { pronghorn antelope } & \text { Antilocapra americana } \\ \text { pygmy rabbit } & \text { Brachylagus idahoensis } \\ \text { sagebrush vole } & \text { Lemmiscus curtatus } \\ \text { spotted bat } & \text { Euderma maculatum } \\ \text { wapiti (elk) } & \text { Cervus elaphus } \\ \text { Washington ground squirrel } & \text { Spermophilus washingtoni } \\ \text { white-tailed deer } & \text { Odocoileus virginianus } \\ \text { wolverine } & \text { Gulo gulo } \\ & \end{array}$

Ambystoma tigrinum

Spizella breweri

Athene cunicularia

Anas cyanoptera

Strix occidentalis caurina

Grus canadensis
Common name

Invertebrates

Crotaphytus insularis

Rana catesbeiana

Phrynosoma spp.

Gambelia wislizeni

Rana pipiens

Sceloporus graciosus

Cnemidophorus spp.

Turdus migratorius

Haliaeetus leucocephalus

Anas discors

Molothrus ater

Pedioecetes (Tympanuchus) phasianellus columbianus

Ammodramus savannarum

Empidonax wrightii

Troglodytes aedon

Lanius ludovicianus

Numenius americanus

Brachyramphus marmoratus

Sialia currucoides

Colaptes auratus

Falco peregrinus

Centrocercus urophasianus

Amphispiza belli

Oreoscoptes montanus

Pedioecetes phasianellus

Charadrius alexandrinus

Bartramia longicauda

Grus americana

Salvelinus fontinalis

Salvelinus confluentus

Oncorhynchus tshawytscha

Oncorhynchus mykiss ${ }^{\wedge}$

Salmonidae

Oncorhynchus mykiss^

Catostomidae

Oncorhynchus clarki bouvieri

Oncorhynchus clarki lewisi

Ochotona princeps springsnails

thatch-building ants

zebra mussel

Hydrobiidae

Formica spp.

Dreissena polymorpha

\section{Plants}

$\begin{array}{ll}\text { alder } & \text { Alnus spp. } \\ \text { cheatgrass } & \text { Bromus tectorum } \\ \text { cordgrasses } & \text { Spartina spp. } \\ \text { cottonwood } & \text { Populus spp. } \\ \text { crested wheatgrass } & \text { Agropyron cristatum } \\ \text { dalmatian toadflax } & \text { Linaria dalmatica } \\ \text { diffuse knapweed } & \text { Centaurea diffusa } \\ \text { juniper } & \text { Juniperus spp. } \\ \text { leafy spurge } & \text { Euphorbia esula* } \\ \text { lodgepole pine } & \text { Pinus contorta } \\ \text { low sagebrush } & \text { Artemisia arbuscula } \\ \text { medusahead } & \text { Taeniatherum caput-medusae } \\ \text { mountain big sagebrush } & \text { Artemisia tridentata ssp. vaseyana } \\ \text { ponderosa pine } & \text { Pinus ponderosa } \\ \text { purple loosestrife } & \text { Lycopodium sabinifolium or } \\ & \text { Lythrum salicaria } \\ \text { quaking aspen } & \text { Populus tremuloides } \\ \text { rush skeletonweed } & \text { Chondrilla juncea or Lygodesmia juncea } \\ \text { Russian olive } & \text { Elaeagnus angustifolia } \\ \text { sagebrush } & \text { Artemisia spp. } \\ \text { saltcedar, tamarisk } & \text { Tamarix spp. } \\ \text { Sandberg bluegrass } & \text { Poa secunda } \\ \text { spotted knapweed } & \text { Centaurea biebersteinii or } \\ & \text { Centaurea melitensis } \\ \text { Ute lady's tresses } & \text { Spiranthes diluvialis } \\ \text { western juniper } & \text { Juniperus occidentalis } \\ \text { whitetop } & \text { Cardaria draba } \\ \text { willow } & \text { Salix spp. } \\ \text { Wyoming big sagebrush } & \text { Artemisia tridentata ssp. wyomingensis } \\ \text { yellow starthistle } & \text { Centaurea solstitialis } \\ & \\ & \end{array}$

USDA NRCS, 2001. The PLANTS Database, Version 31 (hitp:/plants usda govl National Plant Data Center Beton Rouge, LA 70874 1990 USA.

ASource: Common and Scientific names of fishes from the United States and Canada. 
Public reporting burden for this collection is estimated to average 1 hour per response, including time for reviewing instructions, searching existing data sources, gathering and maintaining the data needed, and completing and reviewing the collection of information. Send comments regarding this burden estimate or any other aspect of this collection of information, including suggestions for reducing this burden, to Washington Headquarters Services. Directorate for Information Operations and Reports, 1215 Jefferson Davis Highway, Suite 1204, Arlington, VA 222024302 , and to the Office of Management and Budget, Paperwork Reduction Project (0704 0188) Reports, 1215 Jefferson Davis Highway, Suite 1204, Arlington, VA 22202-4302, and to the Office of Management and Budget, Paperwork Reduction Project (0704-0188)
Washington, DC 20503

\begin{tabular}{l|l|l}
\hline $\begin{array}{l}\text { 1. AGENCY USE ONLY (Leave } \\
\text { Blank) }\end{array}$ & $\begin{array}{l}\text { 2. REPORT DATE } \\
\text { June } 2002\end{array}$ & $\begin{array}{l}\text { 3. REPORT TYPE AND DATES COVERED } \\
\text { Information and Technology Report }\end{array}$ \\
\hline
\end{tabular}

4. TITLE AND SUBTITLE

Research Plan for Lands Administered by the U.S. Department of the Interior in the Columbia Basin and Snake River Plateau

\section{AUTHOR(S)}

David A. Pyke and Erik A. Beever

7. PERFORMING ORGANIZATION NAME(S) AND ADDRESSES

U.S. Department of the Interior, U.S. Geological Survey

\begin{tabular}{l|l} 
& \\
\hline 9. SPONSORING/MONITORING AGENCY NAME(S) AND ADDRESSES & \\
U.S. Department of the Interior, U.S. Geological Survey &
\end{tabular}

11. SUPPLEMENTARY NOTES

Prepared as part of an interagency agreement between USGS Forest and Rangeland Ecosystem Science Center and the Bureau of Land Management, Oregon/Washington State Office.

12a. DISTRIBUTION/AVAILABILITY STATEMENT
Release unlimited. Available from the national Technical Information Service,

5825 Port Royal Road, Springfield, VA 22161 (1-800-553-6847 or

703-487-4650). Available to registered users from the Defense Technical

Information Center, Attn: Help Desk, 8722 Kingman Road, Suite 0994,

Fort Belvoir, VA 22060-6218 (1800-225-3842 or 703-767-9050)

13. ABSTRACT (Maximum 200 words)

This document presents a long-term research strategy to address current and future research needs for management of semiarid ecosystems administered by the Department of the Interior in the northern portion of the Intermountain West, including the Snake River Plateau, as well as the Klamath, Columbia, and northern Great Basins. The plan focuses particularly on semiarid rangelands and their associated streams, riparian areas and wetlands. These range from juniper woodlands at the higher elevations and precipitation zones to the lower elevation and drier sagebrush grasslands and salt desert shrublands. The five categories of research emphasis consist of restoration, rangeland health, aquaticterrestrial connections, development of monitoring and evaluation protocols, and species and habitats at risk. The ultimate goal of the research strategy is to provide ideas for integrating emerging scientific understanding into future management by maintaining and restoring long-term ecosystem health and ecological integrity, by providing consistent management over the long term, by restoring and maintaining habitats for plant and animal species, and by supporting economic and social needs of people.

\begin{tabular}{|c|c|c|c|}
\hline \multirow{2}{*}{\multicolumn{3}{|c|}{$\begin{array}{l}\text { 14. SUBJECT TERMS (Keywords) } \\
\text { Great Basin, Intermountain West, Restoration, Rangeland health, Aquatic, } \\
\text { Riparian, Wetland ecosystems, Terrestrial ecosystems, Fire, Cheatgrass, } \\
\text { Sagebrush, Juniper woodlands, Salt desert shrub, Species at risk, Monitoring. }\end{array}$}} & \multirow{2}{*}{$\begin{array}{l}\text { 15. NUMBER OF PAGES } \\
\text { 16. PRICE CODE } \\
\text { To be determined }\end{array}$} \\
\hline & & & \\
\hline $\begin{array}{l}\text { 17. SECURITY CLASSIFICATION } \\
\text { OF REPORT }\end{array}$ & $\begin{array}{l}\text { 18. SECURITY CLASSIFICATION OF } \\
\text { THIS PAGE }\end{array}$ & $\begin{array}{l}\text { 19. SECURITY CLASSIFICATION OF } \\
\text { ABSTRACT }\end{array}$ & 20. LIMITATION OF ABSTRACT \\
\hline Unclassified & Unclassified & Unclassified & UL \\
\hline
\end{tabular}


USGS - Forest and Rangeland Ecosystem Science Center and Oregon State University

\section{Production Staff}

Editor

Editorial Assistant

Designer

Technical Information Specialist
Caryn M. Davis

Leah Rosin

Sandra L. Arbogast

Ruth W. Jacobs

NOTE: The mention of trade names does not constitute endorsement or recommendation for use by the Federal Government. 


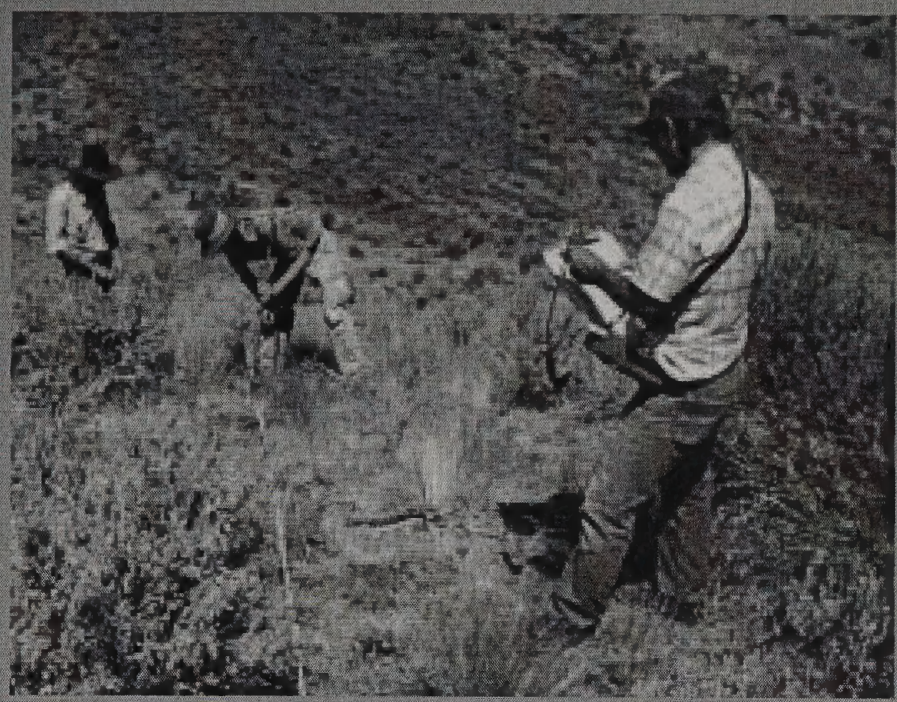

US. Deparment nit interior

U.S. Geological Survey

As the Nation s principal conservation agency, the Department of the Interior has responsibility for most of our nationally owned public lands and natural resources. This responsibility includes fostering the sound use of our lands and water resources: protecting our tish. wildife and biological diversity: presenving the environmental and cultural walucs of our national parks and historical placess, and providing for the enjoyment of life through oundoor recreation. The Department assesses our energy and mincral resourees and Morks to ensure that their development is in the host interest if all our people hy encouragung ste wardship and citiven partienation in their tare. The Departmont also has a major responsibility for A merican Indan reservarton communitic
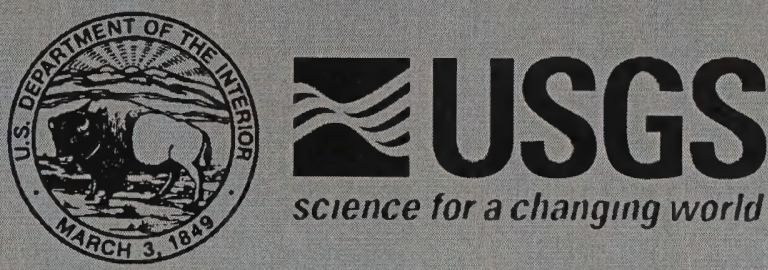

science for a changing world
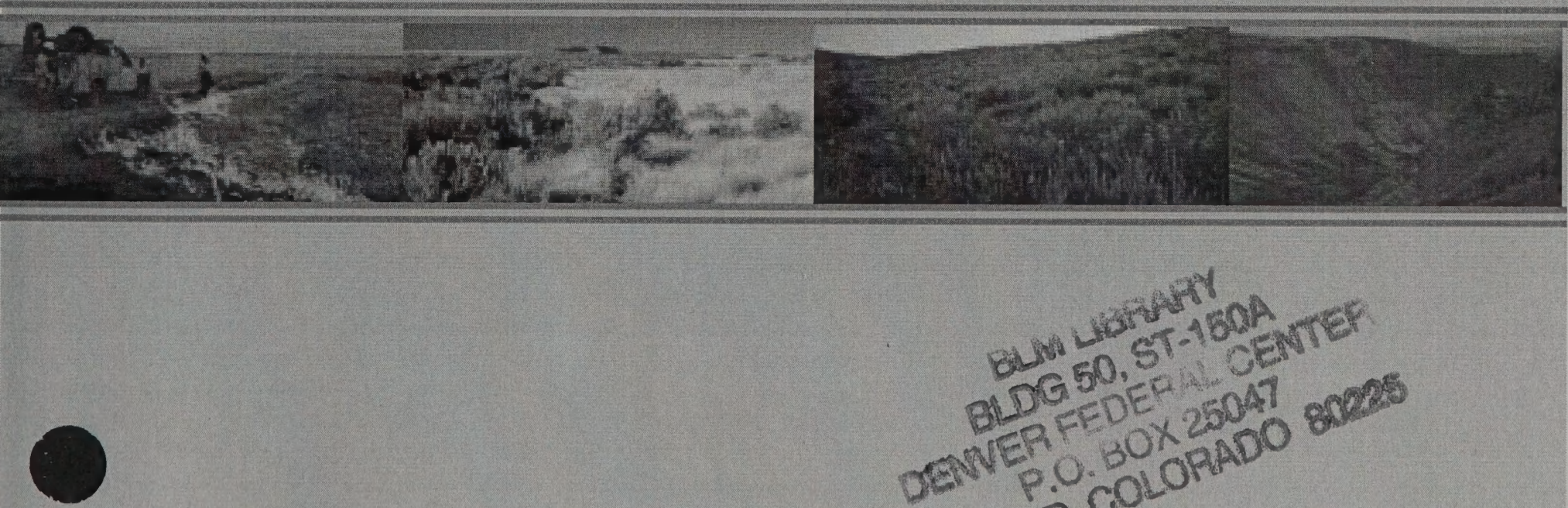

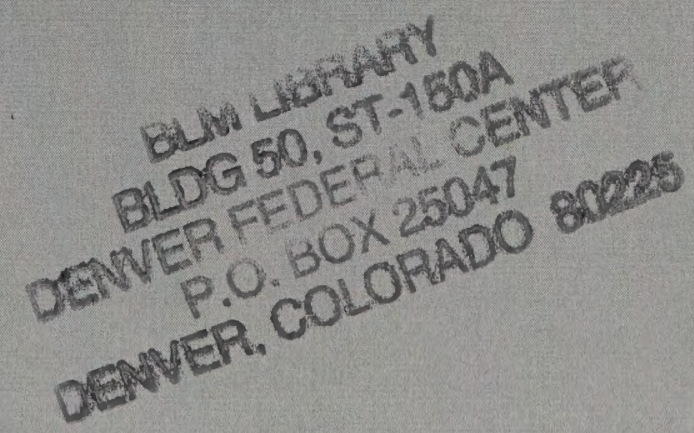


3. it

-

-

- 